\title{
Satisfaction \\ as an Outcome, as a Means and as a Cause
}

\author{
Inaugural-Dissertation \\ zur Erlangung der Doktorwürde \\ — Doctor rerum politicarum — \\ an der Otto-Friedrich-Universität Bamberg
}

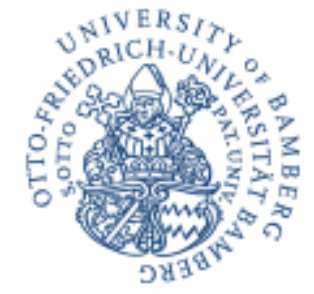

vorgelegt von

Dipl.-Soz. Susanne Elsas

2020 
Dieses Werk ist als freie Onlineversion über das Forschungsinformationssystem (FIS; https://fis.uni-bamberg.de) der Universität Bamberg erreichbar. Das Werk steht unter der CC-Lizenz CC-BY.

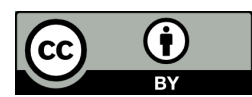

URN: urn:nbn:de:bvb:473-irb-493082

DOI: https://doi.org/10.20378/irb-49308

Erstgutachter

Zweitgutachter

Drittgutachter

Tag der Disputation
Prof. Dr. Guido Heineck

Prof. Dr. Christoph Wunder

Prof. Dr. Michael Gebel 


\section{Contents}

1 Synopsis 1

1.1 Introduction . . . . . . . . . . . . . . . . . . . 1

1.1.1 Why analyzing subjective well-being? . . . . . . . . . . . . 1

1.1.2 Well-being, happiness, utility and satisfaction . . . . . . . . . 2

1.2 Three branches of empirical happiness research . . . . . . . . . . . . . 4

1.2.1 Satisfaction as an outcome . . . . . . . . . . . . . . 4

1.2.2 Satisfaction data as a means . . . . . . . . . . . . . . 5

1.2.3 Satisfaction as a cause . . . . . . . . . . . . . 7

1.3 Challenges in empirical happiness research f . . . . . . . . . . 8

1.3.1 Data issues . . . . . . . . . . . . . . . . . 8

1.3.2 Reference dependence . . . . . . . . . . . . . . . . 9

1.3 .3 Endogeneity . . . . . . . . . . . . . . . . . 11

1.4 This dissertation . . . . . . . . . . . . . . . . . . . . . . 13

2 Satisfaction as an Outcome: Direct and Indirect Utility of Education 16

2.1 Introduction . . . . . . . . . . . . . . . . . . . . . . . . 16

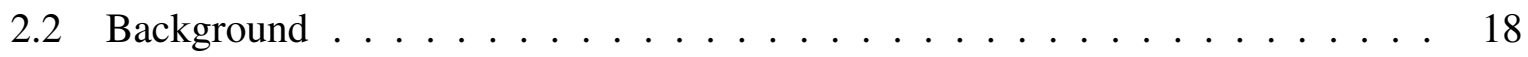

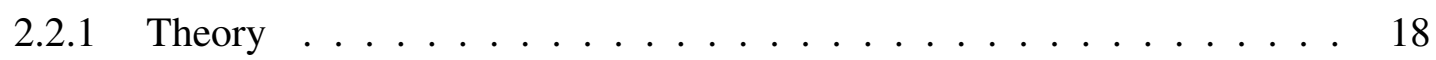

2.2 .2 Literature . . . . . . . . . . . . . . . . 20

2.2 .3 The schooling reform . . . . . . . . . . . . . . . 22

2.3 Identification of direct and indirect effects of education on happiness . . . . . . 27

2.4 Empirical analysis . . . . . . . . . . . . . . . . . 30

2.4 .1 Data . . . . . . . . . . . . . . . 30

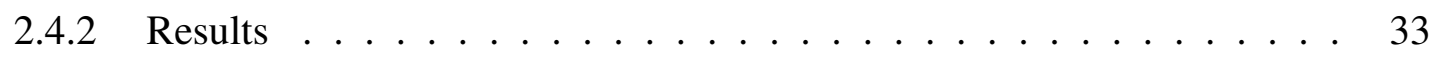

2.5 Discussion and conclusion . . . . . . . . . . . . . . . 39

3 Satisfaction Data as a Means: Income Sharing Within Households 44

3.1 Introduction . . . . . . . . . . . . . . . . . . . 44

3.2 Background .......................... 46 
3.2.1 Norms and Expectations Regarding Income Sharing . . . . . . . . 46

3.2.2 Empirical Findings about Income Sharing from Satisfaction Data . . . 47

3.2.3 Validity of Financial Satisfaction for Analyses of Intra-Household Sharing 48

3.3 Theoretical Approach . . . . . . . . . . . . . . . . . . . . . . . . 49

3.4 Data and Empirical Specification . . . . . . . . . . . . . . . . . . . . . 52

3.4.1 Differences in Financial Satisfaction and the Distribution Factor . . . . 54

3.4 .2 Further Covariates . . . . . . . . . . . . . . . . . 55

3.5 Estimation and Results . . . . . . . . . . . . . . . . . . . . . 56

3.5.1 Joint Estimates . . . . . . . . . . . . . . . . . . . . . 56

3.5 .2 Subsample Estimates . . . . . . . . . . . . . . . . . . 59

3.5 .3 Interpretation . . . . . . . . . . . . . . . 61

3.6 Concluding Remarks . . . . . . . . . . . . . . . . . . . . . . . 62

4 Satisfaction as a Cause: Causality in the Income-Satisfaction-Link 63

4.1 Introduction . . . . . . . . . . . . . . . . . . . . . . . . . . 64

4.2 Related literature . . . . . . . . . . . . . . . . . . . . 65

4.3 Model and identification . . . . . . . . . . . . . . . . . 68

4.3.1 Model . . . . . . . . . . . . . . . . . . . . . . 69

4.3 .2 Identification . . . . . . . . . . . . . . . 70

4.4 Data . . . . . . . . . . . . . . . . . . 72

4.5 Results . . . . . . . . . . . . . . . . . . 76

4.5.1 RQ1: Income causing satisfaction . . . . . . . . . . . . . 77

4.5.2 RQ2: Satisfaction causing income . . . . . . . . . . . . 78

4.5.3 Robustness check . . . . . . . . . . . . . . . . . . . . 79

4.5.4 Re-estimation of $\mathrm{H} 1$ and $\mathrm{H} 2$ for financial satisfaction . . . . . . . . 81

4.6 Conclusion . . . . . . . . . . . . . . . . . . . . . . 82

$\begin{array}{ll}\text { Appendices } & 84\end{array}$

A1 Supplementary material for Chapter $2 \ldots \ldots \ldots$. . . . . . . . . . . 84

A1.1 Complete estimation results . . . . . . . . . . . . . 86

A2 Supplementary material for Chapter $3 \ldots \ldots$. . . . . . . . . . . . . 99

A2.1 Income pooling as a prerequisite for income sharing . . . . . . . . . 99

A2.2 Relative employment status as distribution factor . . . . . . . . . . 100

A2.3 Determinants of differences in financial satisfaction and of financial satisfaction in three subsamples . . . . . . . . . . . . . . . . . . . . 101

A3 Supplementary material for Chapter $4 \ldots \ldots$. . . . . . . . . . . 107

A3.1 Heteroskedasticity in financial satifaction . . . . . . . . . . . 107

A3.2 Simulated Income data . . . . . . . . . . . . . . . . . . 108 
A3.3 Manipulated satisfaction data . . . . . . . . . . . . . . . . . 109

A3.4 Complete estimations results for the tables in the paper . . . . . . . 110

A3.5 Estimates for RQ1 and RQ2 with unequivalized household income . . 114

Bibliography

115 


\section{List of Figures}

1.1 Lowess regression of life satisfaction and income on years spent in school . . . 2

1.2 Life satisfaction question in the SOEP questionnaire . . . . . . . . . . . 4

2.1 Simplified illustration of the German school system . . . . . . . . . . . . . 23

2.2 Implementation of the C9 reform in West German federal states . . . . . . . . 24

2.3 Median duration of schooling before and after the reform, target and control group 26

2.4 Sample structure: sampled birth cohorts, relative to reform . . . . . . . . . . 32

2.5 Overall, direct and indirect effects of education on life satisfaction . . . . . . 38

2.6 Overall, direct and indirect effects of education on life satisfaction . . . . . . 41

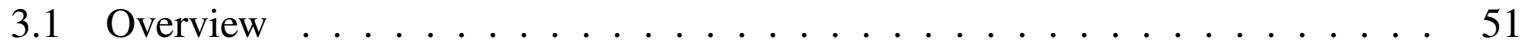

3.2 Within-couple differences in financial satisfaction. . . . . . . . . . . 54

4.1 Age- and wave-related heteroscedasticity in income . . . . . . . . . . . . 74

4.2 Age- and wave-related heteroscedasticity in life satisfaction . . . . . . . . . 75

A1.1 Median duration of schooling before and after the reform, target group in Bavaria 84

A1.2 Education distribution in the target sample, by gender and reform status . . . . 86

A3.1 Age- and wave-related heteroscedasticity in financial satisfaction . . . . . . . 107

A3.2 Kernel density estimation for observed income and random income-like variable 108

A3.3 Frequencies for reported and manipulated satisfaction levels . . . . . . . . . 109 


\section{List of Tables}

1.1 Overview on Studies _. . . . . . . . . . . . . . . . . 15

2.1 Sample descriptives for the target sample . . . . . . . . . . . 33

2.2 Endogeneity of track choice . . . . . . . . . . . . . . . . 34

2.3 OLS, RE and RE-IV regression of life satisfaction on years of education . . . . 36

2.4 RE-IV regression of life satisfaction on years of education and mediators, and of mediators on years of education . . . . . . . . . . . . . . . . 37

2.5 Gender-separated RE-IV regression of life satisfaction on years of education and mediators, and of mediators on years of education . . . . . . . . . . . 40

3.1 Sample mean and standard deviation of relevant variables . . . . . . . . 53

3.2 Determinants of differences in financial satisfaction and of financial satisfaction 58

3.3 Subsample estimates . . . . . . . . . . . . . . . . . . . 60

4.1 Sample descriptives . . . . . . . . . . . . . . . . . . . . . 74

4.2 Squared residuals of endogenous regressors and exogenous controls . . . . . 75

4.3 FE-IV and FE estimations of RQ1: Utility of equivalized household income . . 77

4.4 FE-IV and FE estimations of RQ2: Life satisfaction causing household income 79

4.5 Re-estimations of $\mathrm{H} 1$ and $\mathrm{H} 2$ : For simulated random income and manipulated satisfaction depending on simulated income . . . . . . . . . . . . . . 80

4.6 FE-IV and FE estimations of RQ1: Income causing financial satisfaction . . . . 81

4.7 FE-IV and FE estimations of RQ2: Financial satisfaction causing equivalized income . . . . . . . . . . . . . . . . . . . 82

A1.1 National unemployment and employment rates . . . . . . . . . . . . 85

A1.2 OLS, RE and RE-IV regression of life satisfaction on years of education - target sample . . . . . . . . . . . . . . . . . . . . 87

A1.3 OLS, RE and RE-IV regression of life satisfaction on years of education - control sample . . . . . . . . . . . . . . . . . 88

A1.4 First stage regression of years of education on reform $\ldots \ldots \ldots$ 
A1.5 RE-IV regression of life satisfaction on years of education and mediators and of mediators on years of education . . . . . . . . . . . . . 90

A1.6 RE-IV regression of life satisfaction on years of education and mediators and of mediators on years of education - Females . . . . . . . . . . . . . . . 92

A1.7 RE-IV regression of life satisfaction on years of education and mediators and of mediators on years of education - Males . . . . . . . . . . . . . . . . . . 94

A1.8 IV regression of life satisfaction on duration in school . . . . . . . . . . . 97

A1.9 IV regression of life satisfaction on years of education - without respondents from Lower Saxony and Saarland ． . . . . . . . . . . . . . . . . . . . . . . 98

A2.1 Financial satisfaction and relative employment status as distribution factor . . . 100

A2.2 Differences in financial satisfaction and financial satisfaction in strict male breadwinning couples . . . . . . . . . . . . . . . . . . . . . . 101

A2.3 Differences in financial satisfaction and financial satisfaction in mild male breadwinning couples . . . . . . . . . . . . . . . . . . . . 102

A2.4 Differences in financial satisfaction and financial satisfaction in double full-time couples . . . . . . . . . . . . . . . . . . 103

A2.5 Differences in financial satisfaction and financial satisfaction in strict male breadwinning couples $-2 \ldots \ldots \ldots$. . . . . . . . . . . . . 104

A2.6 Differences in financial satisfaction and financial satisfaction in mild male breadwinning couples $-2 \ldots \ldots \ldots \ldots$. . . . . . . . . . . . . 105

A2.7 Differences in financial satisfaction and financial satisfaction in double full-time couples $-2 \ldots \ldots \ldots \ldots$. . . . . . . . . . . . . . 106

A3.1 Estimates for RQ1: Equivalized income causing life satisfaction . . . . . . . 110

A3.2 Estimates for RQ2: Life satisfaction causing equivalized income . . . . . . . . 111

A3.3 Estimations for RQ1 and financial satisfaction . . . . . . . . . . . . . . . . 112

A3.4 Estimations for RQ2 and financial satisfaction . . . . . . . . . . . . . 113 


\section{Acknowledgements}

Writing this dissertation took me longer than I would have expected if I have had any expectations. I started this endeavor without much reflection; it was an opportunity that I took.

I would neither have begun nor finished the dissertation without the endowment that I owe to my parents. They exemplified me that happiness is fundamental for a good life and they taught me the discipline that is necessary to bring things to an end.

I am grateful to three academic teachers for their influence and support. Johannes Schwarze was the first who made me aware of welfare and happiness economics. His liberal mind set, his focus on the happiness of people without putting individual happiness above everything, still shapes my ideals. Guido Heineck promoted me in all the years. I am very grateful that he had so much confidence in my ability for empirical research that he encouraged me in pursuing my interests. He supported my research patiently with advice on all questions and by keeping the unproductive activities that the daily routine of a chair entails as far away as possible from his doctoral students. It was foremost Guido who showed me that academic content can be presented in an easy and pleasant way. Thanks to his encouragement to participate in international conferences, I was able to practice this and enter into scientific exchange with other researchers. My family and I benefited greatly from his generosity and understanding whenever non-academic tasks required my attention. Christoph Wunder generously offered clear and helpful comments on all research outputs that I presented him. I gladly let myself be guided by his joy of thinking in one direction and in the other, and I was encouraged by his attitude of seeing scientific problems as a welcome challenge and open scientific exchange as an opportunity to learn from each other.

I am glad that Caspar Kaiser spontaneously joined in my research idea, which was based on an econometric method that is not yet established. Thanks to him, who challenged my ideas and methods with his clear and critical thinking, I could improve my understanding and my arguments. Anica Kramer gave me advise on how to organize and solve tasks efficiently whenever I asked her - straightforwardly and cordially. When I struggled with the NEPS data, I benefited a lot from Jacqueline Lettau's expertise that she generously offered. I would not have had that much fun and pleasure if I had not met so many nice and inspiring people at conferences. The ISQOLS-based friendship with Antje Jantsch helped me through the ups and downs of the final phase of writing, hesitating and going on.

Without the support of my mother-in-law I would not have been able to write my dissertation - she had great respect for my research and happily took on as much childcare and housework as possible to give me more time for my work. The daily distraction and love from my children kept me going when scientific success seemed a long way off. I owe immeasurable thanks to my husband, who enabled me to attend conferences by taking over the household with three small 
children as a matter of course and allowing me to retreat at home at any time. He comforted me when I had setbacks, he shared my enthusiasm and joined in my happiness about what I achieved.

Writing this dissertation was not satisfying every day, but looking from the end it was an opportunity to flourish and grow. I am grateful and happy that this opportunity was given to me.

Bamberg, May 11, 2020

Susanne Elsas 


\section{Chapter 1}

\section{Synopsis}

\subsection{Introduction}

The conditions for a happy life are discussed in antique moral philosophy, most prominently by Aristotle, and in 17th century utilitarian philosophy. They have been empirically analyzed by social scientists since the 1970s. My thesis is placed in the field of empirical, socioeconomically oriented happiness research, which focuses subjective well-being, and within this contributes to each of its three main branches (Clark 2018): satisfaction as an outcome (Chapter 2), satisfaction data as a means to test a crucial hypothesis in welfare economics (Chapter 3 ) and satisfaction as a cause (Chapter 4).

\subsubsection{Why analyzing subjective well-being?}

One might argue that objective measures of well-being (such as income, access to and quality of education, housing and health care, or implementation of human rights) are sufficient, and whenever people live in objectively good conditions, they live a good life. However, it is possible that people who live in objectively good conditions are unhappy with their lives or, vice versa, people living in objectively bad conditions are happy. For a thorough understanding of well-being, objective welfare measures can be complemented by analyses of subjective evaluations. Especially when results from objective and subjective measures diverge, comparing both can be fruitful and reveal, for example, unintended consequences of policies.

Such a case is depicted in Figure 1.1. It shows a plot of lowess estimates of equivalized income and of life satisfaction, which is interpreted as a measure for subjective well-being. Both income and life satisfaction are conditioned on education. Higher incomes coincide with higher education, yet life satisfaction does not increase but rather decreases with years in school. ${ }^{1}$ The

\footnotetext{
${ }^{1}$ This estimation refers to a sample of adults aged 51 to 72 who attended basic or intermediate-track schools in West Germany, the "target sample" in Chapter 2.
} 


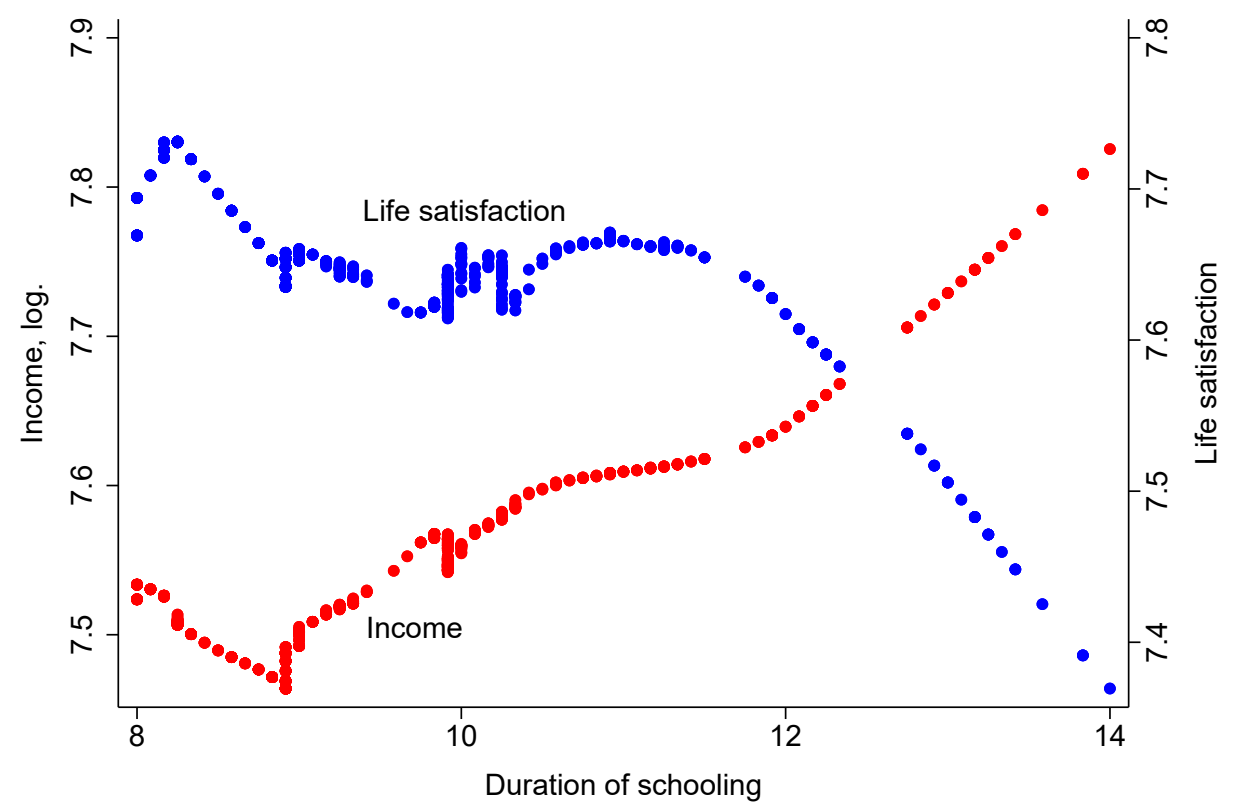

Figure 1.1: Lowess regression of life satisfaction and income on years spent in school

Source: NEPS SC6 v9.0.1, own calculations.

Notes: Income is monthly net household income, equivalized and in log values. $\mathrm{x}$ are lowess estimates with a bandwidth of 0.8 on 605 individuals who reported 8 to 14 years of schooling, where duration in schooling is the reported years in general education. Variable and sample description in Chapter 2.

mandatory increase in education, though it increased income, obviously had side effects that negatively affected the individuals' overall assessments of their lives. Analyses of satisfaction data can reveal such unexpected effects that would not be found if research focused only on isolated effects of education, for example on income or health behavior or social participation. Revealed divergence between subjective and objective measures can then be the starting point to searching systematically for unintended side effects. Research on subjective well-being can thus provide the information required to build and maintain a good society that promotes people's happiness.

\subsubsection{Well-being, happiness, utility and satisfaction}

No general agreement exists about the meaning of and relations between the concepts utility, happiness, well-being and satisfaction. For the subsequent analyses, satisfaction data are interpreted as a manifestation of prudential happiness. According to Sirgy (2012), prudential happiness is one of three separate theoretical concepts of happiness or well-being; it is distinct from psychological happiness and eudaimonic well-being and can be understood as the cognitive and evaluative component of happiness or well-being. 
There are two different approaches to the concepts well-being and happiness: the eudaimonic and the hedonic approaches. Eudaimonic well-being is reached when people grow to their full potential, in every aspect of life, morally, cognitive and physically; researchers from the eudaimonic tradition thus prefer the word well-being over happiness because the latter does not capture the full spectrum of human flourishing (Zevnik 2014, (p.8)). Empirical research based in the hedonic tradition often uses the words well-being and happiness without any thorough distinction and hence interchangeably (Haybron 2000) to label the latent theoretical concept. Within the hedonic tradition, Sirgy (2012) further distinguishes two separate happiness concepts - psychological and prudential happiness. Psychological happiness focuses only on the emotional aspects of well-being while prudential happiness is placed in between eudaimonic well-being and psychological happiness: It is a "state of well-being that involves both, feelings of happiness and the action that generates personal growth" (Sirgy 2012, p. 13). In the hedonic tradition, whether or not an action generates personal growth is subject to introspection and cognitive evaluation. Prudential happiness, hence, emphasizes an individual's integrity in focusing on his or her own, subjective, judgment about what makes him or her happy.

The integrity of the individual, the focus on individual judgment of happiness and the cognitive evaluation are manifested in satisfaction data. When individuals answer satisfaction questions, they evaluate their lives, or certain domains of it. Thereby they emphasize the different aspects of their lives according to their own needs, goals and ideals - at best. One person gives more weight to immediate pleasure while the other gives more to contemplation and a third emphasizes altruism. Many empirical happiness studies use satisfaction data to measure either well-being or happiness and are more or less explicitly based on the conceptualization sketched above (Sirgy 2012). Happiness studies in Economics to some extent interpret satisfaction data as a measure of utility, which they more or less explicitly equate to the philosophical concept of happiness. This equation stems from (Bentham 2000, pp. 14), who emphasized the pleasure aspect of happiness or utility, which clearly matches the psychological happiness concept. Nevertheless, happiness economics is not restricted to the narrow psychological understanding of happiness since the concept of prudential happiness integrates the cognitive-evaluative component. And cognitive evaluation is in accordance with the idea of an economic agent who (rationally) chooses between alternatives and who is ex-post satisfied or disappointed with his or her choice. This ex-post evaluation (of own choices) relates utility to satisfaction data (Layard et al. 2008).

In the three subsequent studies, I focus on prudential happiness and therefore use data on either satisfaction with household income or satisfaction with life in general. For utility, for happiness and for well-being, satisfaction data are not an exact measure but a measure that is based on assumptions, which I mention in Section 1.3. 


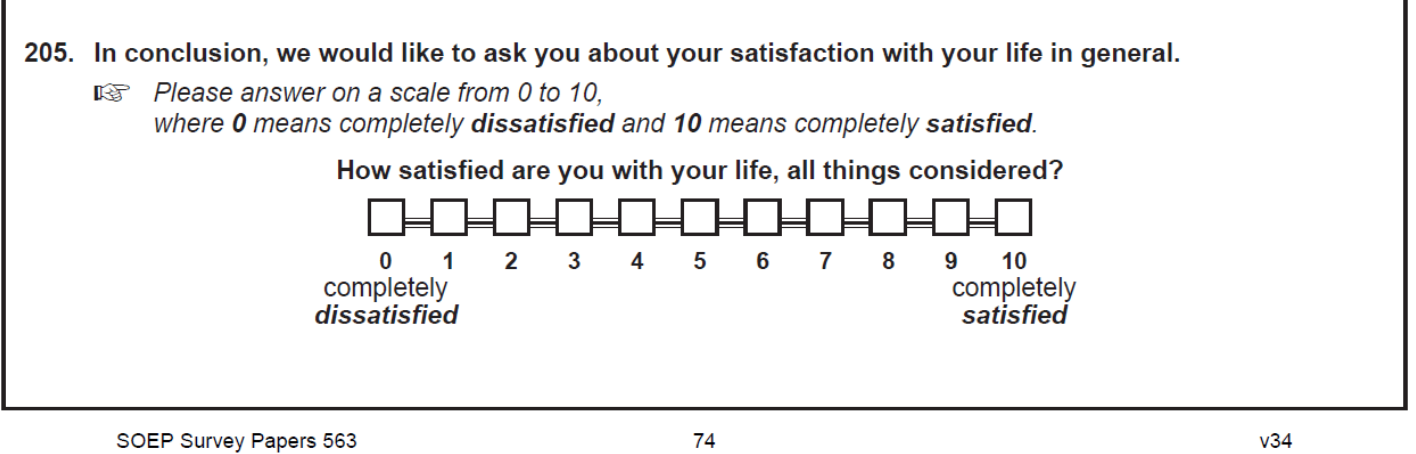

Figure 1.2: Life satisfaction question in the SOEP questionnaire

Source: Kantar Public (2020)

The satisfaction data used in the subsequent chapters come from the German Socio-Economic Panel Study (SOEP) and the National Educational Panel Study (NEPS). In both studies, the satisfaction data are measured on an eleven-point scale and the SOEP questionnaire visually supports the scale, see Figure 1.2. NEPS data are gathered without this visual support because they are mostly gathered in telephone interviews.

\subsection{Three branches of empirical happiness research}

Empirical happiness research (in the hedonic tradition) uses satisfaction data for broadly three different purposes, which I pickup in the three studies of this dissertation. First, it is used to investigate the question of what makes people happy or what promotes happiness in societies. Second, empirical happiness research, and therein especially happiness economics uses satisfaction data to analyze puzzles and paradoxes in economic theory, whereof the Easterlin Paradox is probably the most famous. The third major purpose is for research on the "objective benefits of subjective well-being" (De Neve et al. 2013), i.e. research on the consequences of happiness or questions about what happy people do.

\subsubsection{Satisfaction as an outcome}

Thousands of studies analyze correlates of life satisfaction such as income, family, employment, air quality and many more (for an overview, see Clark 2018). All those studies where satisfaction is the outcome require that satisfaction scores can be meaningfully compared between individuals and over time. If and under what conditions this requirement is met is discussed in Section 1.3. 
This strong research branch can be structured according to the time dimension considered: most studies analyze satisfaction and its simultaneous correlates, such as marital status, income, occupation, educational achievement; some studies focus on how people recover in terms of life satisfaction after detrimental life events, such as divorce, unemployment or accidents (Lucas 2007, Clark and Georgellis 2013). Orthogonal to the considered time dimension, the distinction can be made between studies that analyze the effect of exogenous shocks, for example, the award to host Olympic games (Dolan et al. 2019), and those that analyze correlates of happiness with individual actions or choices or their consequences, for example, income, marital status, occupation or education.

Studies that are able to identify causal effects of these individual attributes on satisfaction are, though, rare, except for those that are ontologically exogenous, such as gender or age. My study on direct and indirect utility of education addresses exactly this scarcity since I analyze the effect of an exogenous increase in education on later adult life satisfaction. Since the increase in education was exogenous, it identifies the subjectively perceived value of one further year of education, i.e. the causal effect of education on life satisfaction. Few other studies identify causal effects of education on life satisfaction; long-term effects of education in Germany have only been analyzed in one other study by Dahmann and Schnitzlein (2019).

When a focus is put on objective welfare, it would be sufficient to know objective outcomes of education (higher incomes, better health, more stable partnerships, ...) to conclude that education fosters individual well-being. The individuals themselves, however, might evaluate also other, less tangible aspects of education, and they evaluate all aspects as these blend. Complementary to the holistic perspective, which investigates the overall effect of one further year of education on life satisfaction, the analysis in Chapter 2 aims to separately estimate the direct effect of education on life satisfaction and the effects that are mediated through income, health or other adult outcomes of education. The results of my analysis indicate that the additional mandatory year of education negatively impacts life satisfaction. They hence challenge the naive assumption that more education is better than less, and open the door to deliberating the conditions of valuable education.

\subsubsection{Satisfaction data as a means}

Happiness economists typically apply satisfaction data to challenge hypotheses of economic theories. This is possible because micro-economic theory is based on the concept of individual utility, and individuals are understood as maximizing their own utility. Classic economic theory starts from the notion of hypothetical, self-interested individuals who seeks to maximize their personal utility (Mill 1844). Based on that notion, the theory of revealed preferences states that every observed set of choices is the optimal set that yields the highest utility under the given conditions (Samuelsen 1947). The theory of revealed preferences, which assumes rationally 
choosing agents, can be challenged by results from satisfaction data analyses that yield further insights about choices and especially about the individual's ex post evaluation of choices. Such results then show that not all choices reveal an individual's preferences but even more bounded rationality that causes suboptimal choices. The analysis of satisfaction data could as well yield insights about conditions that were not part of the theory, e.g., certain arguments in the utility function.

Three arbitrarily chosen studies provide examples for that kind of happiness economics research. The study by Schwarze and Winkelmann (2011), who use satisfaction data to analyze how parents' preferences are altruistic regarding their children, i.e. how individual utility functions can be inter-personally related. Wunder and Schwarze (2014) test and reject Posner's argument for intra-couple transfer of health spending from old women to old men. Bartolini and Sarracino (2018) use satisfaction data to derive long-term discount rates regarding concerns for future generations.

Analyzing satisfaction as an outcome requires that satisfaction data are comparable between individuals (and over time). Using satisfaction data as a means to challenge hypotheses about utility, however, poses a further demand on satisfaction data: They must not only be comparable between individuals and over time but also a valid measure for the concept of utility. Satisfaction data then allow the concept of utility to be analyzed more directly than it could be through revealed preferences and also allows some founding assumption about it to be challenged.

The study in Chapter 3 uses satisfaction data to analyze income sharing in couples. There, I argue that systematic satisfaction differences between partners in a joint household represent systematic differences in the utility they each get from their household income, and differences stem from unequal income sharing. The conclusion from satisfaction differences to income sharing is built on the argument that household partners expect equal sharing and adjust their expectations to the same overall amount of income. Partners whose experienced utility of their income is relatively lower than their expectation are less satisfied than partners who are relatively better off.

The result that partners do not share their household income equally refutes the equal sharing assumption, which is one crucial assumption in welfare economics. Couples rather share their household income according to their financial contribution, and men and women even value their contributions differently. The study thus uses satisfaction data to test the equal sharing hypothesis and moreover enhances the understanding of sharing behavior in couples. In principle, such a result should be followed by a refinement of the sharing-within-households assumption. This refinement, however, is difficult because each partner's share of the household income cannot be straightforwardly computed, even after the pattern of unequal sharing is detected. 


\subsubsection{Satisfaction as a cause}

A problem for both aforementioned approaches, satisfaction as an outcome and satisfaction data as a means, is that of reverse causality, i.e. simultaneity of satisfaction and its determinants. If satisfaction causes its determinants, straightforward statements on determinants of happiness might be biased.

Satisfaction could cause its determinants in two different ways, ways that are even opposing and would predict different effects: Dissatisfaction as a motivation to improve things on the one hand and satisfaction as a prerequisite for success on the other hand. First, people can purposely act on their dissatisfaction. Freeman (1978) was one of the first to show that job dissatisfaction can predict job quitting behavior. The subjective evaluation inherent in the job satisfaction measure entailed the individuals' evaluation of their (work place related) circumstances, their expectations and thus finally their intentions to change something to restore happiness. The argument, though, that dissatisfaction is a motivation to induce changes is scarcely present in the empirical happiness research.

Second, satisfaction might trigger physiological processes within the individual or actions in people's social environment that are outside the scope of the happy person's purpose. Examples of the physiological processes that are positively influenced by happiness are linked to the immune and the cardiovascular systems (Diener and Chan 2011). With regard to outcomes out of the individual's scope, Boehm and Lyubomirsky (2008) conclude that happy people are more popular and likable, which might turn into a higher probability of being married (Stutzer and Frey 2006), being contacted in a social network or offered a job or a promotion (Peterson et al. 2011).

All such studies show positive effects of happiness on desirable outcomes. Consequently such research, though it usually states that normative arguments are sufficient to make happiness an end in itself, often emphasizes the instrumental value of happiness: De Neve et al. (2013, p. 2), for example, argue that "However, a better understanding of the objective benefits of raising happiness may also help to put happiness more center-stage in policy-making [...]." I do not want to follow the line of objective benefits of subjective well-being because this could - in the logical extrapolation - lead to an Orwellian society where policies manipulate people's perceptions and evaluations instead of improving their real-world living conditions.

The study in Chapter 4 (co-authored by Caspar Kaiser ${ }^{2}$ ) emphasizes that causal effects must be identified because endogeneity is present in many applications in empirical happiness research. If this endogeneity is neglected, the effects of the determinants of happiness are likely to be estimated with bias. Since it is known that happiness and satisfaction promote productiv-

\footnotetext{
${ }^{2}$ Kaiser contributed half of the literature review, the first data retrieval, critical comments about the method, the idea to employ J-Test to judge the quality of the estimation, the residual plots, and editorial improvements especially in the description of model and identification strategy.
} 
ity and thus earned income, the analysis in Chapter 4 therefore investigates whether satisfaction effects transmit even to the equivalized household income. This is a priori not clear because equivalized household income is less closely connected to productivity than is earned income so that one could therefore argue that the simultaneity issues is mitigated. Equivalized income is so far the most used income measure for welfare analyses that analyze satisfaction as an outcome of income. It must therefore be ensured that estimates of the welfare effect of income are not overestimated due to reverse causality.

Results show that life satisfaction has no causal effect on equivalized income. This is both good and bad news: Good news because it means that reverse causality is no problem in estimating the utility of income; bad news because results also show that the causal effect of income on life satisfaction could be zero, which would mean that most other estimates overstate the utility of income. This overstatement probably arises because the estimates suffer from some other form of endogeneity, other than individual-specific fixed effects or reverse causality.

\subsection{Challenges in empirical happiness research}

Using subjective data for objective research provokes objections and discomfort: Is satisfaction a reliable measure or prone to measurement error? Is it a valid measure for true happiness? And is satisfaction data comparable between individuals and over time?

\subsubsection{Data issues}

With respect to reliability of satisfaction, objections may arise that life satisfaction data are influenced by random and non-random noise, such as interview mode, interviewer personality, interview weekday and events in the last days. Thus in the 1980s and 1990s, the early years of happiness studies, much psychological research focused on biases in self-assessed well-being (for an overview, see Sirgy 2012, pp.574). Most studies concluded that satisfaction data suffer from measurement error due to random and non-random noise, and moreover that people's answers are differently affected by this noise (for an overview, see Schwarz and Strack 1999). In response to these findings, studies focused on the severity of this bias and hence on whether self-assessed well-being (measured, inter alia, with satisfaction data) was reliable and valid despite measurement error. Diener and Suh (1999) report that self-assessed well-being correlates strongly with well-being assessments by friends or relatives or interviewers. This correlation, the predictive power of satisfaction data and the fact that satisfaction data follow patterns that theories on well-being would predict are taken as arguments for the reliability and validity of subjective measures such as satisfaction (for an overview, see Sirgy 2012, pp.574).

A further data issue concerns scaling of satisfaction data and thus the question of which methods and techniques are suitable for data analysis: Does satisfaction data require refraining 
from using any method that assumes metrically scaled data, or does it allow such methods to be applied. This discussion was first closed with the work by Ferrer-i-Carbonell and Frijters (2004), who found that results from happiness regressions are not particularly sensitive to the choice between estimators for discrete data or those for continuous data. Their work therewith set the standard for estimations in empirical happiness research and also the estimations in the subsequent studies. Using linear estimators, which are appropriate for continuous data, for analyses of data in eleven discrete units is justifiable if the individuals who perceive a continuum of true satisfaction divide their personal continuum into eleven equally-spaced units. If the individuals are then able to locate their true satisfaction in one of these units and then respond to the satisfaction question in giving the number of the unit wherein their truly perceived satisfaction lies, methods for continuous data can be applied.

The discussion re-started with Bond and Lang (2019) stating that the results of most happiness research are reversible if other than the normal distribution of the error term in the econometric model are assumed. The distribution of the error term also determines the appropriateness of estimation methods. Kaiser and Vendrik (2019b) show how Bond \& Lang's reversal conditions turn out to be implausible for household income, unemployment, childbirth, sickness and marriage. Thus, the results in Kaiser and Vendrik (2019b) support again applying methods normally used for metrically scaled data when analyzing satisfaction data (on an eleven-point scale). In the subsequent chapters (and many other studies in empirical happiness research), estimation methods for metrically scaled data are thus applied.

\subsubsection{Reference dependence}

One aspect that psychologists discuss under the headline of bias requires special focus; the valuation of one's life, or aspects thereof, depends on the surrounding situation and circumstances and past experiences, i.e. is reference dependent. To some extent, this dependency can be understood as a bias or a sort of bounded rationality, when, for example, the value of a certain amount of money depends on winning or loosing this amount, on the amount the person won before or on the amounts others won in the same situation (Kahneman and Tversky 1979).

Reference dependence, on the one hand, clearly challenges comparability of satisfaction data, when objective well-being is the focus, and an objective welfare effect of, e.g., income should be measured. On the other hand, outside the laboratory, and bearing in mind that satisfaction is a subjective measure, these patterns appear less irrational since they anchor people's valuations to their own histories and to society. People form expectations about (aspects of) their life with respect to past experiences, relevant others and of course wider societal trends (Duesenberry 1949, Kapteyn et al. 1978, Stutzer 2004, Gilboa and Schmeidler 2001). They then value their own achievements and conditions with reference to these expectations. Much work in social science happiness research therefore focuses on social and inter-temporal comparison 
(i.e. adaptation) in the evaluation of a person's own life or aspects thereof (for an overview, see Clark et al. 2018).

The importance of social comparison was most prominently introduced by Duesenberry (1949), who states that an individual's utility depends on her or his consumption relative to the consumption of others. Individuals feel relative satisfaction if their own consumption is relatively high, and relative deprivation if their own consumption is relatively low. The former increases satisfaction while the latter decreases it, meaning that the same absolute level of consumption differently impacts satisfaction depending on an individual's reference level. This concept is transferred to other domains of life and satisfaction, with probably most research on income satisfaction and reference or comparison income. An overview of the earlier studies in this large strain of literature is given in Clark et al. (2008b). They mainly address the question of whether income comparisons are relevant for satisfaction and whether this relevance might explain the Easterlin paradox. More recent research on reference dependence analyzes the asymmetry of social comparison, e.g., D'Ambrosio and Frick (2012) find that comparisons with richer people reduce satisfaction while comparisons with poorer people do not enhance satisfaction.

When social comparisons are considered in empirical work, the derivation of the particular reference income level for the individuals under study is both pivotal and also subject to the researchers' decisions. Some practical issues thus need to be addressed concerning the derivation method and the composition of the reference group. Pfaff (2013), for example, examined how results are sensitive to - inter alia - the choice of one of the two concurring methods to generate particular reference income levels; researchers could predict a reference income level from a Mincer type estimation or use the mean income of the group of similar individuals. He concluded that results are indeed sensitive to this choice of method.

Additionally to the choice of method, empirical research on reference income effects must define the comparison group. Comparison groups are usually constructed according to individual and household characteristics in a way that assumes that people compare themselves to similar others. Comparison groups with respect to income are usually constructed along age class, education categories and region (Bartolini et al. 2013, Ferrer-i-Carbonell 2005, Vendrik and Woltjer 2007), whereby regions of very different spatial extent can make sense, from near neighborhoods to counties or even countries. Others add gender (Ferrer-i-Carbonell 2005, Vendrik and Woltjer 2007), but gender is only in single households a relevant and significant predictor of the household income. The majority of households consists of a man and woman who share their incomes. Among others, Goerke and Pannenberg (2015) directly analyzed the intensity of explicit comparisons to different self-reported reference groups (i.e. colleagues, friends or neighbors) and the impact of these comparisons. Using SOEP data, they found sup- 
port for the assumption that people compare to similar others, colleagues and friends but less so to neighbors.

Other domains of life are also subject to comparison, e.g., education (Nikolaev 2016, Kristoffersen 2018), unemployment (Knabe et al. 2016) and body weight (Blanchflower et al. 2009). Reference levels for these domains, i.e. an individual's reference level of education or body weight, might need to be constructed with reference to other individual characteristics such as, e.g., gender. In the subsequent analyses, social comparison is directly taken into account in Chapter 4. There, a comparison income is computed and considered in one of the satisfaction equations. In Chapter 3, however, where I analyze within-couple differences in satisfaction, I assume that both partners in a household compare their household income to the same reference level, and thus controlling for this reference level would not add anything in explaining satisfaction differences between the partners. In Chapter 2, I refrained from controlling for reference effects because the focus of the analysis is the overall effect of education, which can be understood as the effect of education for the given education distribution.

In addition to social, i.e. inter-personal comparison, inter-temporal comparison, i.e. adaptation, forms people's expectations, which then determine their current valuations of (aspects of) their lives. ${ }^{3}$ If people adapt to living conditions, objective and subjective measures of wellbeing diverge further and the latter become thus more important as an additional source of information.

\subsubsection{Endogeneity}

The data issues mentioned before are suspected to bias the conclusions from satisfaction data on happiness. Endogeneity is a further challenge in empirical happiness research because it could bias the estimates of satisfaction determinants if the chosen estimator does not sufficiently consider endogeneity. Simply put, endogeneity means that many possible causes of satisfaction might themselves be results of satisfaction or dissatisfaction or depend on the the

\footnotetext{
${ }^{3}$ Adaptation has a positive as well as a negative connotation. The negative connotation comes from the notion of bias: The same amount of income is worth more the first year it was earned than in the second, third or any other year (see for example D'Ambrosio and Frick 2012, Bartolini et al. 2013, Layard et al. 2010, Di Tella et al. 2010, Boyce et al. 2013a). A sophisticated analysis that found supportive evidence for adaptation to income is that by Vendrik (2013). Yet Kaiser (2018), in a similar setup but additionally controlling for the household partners employment status, found that people do not adapt to income increases. The positive aspect of adaptation is recovery: People can recover from detrimental life events, for example, widowhood (Clark and Georgellis 2013), but a person does not necessarily recover from every detrimental life event: Unemployment, poverty and disability are examples where research found persistent negative effects on life satisfaction (Clark et al. 2008a, Frijters et al. 2011, Oswald and Powdthavee 2008, Clark and Georgellis 2013). People can, though, recover from unemployment, as Hetschko et al. (2014) found, when their frame of reference changes due to retirement. When people retire, the detrimental effect of unemployment no longer persists because the reference group, those of the same age, also do not work due to retirement. Yet, those who were involuntarily unemployed are, even after retiring, less satisfied with their lives than retirees who did not experience unemployment Hetschko et al. (2019).
} 
same unobserved factors as satisfaction. Endogeneity thus impedes interpreting estimates of straightforward satisfaction regressions as effects on satisfaction, and methods are required that can cope with endogeneity if estimates should be interpreted as effects. The problems raised by endogeneity are mostly the same, regardless of the origin of endogeneity: If endogeneity is not sufficiently taken into account, estimation results cannot be interpreted as effects. Nevertheless, reflecting on the causes of endogeneity might make sense because different causes may produce different forms of endogeneity that could be cured with different estimation procedures.

\section{Time-constant individual specific effects}

A much-addressed form of endogeneity originates in individual time-constant common factors of satisfaction and its determinants, such as innate abilities or personality traits that might foster or hinder happiness and its determinants. Some of the conditions for life satisfaction are likely to be set in childhood (Layard et al. 2014), through early learning or by genes or epigenetics, which summate to a person's family background; a person's basic happiness, as well as his or her earnings potential and state of health, which are important determinants of satisfaction, depend in part on these prerequisites set in early childhood. Family background is thus a typical common factor that causes endogeneity even of early determinants of satisfaction, and it is a factor that is difficult to measure adequately.

This form of endogeneity can be circumvented with individual fixed effects estimations, as applied in Chapter 3. Individual fixed effects estimation requires panel data, and fixed effects also absorb any other time constant effect in the model, e.g., gender effects or effects of birth cohorts. Such time-constant causes hence drop out of the estimation. Mundlak (1978) formulated a solution for this problem by proposing not to subtract but rather to include the mean-overtime in the estimation. Then, the time-constant variables can remain in the estimation (but the estimate for them can only be interpreted as effects if these time-constant variables are not endogeneous themselves). In Chapter 2, I include these Mundlak terms to control for individual fixed effects that influence life satisfaction, income and self-rated health. ${ }^{4}$

Another solution to the same problem (that fixed effects estimation cannot be applied when time-constant determinants of satisfaction are in focus) is personality measures. To some extent, personality measures can proxy individual fixed effects (Lucas and Diener 2009). There is debate if personality traits are more variable than fixed (Boyce et al. 2013b). Yet, even if personality were to be less stable but captured unobservable conditions of both determinants and satisfaction, this approach would still have the advantage that it allows time-constant determinants of satisfaction to be analyzed but does not require panel data. In Chapter 2, personality

\footnotetext{
${ }^{4}$ The education effect is identified with another strategy, though in the same estimation, because full-time formal education is mostly acquired in only one period of full-time formal education and thus does not vary after this period is finished.
} 
measures are used to control for unobservable conditions of life satisfaction and unemployment and partnership stability.

\section{Time-varying endogeneity and reverse causality}

Endogeneity of determinants of satisfaction may also be time-varying. Reverse causality, explained under the heading "satisfaction as a cause" would be one such case. Other examples of time-varying endogeneity of determinants of satisfaction could be stress, mental health, changes at the work place or regional factors (which not only vary when people migrate but also during municipal development). This form of endogeneity is cured not by using panel fixed effects regression but by instrumental variable estimation. Instrumental variable estimation is applied in Chapter 2 to address endogeneity of education in the satisfaction regression. A thorough reflection on exogeneity of instruments in satisfaction regressions, however, reveals that it is difficult to find instruments that affect life satisfaction solely through the instrumented endogenous determinant. This search for instruments is specially difficult for satisfaction as an outcome because life satisfaction is a holistic measure, sensitive even to implicit and unexpected aspects, and subject to reference dependence: A sole influence of the instrument via the instrumented variable is difficult to establish.

If satisfaction is not the outcome of interest but the potential determinant for some other outcome, e.g., economic behavior, endogeneity might also be a problem, and instruments for satisfaction must be found. A convincing example of an instrument for satisfaction in the analysis of consumption and savings behavior is presented in Guven (2012), namely, unexpected sunshine.

In Chapter 4, since convincing instruments for equivalized income and life satisfaction were not available, I pursue a further identification method: internal instruments constructed from the model's data (Lewbel 2012). The broad idea is the same that as for external instruments, such as reforms or policies, but the source of exogenous variation of the endogenous determinant of satisfaction comes from heteroscedasticity in the model's data. These synthetic instruments are available if the model's data are heteroscedastic and if the model includes at least some reasonably exogenous variables. How exactly heteroscedasticity identifies causal effects of endogenous regressors is explained in more detail in Chapter 4.

\subsection{This dissertation}

In the research for this dissertation, I used different methods to address the aforementioned challenges satisfactorily. The most classic fixed effects estimation is applied in Chapter 3. Chapter 4 starts from there but then employs a more recent method to identify causal effects. The work shows that, even though fixed effects control for individual specific heterogeneity 
that influences both income (as one determinant of satisfaction) and satisfaction, the estimation of causal effects remains an issue, although reverse causality is not a problem in the income satisfaction link.

For other determinants, reverse causality might be more of a problem and thus more elaborated identification strategies than just controlling for fixed effects should be employed. This method is employed in Chapter 2, where an educational reform is used as an instrument for education in order to estimate the effect of education on life satisfaction. The analysis, however, reveals one difficulty: As life satisfaction is a holistic measure and subject to reference dependence, it encompasses so many aspects that instruments for distinct causes of happiness (e.g., education in Chapter 2) could violate the exogeneity assumption. The mandatory increase in education, for example, is not only an exogenous increase in education but might have had other, unintended effects on life satisfaction than only those via education. In contrast to other outcomes, satisfaction is prone to unintended side effects because of the inherent reference dependence arising here from people who were affected by the reform probably comparing themselves to those who are similar but were not affected. Similar effects might occur when other policies are used as instruments: Side effects might be negative, as sketched for the educational reform in Chapter 2, or they might be positive if the policy comes with the connotation that those who are affected are privileged in comparison to similar others.

Internal instruments appear to be a promising way out of this problem, and it is one contribution of this dissertation to apply and challenge this relatively recent method to identify causal effects. Internal instruments do not rely on external events, such as policies or eligibility thresholds, which might fail the exogeneity assumption in the satisfaction regression, because subjective evaluations are sensitive to certain other aspects of the external instruments. Internal instruments, in contrast, are free from these other aspects.

Empirical happiness research contributes knowledge about what makes a life good or a bad. Besides that, empirical happiness research helps to improve theories in other fields of research when satisfaction data is used as a means to test theories, e.g., those about income sharing. Research, though, often aims to enhance descriptions of correlates of satisfaction with an understanding of the causal mechanisms that generated the observed patterns. This, however, requires explicit identification of causal effects, which is always a challenge but in particular for holistic measures such as satisfaction.

This dissertation contributes to the body of literature on causes of satisfaction in so far as it is one of only two studies on long-term causal effects of education on life satisfaction in Germany. It shows that a mandatory increase in education had no positive effect on later life satisfaction but did have negative effects on male respondents' life satisfaction, even though the increase in education gave them higher incomes. This study highlights the supplementary value 
Table 1.1: Overview on Studies

\begin{tabular}{|c|c|c|c|}
\hline & 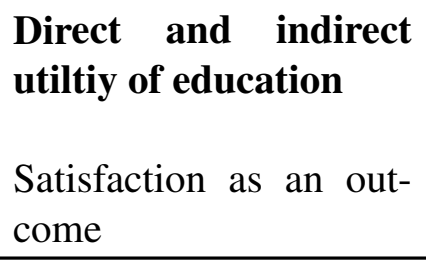 & $\begin{array}{l}\text { Income sharing within } \\
\text { households } \\
\begin{array}{l}\text { Satisfaction data as a } \\
\text { means }\end{array}\end{array}$ & $\begin{array}{l}\text { Causality in the } \\
\text { income-satisfaction- } \\
\text { link } \\
\text { Satisfaction as a cause }\end{array}$ \\
\hline Data & NEPS SC6 & SOEP Core & SOEP Core \\
\hline $\begin{array}{l}\text { Demand on } \\
\text { satisfaction } \\
\text { data }\end{array}$ & $\begin{array}{l}\text { Comparable between in- } \\
\text { dividuals and over time, } \\
\text { and monoton in per- } \\
\text { ceived utility. }\end{array}$ & $\begin{array}{l}\text { Comparable between in- } \\
\text { dividuals and over time, } \\
\text { and monoton in per- } \\
\text { ceived utility. }\end{array}$ & $\begin{array}{l}\text { Comparable between in- } \\
\text { dividuals and over time }\end{array}$ \\
\hline Method & $\begin{array}{l}\text { Instrumental } \\
\text { able (IV) estimation, } \\
\text { Correlated Random } \\
\text { effects }\end{array}$ & $\begin{array}{l}\text { Linear Panel fixed ef- } \\
\text { fects estimation }\end{array}$ & $\begin{array}{l}\text { Heteroscedasticity- } \\
\text { based IV estimation, } \\
\text { linear panel fixed effects }\end{array}$ \\
\hline Co-authors & - & - & Caspar Kaiser \\
\hline $\begin{array}{l}\text { Own con- } \\
\text { tribution }\end{array}$ & $100 \%$ & $100 \%$ & $80 \%$ \\
\hline
\end{tabular}

of satisfaction as a welfare measure and as an indicator for unintended effects. Identification of the causal effect relies here on the exogeneity of an education reform.

This dissertation further contributes to welfare economic theory with the analysis of patterns of unequal sharing of income within partnerships. Such a contribution would not have been possible without data on income satisfaction because equal sharing within households cannot meaningfully be analyzed in terms of equal amounts of money spent for each household member's needs. Comparison of satisfaction scores, however, can reveal sharing behind the curtains and disclose welfare inequalities. This study was one of the first to analyze intra-household sharing using satisfaction data from Germany.

This dissertation contributes, finally, to the understanding that estimating causal effects on satisfaction requires proper identification methods. As an example, it analyzes causality in the link between income and satisfaction using a promising internal instruments approach. It shows that, even though life satisfaction does not causally impact on household income, insufficient identification strategies may result in biased estimations of effects on satisfaction.

These subsequent studies, where I analyze satisfaction as an outcome, as a means and as a cause, together show exemplary the potential as well as the difficulties of empirical happiness research. 


\section{Chapter 2}

\section{Satisfaction as an Outcome: Direct and Indirect Utility of Education}

\subsection{Introduction}

The "returns to education" are an important concept to understand the individual motivation to invest in education and its benefits for both the individual and society. There is ubiquitous evidence on particularly monetary or labor-market related effects of education, in general showing that education affects individuals' lives positively through e.g. better labor market options and higher earnings (Becker 1994, Mincer 1974, Card 2001, Oreopoulos and Petronijevic 2013, Heckman et al. 2016). Another well-established research strand addresses so-called non-monetary returns to education including effects on individuals' health and health behavior (Hamad et al. 2018, Cutler and Lleras-Muney 2008, 2010, Silles 2009, Kemptner et al. 2011), or social and political participation (Milligan et al. 2004, Lochner and Moretti 2004, Machin et al. 2011, Hjalmarsson et al. 2015).

There however is only limited research on effects of education on subjective well-being or the overall quality of life, as approximated by individuals' life satisfaction and it is thus a still unsolved issue how different adult outcomes of education blend when contributing to overall quality of life: Many objective outcomes of education are positively associated with an individuals living standard, but with higher education indviduals' aspirations and stress may increase (Oreopoulos and Salvanes 2011) and affect life satisfaction negatively (Ferrante 2009, Kristoffersen 2018). Some authors (Kristoffersen 2018, Dolan et al. 2008, Nikolaev 2016) conclude that education is a positional rather than an absolute good, and increases in education thus only transmit to life satisfaction if education promotes social position. Finally, beyond its mediated impact via income, health, etc., education could have a further, direct effect on individuals' life satisfaction, which could be both positive or negative. Arguments for positive effects would follow the notion better educated people can make more out of every resource, 
such as income and leisure. While common sense would perhaps expect that knowing and understanding too much makes people unhappy.

Reflecting this theoretical ambivalence, previous research, as will be briefly presented in the following, yields inconclusive results and implies either negative, zero, or positive associations. These inconsistent patterns are however not too surprising, given that most of the studies do not employ adequate identification strategies, and that education affects life satisfaction directly, but also indirectly, through mediating factors, which most of the studies do not address adequately.

Beyond econometric arguments whether and how direct and indirect effects can be disentangled, or whether the overall value of education is the joint impact, that is direct and indirect effect together, there is another, yet common challenge to be tackled: The general and wellknown challenge in analyzing returns to education is that investment in education is endogenous and depends on individuals' ability, their expected returns to education, parental background, etc.. These determinants of investment in education and its returns in later life may also directly relate to adult life satisfaction, so that the analysis requires valid identification.

I add to the so far limited research that uses identification strategies to examine effects of education on life satisfaction (Oreopoulos 2007, Oreopoulos and Salvanes 2011, Dursun and Cesur 2016, Quis 2018, Dahmann and Schnitzlein 2019), which can be understood as a measure of cognitive aspects of subjective well-being. Similar to (Powdthavee et al. 2015), I also aim at identifying both the direct and the indirect causal effects of education on life satisfaction. I further contribute to the literature by looking at Germany, for which there is - to the best of my knowledge - only the study of Dahmann and Schnitzlein (2019) that analyzes the long-run effect of education on life satisfaction.

My identification strategy relies on the exogenous increase in compulsory schooling that was implemented across West German federal states at different times between 1949 and 1969 . This variation in schooling has been used as a valid source of exogenous variation before, by e.g. Pischke and von Wachter (2008), Kemptner et al. (2011), Cygan-Rehm and Maeder (2013) and Dahmann and Schnitzlein (2019). The data I use are part of the National Educational Panel Study (NEPS) which is particularly useful for my approach: NEPS respondents report their biography with respect to several domains of life, and especially their educational biography, in more detail than usually provided in data used by other studies. I can therefore identify for each year in the respondents' education biography the federal state where they attended school. This is a substantial improvement in accuracy compared to the data used by Pischke and von Wachter (2008), Kemptner et al. (2011), Cygan-Rehm and Maeder (2013) and Dahmann and Schnitzlein (2019).

Results of a 2SLS regressions indicate a negative overall effect of the additional year of education on life satisfaction. Other adult outcomes of education mediate only very little of this effect. Women and men were differently affected by the reform: Male respondents ex- 
perience negative effects through self-rated health and additionally direct negative effects on life satisfaction. These negative effects appear only for men and are probably only valid in circumstances where immediate opportunity cost but no immediate rewards are attached to a mandatory increase in schooling.

\subsection{Background}

\subsubsection{Theory}

No cohesive theoretical framework in economics explicitly covers the utility of education or its effect on life satisfaction, but two competing theories that explain non-market outcomes of education can contribute in explaining direct effects of education on life satisfaction. Both approaches use Becker's 1965 theory of the allocation of time and his notion of commodities, which are the fundamental objects of choice and actual arguments in the utility function. People produce these commodities using education as one crucial factor. First, according to the notion of productive efficiency (Michael 1972, Grossman 1972), better educated individuals obtain higher utility with the same (amount of) inputs than less educated individuals. Rosenzweig and Schultz (1982), in their theory of allocative efficiency, however question that the same inputs can generate higher utility and instead suggest that educated individuals use different and better inputs for the production of every-day commodities, which then increases utility. ${ }^{1}$ Qualifying one of these theories against the other would require detailed consumption data which I do not have. This however is not harmful for my purpose because both frameworks call for a direct positive effect of education. The productivity argument is mainly based on cognitive skills that students form in school, but education not only focuses on acquiring knowledge-based skills, but might equip students with non-cognitive skills as well. Some of them, such as adaptive coping skills and (techniques to) having positive thoughts (Snyder et al. 1997, Irving et al. 1998) might have long-lasting positive effects on life satisfaction.

Some other non-knowledge-based skills, e.g., critical thinking and social skills are also correlated with education (Cascio and Lewis 2014, Soskice 1993, Glaeser et al. 2005). If these are explicitly part of the curricula or depend on teacher and head master personalities or students composition is not important for my argument, as long as they increase with schooling. Oreopoulos and Salvanes (2011) state that "Social skills facilitate interaction and communication with others. They help individuals distinguish between acceptable and unacceptable behavior in different settings". These capabilities are obviously important in life but especially the ability

\footnotetext{
${ }^{1}$ The notion that education enhances the utility value of leisure (Franz 2013) fits with either theory about direct effects of education on life satisfaction. Both, allocative and productive efficiency imply higher utility value of leisure.
} 
to critically reflect can have negative effects on life satisfaction. Even if education enables the individual to behave (morally) acceptable, the educated individuals might observe behavior in society that they can - by critical thinking - qualify as unacceptable. Education might thus have a direct negative effect on life satisfaction.

In addition to these direct effects, indirect effects might be mediated through other outcomes of education, which affect life satisfaction. These may be understood as causal mechanisms (Imai et al. 2011), too. As mentioned before, a large literature (Card 2001, Oreopoulos and Petronijevic 2013, Heckman et al. 2016) provides evidence on beneficial effects of schooling on the labor market. ${ }^{2}$ Higher income is found in many studies to be associated to life satisfaction (e.g., Easterlin 1995, Oswald 1997, Diener and Oishi 2000, Frey and Stutzer 2002, Boyce et al. 2017). Only very few studies though identify causal effects as for example Frijters et al. (2004), Powdthavee (2010), Vendrik (2013), Kaiser (2018) and Lachowska (2017). Besides income, other labor market outcomes also affect life satisfaction. Most obviously unemployment is strongly associated with dissatisfaction with life (Winkelmann and Winkelmann 1998). If education reduces the risk and duration of unemployment, unemployment could act as a further mediator for the education effect.

On the other hand, education may as well lead to higher stress levels at the job, decreased leisure time and imbalances between career aspirations and success (Solberg et al. 2002, Kristoffersen 2018, Ferrante 2009). Frey and Stutzer (2002) conclude that education is likely to influence people's aspirations, and these strongly determine cognitive evaluations like life satisfaction (Clark et al. 2008a, McBride 2010, Frey and Stutzer 2002, Easterlin 2001, Ferrante 2009).

That education can have positive effects on health and health behavior, is also well-known (Silles 2009, Cutler and Lleras-Muney 2010, Kemptner et al. 2011, Brunello et al. 2016). In their very recent meta study on health effects of education, Hamad et al. (2018) though report mixed evidence. The importance of health for life satisfaction is consensual; for an overview see Garrido et al. (2001). ${ }^{3}$ Thus if education enhances health it could through this mediator contribute to life satisfaction.

In demographic research it is a stylized fact that (female) education and marital stability are positively associated at least in the last decades and in Western societies (for an overview: Boertien and Härkönen (2018)). Causal effects of education on partnership stability are only rarely analyzed, up to now. Oreopoulos and Salvanes (2011) supply one estimate of the change in divorce-rates before and after changes in compulsory schooling laws that increased minimum school-leaving age. They present evidence for a positive effect of education on partnership

\footnotetext{
${ }^{2}$ Interestingly, Pischke and von Wachter (2008), exploiting the same reform I use, find no such returns for Germany. Cygan-Rehm (2017) yet found positive monetary returns in her re-analysis, exploiting the same reform and data but drawing on improvements in observing compliance to the reform.

${ }^{3}$ Garrido et al. (2001) also report findings on the opposite effect.
} 
stability, the share of divorced respondents decreased with the reforms by 0.3 percentage points. Marriage is one important correlate of life satisfaction (Chapman et al. 2016, Dolan et al. 2008, Blanchflower and Oswald 2004). Since in my sample most respondents are married at the time of the interview being married does not qualify for a mediator. Instead, I focus on partnership stability as a mediator. I.e. if the respondent ever experienced a partnership dissolution up to the interview, irrespective of the legal status of the partnership. If partnership stability is affected by education and living in a good partnership is an important aspect of life satisfaction, education might influence life satisfaction through this causal mechanism.

Finally from Cygan-Rehm and Maeder (2013) it is known that education had a negative causal impact on the number of children on the relevant cohorts in Germany. Despite often insignificant associations between living with children and life satisfaction, ${ }^{4}$ Powdthavee et al. (2015) found significant education effects on life satisfaction mediated through the number of children and I therefore include it in my analysis as a possible mediator.

Thus it is an obvious question how these direct and indirect effects blend to an overall effect of education on life satisfaction and what fraction of this effect is mediated through income, health, unemployment or family life.

\subsubsection{Literature}

A large body of research uses education as a control variable in satisfaction equations, and depending on the other covariates the estimated coefficient is positive, negative and often insignificant.

Veenhoven (2010), drawing on hundreds of studies from the World Database of Happiness, ${ }^{5}$ concludes that "... education as such [... ] does not add to individual happiness, probably because its benefits are balanced by costs" (Veenhoven 2010, p. 348). This conclusion however would only hold if the estimates would be estimates of education effects rather than of correlations between education and life satisfaction. Moreover, many of these studies run analyses that condition on factors which themselves are on the one hand affected by education, such as health or labor market outcomes, yet on the other hand also affect individuals' overall assessment of life. Hence, the conceptual difficulty in the analysis of the effect of education on life satisfaction is mediation. The residual, direct effect could be of interest, as it might reflect the intrinsic value of education, while the overall effect might be of interest, because it reflects the blend of intrinsic and mediated instrumental values of education. Powdthavee et al. (2015) explicitly addresses this problem, using Australian panel data and a structural equation modeling approach. They show how the effect of education on life satisfaction is mediated through other outcomes of education, which then explains, why studies that hold these mediators constant

\footnotetext{
${ }^{4}$ One empirical explanation for this finding provides Pollmann-Schult (2014)

${ }^{5} \mathrm{http} / / /$ worlddatabaseofhappiness.eur.nl
} 
estimate negative associations between education and happiness. They found a negative direct effect of education on happiness, yet summing up direct and indirect effects they conclude that the overall effect, the sum of mediated and residual direct effect, is positive. To account for endogeneity of education they use fixed effects vector decomposition and via 3SLS they model cross-equation correlation of error terms. Their econometric approach though is questionable. Greene (2011) demonstrates that the estimator essentially assumes random instead of a fixed individual effects and that the effect of time invariant variables (as education is for most individuals) is unidentified. Powdthavee et al. (2015) however substantially contribute to the understanding of the value of education with their conceptual distinction between direct and mediated effects.

Only very few studies pick up an identification strategy to examine the causal effects of education on life satisfaction. Oreopoulos (2007) and Oreopoulos and Salvanes (2011) exploit changes in compulsory schooling laws in the US, Canada, and the UK for instrumental variable estimations of the effects of schooling on a range of lifetime outcomes, including individuals' reports on happiness and life satisfaction. The authors conclude that an increase in schooling has a positive effect on either of the indicators used. Dursun and Cesur (2016) follow a similar identification strategy and exploit a reform in Turkey in 1996 that raised compulsory schooling from 5 to 8 years to identify the education effect. They found heterogeneous effects: positive for women and negative for men. For young Turkish men the increased education reduced the probability of being married and their perceived economic status in society. The findings of Dursun and Cesur (2016) could be explained by spillover effects: the reduced probability of being married may be not the effect of the men's education but the spillover effect of the women's education on the men's lives. Moreover the perceived reduction of their economic status in society is not the effect of their own education but of the women's education who benefited most from the reform. The authors show in the appendix that females in response to the reform opted for even more education: the reform significantly increased the probability of high school and college graduation for females but not for males. ${ }^{6}$

For Germany I am aware of only two studies that addresse the causal effect of education on life satisfaction. Quis (2018) focuses the immediate effect of a recent schooling reform in Germany on students' well-being. She used a difference-in-difference approach and data from Baden-Wuerttemberg only. The reform was two-fold because it reduced high-school duration while learning intensity was increased. She found by and large no effect of the reform on life satisfaction for the very young adults. The second study is of Dahmann and Schnitzlein

\footnotetext{
${ }^{6}$ This is not the case in the NEPS data I use here. The first stage coefficients in Table 2.5 indicate that the reform increased the years of education more for men than for women. Additionally, the reform increased endogenous choice for more education among males: Table 2.2 shows that the reform significantly increased the probability of attending school in the intermediate track for males but not for females. Figure A1.2 shows the same for the unconditional distribution of school leaving certificates by gender and reform status.
} 
(2019) who use German SOEP data and estimate the effect of the very same reform on three comprehensive measures for mental health. One of these measures is life satisfaction and they found no significant effect of education on life satisfaction, although they could replicate the positive effect of education on physical health. Their set up slightly differs from my analysis: (1) They use a wider window around the pivotal cohorts, namely seven birth cohorts where I use only four before and four after the reform, and (2) other dates of implementation of the reform than I do, i.e. the dates that Pischke and von Wachter (2008) refer to. (3) They included the parents education, individual nationality and an indicator for respondents in urban areas as further controls, which I did not. (4) According to the restrictions in the SOEP data Dahmann and Schnitzlein (2019) had to infer if a respondent was affected by the reform or not from year of birth and place of residence at the time of the interview. Those who repeated classes and therefore moved in the reform or those who were regionally mobile may be inaccurately identified as affected/unaffected by the reform. ${ }^{7}$

\subsubsection{The schooling reform}

The schooling reform that I employ to identify the causal effect of education on life satisfaction took place in West German federal states over a period from 1945 to 1968, and that prolonged the duration of compulsory schooling from 8 to 9 years. Assessing if and how this reform is suitable as an instrument for education hinges on at least basic understanding of the German schooling system.

The West-German school system is characterized by cultural sovereignty of the federal states, meaning that federal states are responsible for funding, content and structure of the school system. The main features of the education system, were in general, however,identical for the last decades and still are to a great extent today: Prior to primary schooling, noncompulsory kindergarten education is provided for children aged three to six. Children start compulsory schooling mainly at the age of six (see Figure 2.1). From grade one to four, i.e. from age six to ten, primary school provides training in basic reading, writing, and mathematical skills. Tracking into secondary schooling paths occurs in most states at age ten. At the times of the reforms we look at, the most dominant secondary school types were lower secondary school (basic track), intermediate secondary school (intermediate track), and upper secondary school (academic track). The tracks differ in duration and cognitive requirements and prepare students for different future educational and vocational paths. Lower secondary schools and intermediate secondary schools nowadays last for five to six years, and prepare for vocational apprenticeship training. Basic and intermediate track graduates qualify for different sorts of vocational training, which can differ in duration, but which terminate with a labor market entry

\footnotetext{
${ }^{7}$ In my sample of basic and intermediate track respondents about $20 \%$ of observations do not live in the state where they went to school.
} 


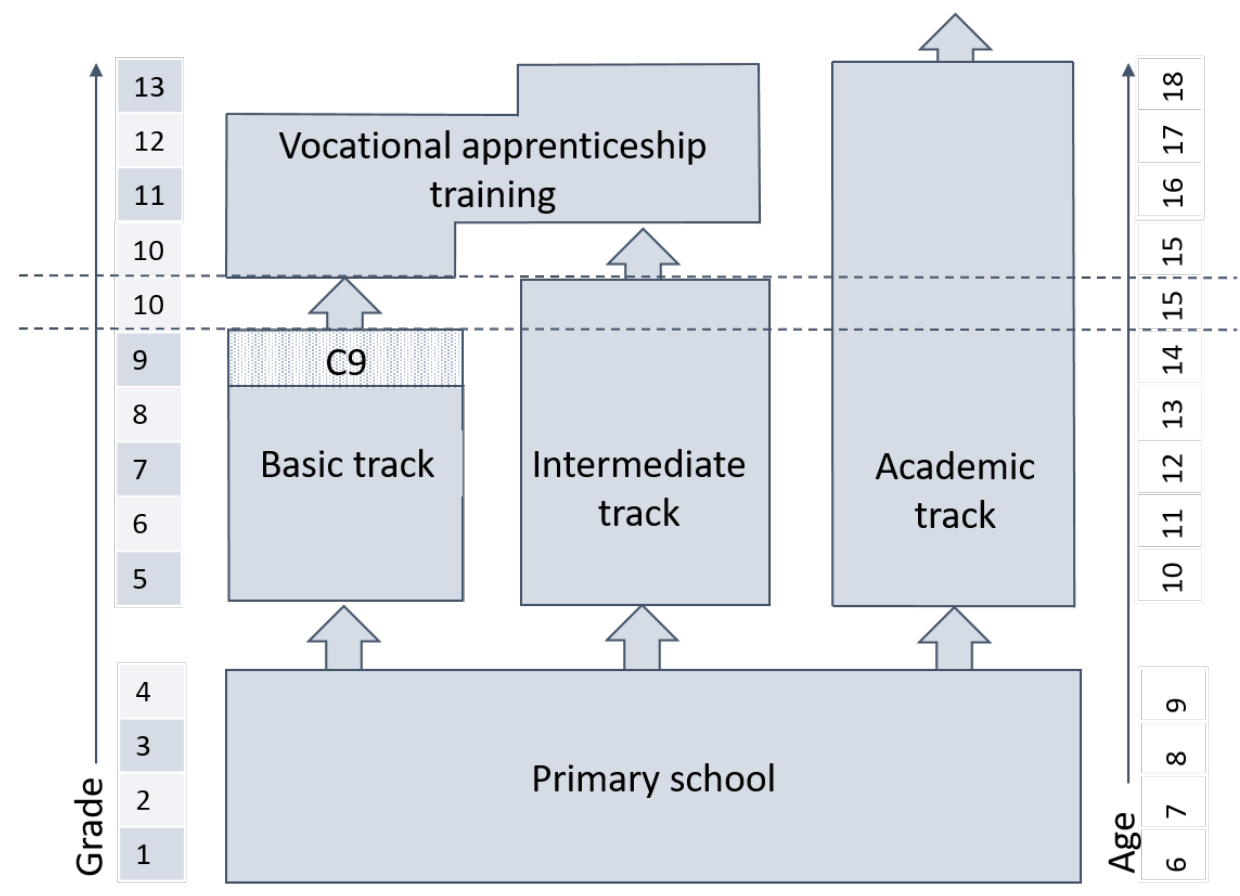

Figure 2.1: Simplified illustration of the German school system

Source: Kultusministerkonferenz (2017). Own adaptation.

certificate. The upper secondary school or academic track takes eight or nine years and offers graduates the fastest and most direct path to tertiary education at universities and universities of applied sciences.

Prior to World War II, compulsory schooling ended after eight years in most federal states. After the war, the West-German schooling system experienced changes and different interventions took place. I look at the time between 1949 and 1969, and therein especially at the extension of compulsory schooling from eight to nine years (C9). Extension of compulsory schooling varied over time and federal states, Figure 2.2 vizualizes the variation. I mostly follow the definitions of Helbig and Nikolai (2015) for the timing of the reforms across federal states. This is important as it differs to some extent from the definitions of the reform used by Pischke and von Wachter (2005) which served as default for their own 2008 follow-up study or for Cygan-Rehm and Maeder (2013), Cygan-Rehm (2017), Kemptner et al. (2011). ${ }^{8}$

\footnotetext{
${ }^{8}$ Helbig and Nikolai (2015) analyzed the differential institutional frames for education in Germany since 1945, where they also compile information about the reform of compulsory schooling. Their findings about the timing of the reform slightly differ from those of Pischke and von Wachter (2008), presumably because the former identify implementation according to school years and also took into account the shortened school years between 04/1966 and 08/1967 whereas the latter refer to calender years.
} 


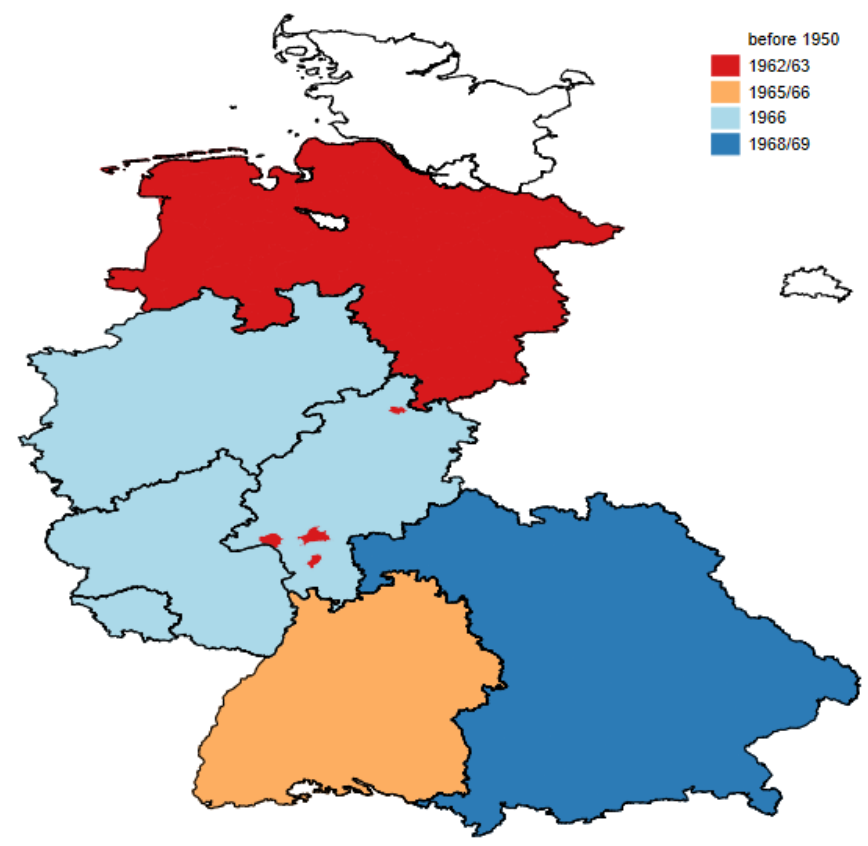

Figure 2.2: Implementation of the C9 reform in West German federal states

Source: Esri Deutschland (2019), Helbig and Nikolai (2015), Pischke and von Wachter (2005). Own presentation.

The expansion was first implemented in 1949 in Hamburg, Bremen, West-Berlin and SchleswigHolstein. Lower Saxony, Rhineland-Palatinate, Saarland ${ }^{9}$, North Rhine-Westphalia, Hesse, and Baden-Wuerttemberg increased compulsory schooling between 1962 and 1966 . For Bavaria, the NEPS data, and herein especially the education biography data, strongly suggests that the reform was implemented in the school year 1968/69. Figure A1.1 in Appendix A1 shows that the jump from eight to nine years of reported duration in school occurred then. This however contradicts to Helbig and Nikolai (2015), yet Pischke and von Wachter (2005) and Cygan-Rehm (2017) find the same timing of the C9 reform for Bavaria. Finally, some specifics of the reform have to be noticed: First, because of a lack of teachers, some federal states implemented a transitional arrangement (Helbig and Nikolai, 2015). In Hesse, the introduction of the 9th grade took place in all urban municipalities in 1962, all rural districts followed in 1966. Lower Saxony introduced the reform gradually ending in 1962/1963. In Saarland all individuals who started school since 1958 had to attend at least nine years.

Pischke and von Wachter (2005) mention that the content of the curricula for the additional 9th grade differed between states.

\footnotetext{
${ }^{9}$ Cygan-Rehm (2017) revised the work of Pischke and von Wachter (2008), and found, referring to social security records, that in Saarland the reform was nearly fully implemented in 1958. Helbig and Nikolai (2015) refer to a law amendment stating that the reform was implemented step-wise for students enrolled in 1958. This cohort finished 8th grade in November 1966. In the NEPS data I do not find suggestive evidence when the reform was implemented and therefore I stick to the identification suggested by Helbig and Nikolai (2015).
} 
Simultaneously with the C9 reform, a second major reform occurred in 1966/1967. All federal states except for Bavaria shifted the beginning of school years from spring to autumn Helbig and Nikolai (2015). As a consequence, a large group of West German federal states (Baden-Wuerttemberg, Bremen, Hesse, Lower Saxony, North Rhine-Westphalia, RhinelandPalatinate, Saarland and Schleswig Holstein) introduced two short school years, from April to November 1966 and from December 1966 to June 1967, whereas West-Berlin and Hamburg implemented one long school year, from April 1966 to August 1967. Pischke (2007) showed that the shortened school years increased the risk of repeating classes. Thus the two reforms coincide in Rhineland Palatinate, rural Hesse, Saarland and North-Rhine Westphalia. This could bias the effect of the additional year that was introduced by the C9 reform. Though I do not expect that for my analysis, because the education measure that comes into place is insensitive for both class repetition and short school years; robustness checks thereon are presented in Appendix (A1).

Figure 2.3 shows, how the reform increased the actual reported number of years until the respondents left school. Each dot shows the median duration in school of all those respondents who left school at the end of each school year relative to the reform implementation. The duration is the actual number of years the respondent stayed in full-time schooling, as can be read out from the education biography data. The median in the left panel refers to the distribution of only those who attended a basic or middle track school at 8th grade, because they were the target population of the reform. The right panel shows for comparison the median duration in school for those who left an academic track school or one of the rare schools that could not be assigned to a certain track. Their duration of schooling was obviously not altered by the reform.

This exogenous variation in education over time and federal states is used as an instrument for years of schooling in my empirical analyses. In contrast to Pischke and von Wachter (2005, 2008), Kemptner et al. (2011) and Cygan-Rehm (2018), I can refer to information about both state and municipality where the individuals went to school as well the particular school type at 8 th grade. I can thus identify whether an individual was affected by the reform or not much more precisely than previous studies could.

The reform, as it addressed compulsory schooling, triggered exogenous variation in individuals' schooling duration and was thus already used for other analyses of causal effects of schooling, e.g., on wages (Pischke and von Wachter 2008, Cygan-Rehm 2017), health (Kemptner et al. 2011), fertility (Cygan-Rehm and Maeder 2013), and political participation (Siedler 2010). Yet one further aspect of the reform besides the education effect must be mentioned. The major advantage of the reform is that it exogenously increased duration of schooling for the entire targeted population. This is clearly an advantage from an econometric point of view. It could though be a disadvantage, because this nearly complete complience results from co- 

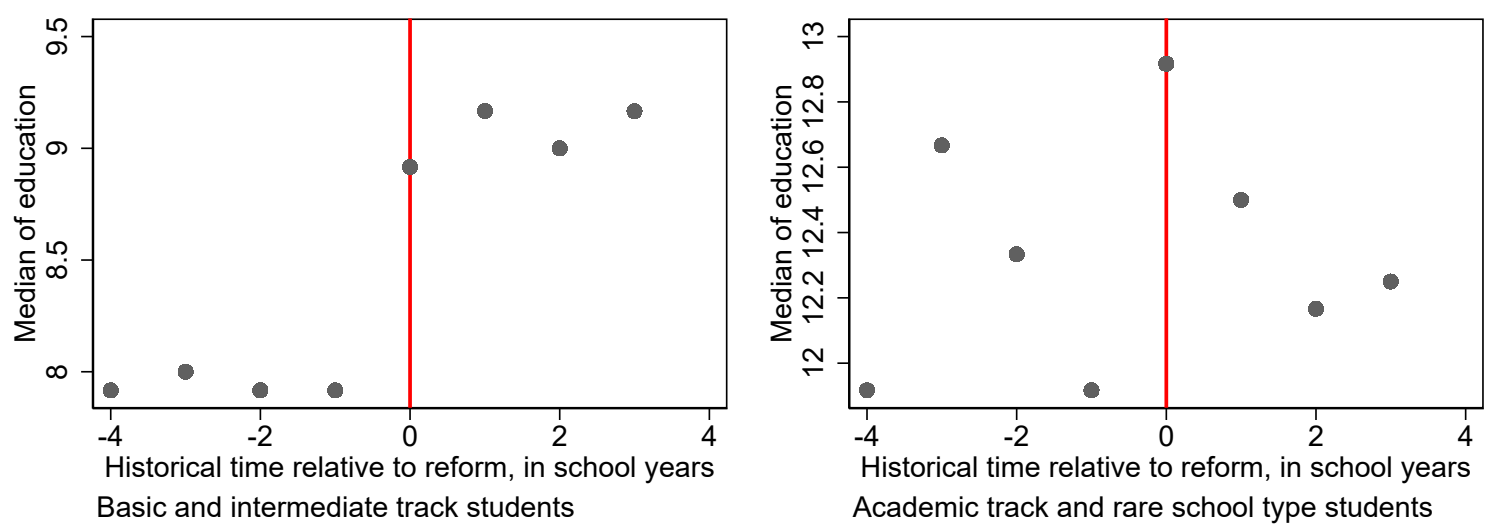

Figure 2.3: Median duration of schooling before and after the reform, target and control group

Source: NEPS SC6 v9.0.1; own calculations

ercion. So that those respondents who were affected by the reform were not only subject to one further year of education but also subject to the obligation to stay in school one additional year. Avendano et al. (2017) found negative effects of similar reforms in Britain and France on mental health and Courtin et al. (2019) found negative effects of the same reforms on some biomarkers in the subsample of adults who grew up in low socio-economic status households. The authors explain that these negative effects stem from the constraint on the compliers. If the mandatory constraint, which is inherent in such reforms, negatively affects mental and even physical health, the education effects that are estimated from these reforms could be negatively biased. Probability and extend of such bias depend on the circumstances of the reform and the outcome of interest. I will discuss this in more detail with the results.

The reform may as well have triggered endogenous variation in education if it affected respondents' (or their parents') choice for even more investment in education, to achieve a higher degree. This might especially be the case in Lower-Saxony or Saarland, where the reform was implemented successively. To address this problem we run robustness checks without these states.

Estimations of the probability of each school leaving degree with respect to reform implementation show that with the implementation of the reform the probability of having a basic school leaving degree was significantly lower, the probability of having middle or high school leaving degree was significantly higher. Tables are presented in Appendix (A1). If these differences occurred because students choose middle or academic track in response to the reform, estimations of the returns to education in subsamples that are limited to any school track would produce biased results (Pischke and von Wachter 2008, Cygan-Rehm 2017). 


\subsection{Identification of direct and indirect effects of education on happiness}

Identification of the causal effect of education on happiness relies on the exogenous variation of schooling due to a reform that increased the duration of compulsory schooling from eight to nine years. This reform serves as an instrument for education, which is otherwise a choice variable and thus suspected to be endogenous in a happiness regression.

Every instrument must meet three requirements: (1) it must satisfy the exclusion restriction in the second stage equation, i.e. in the happiness equation, meaning that it has no impact on happiness other than through education. (2) the instrument must be relevant, meaning that it changes the duration of education, conditional on the covariates, in the first stage. (3) The effect of the instrument on the endogenous regressor must be monotone.

The first requirement is untestable, and must hence be argued and supported with adequate exogenous covariates. Following Kemptner et al. (2011) we control for differences in levels and trends in happiness by state. We do so, to address possible endogeneity of the instrument, caused by cultural differences between states that might also affect happiness.

So we can identify the net causal effect of education on happiness in a classical two stage least squares (2SLS) estimation, with first stage:

$$
\mathrm{edu}_{i}=\alpha_{0}+\alpha_{1} \operatorname{reform}_{i}+\mathbf{x}_{i t}^{\prime} \boldsymbol{v}+v_{i}
$$

and second stage:

$$
\operatorname{sati}_{i t}=\beta_{00}+\beta_{01} \widehat{\operatorname{edu}}_{i}+\mathbf{x}_{i t}^{\prime} \delta_{0}+u_{0 i}+\varepsilon_{0 i t},
$$

where edu $u_{i}$ is education of person $i$, sati $_{i t}$ is life satisfaction of person $i$ at survey year $t$ and reform $_{i}$ identifies individuals who were affected by the reform. $\mathbf{x}_{i t}$ is a vector of exogenous covariates, $v_{i}$ and $\varepsilon_{0 i t}$ are indiosyncratic errors, while $\mathrm{u}_{0 i}$ is an individual-specific random error.

For estimation of causal effects it is not necessary, that the reform affects all compliers identically. Following Angrist and Pischke (2009, p.153) identification of causal effects is also possible when potential outcomes are heterogeneous. Heterogeneity probably occurs because students respond to the reform differently: Some students might have rested with the nine years of basic track education, while some others might have valued opportunity cost for the middle track degree low enough, then, to invest in further education. If all variation in life satisfaction that is associated with the reform, is monotonously transmitted via education, the heterogeneous response to the instrument is not problematic. 
Identification of causal mechanisms or indirect effects of education on happiness is based on the notion that education affects e.g. health, which positively affects life satisfaction.

Besides self-rated health we regard equivalized household income ${ }^{10}$ stability of partnership, fertility and unemployment history as mediators of education effects on happiness. Traditionally, economists would view fertility and partnership stability as choice variables, so that observed interpersonal differences in fertility and partnership stability reveal the individual differences in preferences towards family issues, and are not the cause of differences in happiness. On the other hand, aspects of family life are common predictors of life satisfaction in the happiness economics literature.

In terms of the econometric model these arguments highlight the need for procedures to address these problems of endogeneity.

Intuitively, the indirect effect is identified in a sequential setting. In a first step, the effect of education on possible mediators (adult outcomes of education, which are themselves causes of life satisfaction) is estimated. In a second step the outcome of interest is regressed on education and the mediators. This is the standard approach to estimate mediation effects (MacKinnon et al. 2007, Imai et al. 2011).

Yet identification in an econometric sense is less straightforward, because it requires that the errors of the outcome equation and the mediator equation are uncorrelated. In other words, it requires that the effect of the mediators is the same, irrespective of the treatment status, i.e. the potential outcome when holding the treatment fixed but varying the mediator must be identical for each treatment status (Angrist and Pischke, 2009, p. 65; Imai et al., 2011, p. 773).

Analyzing the causal mechanism hence requires exogeneity of both the treatment and the mediators. Exogeneity of the treatment is addressed by instrumenting education with the reform of compulsory schooling. Ensuring exogeneity of the mediators is far more challenging, I therefore combine two strategies: First, we condition on "BigFive" personality measures to avoid cross equation correlation of the error terms, since personality is one of the strongest predictors of well-being (Diener and Lucas 1999) so that the most part of usually unobserved heterogeneity in life satisfaction can be explained with the Big Five personality measures (Boyce 2010). ${ }^{11}$ Second, since panel data are available, I pursue the Mundlak (1978) approach, i.e. additional to the mediator each individual's mean over time of the mediator is included, which captures individual-specific time-constant influences on happiness and the mediator, so that the problem

${ }^{10}$ We use the square root rule (Buhmann et al. 1988) to adjust household income to household size in order to attain comparability between households of different size.

${ }^{11}$ Boyce et al. (2013a) further found that this association even holds when personality is changing. In auxiliary regressions I tested if personality traits changed with the reform, they did not change, they thus can be included in the models. 
of additive time-constant heterogeneity is addressed. ${ }^{12}$ The following analyses thus rely on the following equations:

$$
\begin{aligned}
& \text { life sat } i t=\beta_{10}+\beta_{11} \widehat{\operatorname{edu}}_{i}+\beta_{12} \text { health }_{i t}+\beta_{13}{\overline{\text { health }_{i}}}_{\text {. }} \\
& +\beta_{14} \log (\text { income })_{i t}+\beta_{15} \overline{\log (\text { income })}_{i} . \\
& +\beta_{16} \text { children }_{i}+\beta_{17 \text { partners.dissol }}{ }_{i t} \\
& +\beta_{18} \text { everunemployed }_{i t} \\
& +\mathbf{B 5}_{i}^{\prime} \gamma_{1}+\mathbf{x}_{i t}^{\prime} \delta_{1}+u_{1 i}+\varepsilon_{1 i t} \\
& \text { health }_{i t}=\beta_{20}+\beta_{21} \widehat{\operatorname{edu}}_{i}+\mathbf{x}_{i t}^{\prime} \delta_{2}+u_{2 i}+\varepsilon_{2 i t} \\
& \log (\text { income })_{i t}=\beta_{30}+\beta_{31} \widehat{\operatorname{edu}}_{i}+\mathbf{x}_{i t}^{\prime} \delta_{3}+u_{3 i}+\varepsilon_{3 i t} \\
& \text { children }_{i}=\beta_{40}+\beta_{41} \widehat{\operatorname{edu}}_{i}+\mathbf{x}_{i}^{\prime} \delta_{4}+\varepsilon_{4 i} \\
& \text { partners.dissol }_{i t}=\beta_{50}+\beta_{51} \widehat{\operatorname{edu}}_{i}+\mathbf{x}_{i t}^{\prime} \delta_{5}+u_{5 i}+\varepsilon_{5 i t} \\
& \text { everunemployed }_{i t}=\beta_{60}+\beta_{61} \widehat{\operatorname{edu}}_{i}+\mathbf{x}_{i t}^{\prime} \delta_{6}+u_{6 i}+\varepsilon_{6 i t}
\end{aligned}
$$

and equation (2.1).

The overall causal effect of education on happiness is directly estimated as $\beta_{01}$ in equation (2.2). The causal effect of education on happiness, mediated through health is the product of $\beta_{21}$ and $\beta_{12}$ from equations (2.3) and (2.4). The causal effect of education on happiness, mediated through income is $\beta_{31}$ and $\beta_{14}$ from equations (2.3) and (2.5). ${ }^{13}$ The causal effect of education on happiness, mediated through partnership stability is $\beta_{51}$ and $\beta_{17}$ from equations (2.3) and (2.7). The causal effect of education on happiness, mediated through unemployment (experience) is the product of $\beta_{61}$ and $\beta_{18}$ from equations (2.3) and (2.8).

\footnotetext{
${ }^{12}$ This is the most straightforward application of correlated random effects models (Wooldridge 2010). I could solve the endogeneity problem by including lagged values of the mediators, according to the idea that past income or health cannot be influenced by current life satisfaction. This however would reduce the analyses to those respondents who answered the questionnaire in consecutive years. It is yet very likely that consecutive participation is not independent of life satisfaction. I estimated models with either current health or lagged health status on the same sample of consecutive observations and found that the estimates where sensitive to the selection of observations but not to the choice of lagged vs. current health status.

${ }^{13} \beta_{15}$ is not subject to the calculation of the income-mediated effect, because it is used only to address unobserved heterogeneity, correlated to income, to avoid correlation between $u_{3 i}$ and $u_{1 i}$. The same applies for the calculation of the health mediated effect.
} 
Direct and indirect effects (theoretically) sum up to the overall effect.

One method to estimate the asymptotic variance of the indirect effects was derived by Sobel (1982, 1986) (citet in MacKinnon and Dwyer 1993). If the two factors of the product are independent random variables, the asymptotic variance of the mediated education effect can be computed as

$$
\operatorname{VAR}\left(\beta_{12} \beta_{21}\right)=\beta_{12}^{2} \operatorname{se}\left(\beta_{21}\right)^{2}+\beta_{21}^{2} \operatorname{se}\left(\beta_{12}\right)^{2} .
$$

\subsection{Empirical analysis}

\subsubsection{Data}

I use data from the Adult Starting Cohort of th National Educational Panel Study (NEPS). ${ }^{14}$ The NEPS provides extensive data on formal and non-formal education in all stages of life, determinants of decisions to invest in education, education biographies of adults, ... It is set up as a panel study and covers data from 2007/08 to 2016/17.

My dependent variable is general life satisfaction on a Likert type scale $(0=$ completely dissatisfied, ..., $10=$ completely satisfied). To measure education I use a synthetic variable: The number of years of schooling that is necessary to achieve the highest degree that the respondent reports. According to that degree, I assigned to each respondent the number of years of schooling that is usually necessary to achieve it. From the education biography data I know where and when each respondent attended what type of school and even which classes someone repeated, and thus I can identify precisely if they were exposed to the reform or not. According to their reform status I assigned 8 or 9 years of education to respondents with basic track school leaving certificate. With this synthetic education measure I purposely capture later life education too, because it might be triggered by exposure to the reform and should then add to the reform effect. This measure captures at best the content of education, while a years-in-school measure that can be read out from the education biography data, addresses more the duration aspect. I will label the content-focused measure "years of education" and the duration measure "years in school".

Sample averages for both measures do not differ very much though, the years in school are on average half a month longer than the years of education. The difference is yet systematic: For respondents who were exposed to the short school years, I observe on average 3 month

\footnotetext{
14 doi:10.5157/NEPS:SC6:9.0.1. From 2008 to 2013, NEPS data was collected as part of the Framework Program for the Promotion of Empirical Educational Research funded by the German Federal Ministry of Education and Research (BMBF). As of 2014, NEPS is carried out by the Leibniz Institute for Educational Trajectories (LIfBi) at the University of Bamberg in cooperation with a nationwide network. Further description of the data can be found in Blossfeld and von Maurice (2011).
} 
more in school than I assigned for the synthetic education measure. This seems contra-intuitive at first sight, but is probably due to the increased risk to repeat classes, which was induced with the short school year reform as Pischke (2007) shows. Respondents who repeated classes stayed on average 8 month longer in school than the synthetic education measure assigns. Since no hypothesis links life satisfaction to duration in school instead of amount of education, I opted for the latter instead of the former. Analyses with the years in school are presented as robustness check in Appendix A1 and reveal slightly smaller coefficients, but the same pattern and significance tests.

The education measure restricts the sample to those who ever obtained any school-leaving certificate. ${ }^{15}$ To avoid influential outliers I further drop all observations in the top and bottom percentile of the income distribution, in sum 135 observations.

The instrument affected only individuals who attended school in basic and intermediate track, thus the analyses are focused on individuals who attended basic or intermediate track, except from the estimates showing that the reform had no effect on respondents who attended academic track schools.

I further restrict the sample to individuals who, according to the starting time of their schooling episode, should have passed 8th grade between 4 years before and after the reform. This then results in a moving-window sample, where different birth cohorts are sampled for the different states. Figure 2.4 illustrates this moving cohort design, and how sampled birth cohorts differ between states, depending on the timing of the reform. Shaded cells indicate data, dark gray for pre-reform observations and light grey for post-reform observations. Additionally, the first row displays the birth cohorts and the bottom row the year, when respondents from these birth cohorts started their 9th school year if they did not leave school after grade 8. Respondents born in 1949 should have passed 8th grade in 1963. If they went to school in Lower Saxony they had to stay an additional year in school because they were affected by the reform. If they went to school in Bavaria, they would not be in my sample, if they went to school in BadenWuerttemberg I coded them as not affected by the reform, because the reform was implemented there in 1965. The figure also shows how short school years and C9 reform coincide.

Cultural differences between states might have affected timing of the reform as well as individuals' happiness. With state fixed effects I thus control for level differences in life satisfaction between individuals from different states. ${ }^{16}$ General time trends are addressed with a binary cohort indicator, that discriminates between individuals born until 1950 and after. Finally different time trends in the states are captured with interaction effects between state and cohort fixed effects, as Kemptner et al. (2011) suggest.

15 This restriction costs 422 , i.e. $6.1 \%$ of observations.

${ }^{16}$ I control for state at 8th grade, because I also define the respondents' reform status according to state at 8th grade. Using current state of residence as a covariate would overemphasize observations from individuals who changed the state of residence between 8th grade and the time of the interview. 


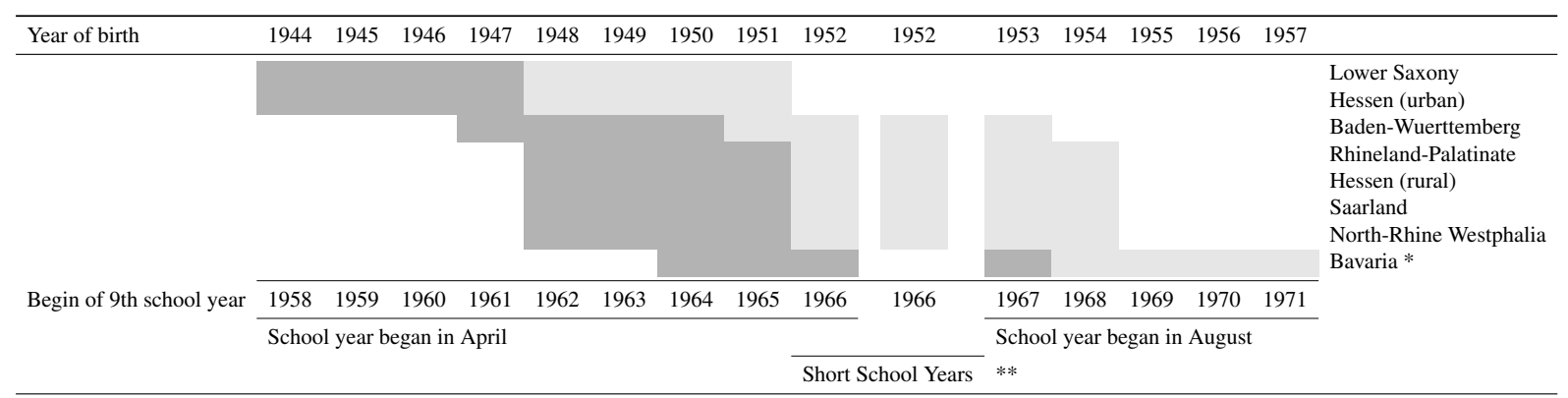

Figure 2.4: Sample structure: sampled birth cohorts, relative to reform

Notes: Shaded cells indicate data, dark gray for pre-reform observations, light gray for post-reform observations.

* School year started in September. ** Short School years from April 1966 to November 1966 and from December 1966 to July 1967

I define all those to be affected by the reform, who were in 8th grade or below when the reform took effect. All those, who passed 8th grade before implementation of the reform are defined to be unaffected by the reform.

The five mediators are defined as follows: (1) Income is the log of equivalized household income ${ }^{17}$ since this is the welfare relevant income measure, as for example Schwarze (2003) showed. (2) Health is measured on a Likert-type scale $(1=$ very good health, ..., $5=$ very poor health), ${ }^{18}$ and then recoded into a binary variable for the analysis, self-rated poor health, to attenuate the risks of over- or under-reporting, as Brunello et al. (2016) suggest. (3) Stability of partnership refers to the partnership biography data and is binary coded: 0 if the person is constantly without a partner, or constantly together with the same partner, 1 if the respondent ever experienced dissolution of a partnership, but not because of widowhood. ${ }^{19}$ Only partnerships are considered if partners live together in the same household, whether married or not. The indicator can change during period of observations, yet it barely changes. (4) A measure for fertility is included to address another facet of family life. For both men and women, I use the number of children they mentioned in their biography data. Since the respondents in my sample are beyond their fertile stage this measure does not vary over time. (5) Unemployment experience is generated from employment biography data, the variable is binary coded: 0 if the person has never experienced unemployment until the date of interview, 1 if the person ever experienced unemployment until the date of interview.

Table 2.1 displays descriptive statistics for the target sample as a whole and by reform status.

\footnotetext{
${ }^{17}$ Household income is equivalized according to the square root rule, net household income is divided by the square root of the number of individuals in the household (Buhmann et al. 1988).

18 Eriksson et al. (2001) demonstrates how self-rated health, measured on the same 5 point Likert-type scale, is associated with mental health, physical health and and functional health (each of these three explains between $30-40 \%$ variance of the self-rated health measure, in separate regressions. Brunello et al. (2016) found for a sample of similarly old adults - which does not include Germans - that self-rated health is strongly associated with objectively measured health.

19 This measure is similar to the measure of partnership stability that Oreopoulos and Salvanes (2011) used.
} 
Table 2.1: Sample descriptives for the target sample

\begin{tabular}{|c|c|c|c|c|c|c|c|c|}
\hline \multirow[b]{2}{*}{ Variable } & \multicolumn{4}{|c|}{ Whole target sample } & \multicolumn{2}{|c|}{ Pre reform } & \multicolumn{2}{|c|}{ Post reform } \\
\hline & Mean & SD & Min & Max & Mean & SD & Mean & SD \\
\hline Life satisfaction & 7.65 & 1.61 & 0 & 10 & 7.74 & 1.61 & 7.48 & 1.59 \\
\hline Age & 61.68 & 3.21 & 51 & 72 & 62.84 & 2.83 & 59.50 & 2.70 \\
\hline Years of education ${ }^{1}$ & 9.32 & 1.41 & 8 & 13 & 9.05 & 1.48 & 9.83 & 1.11 \\
\hline Years in school ${ }^{2}$ & 9.38 & 1.66 & 0.92 & 18.9 & 9.13 & 1.65 & 9.85 & 1.57 \\
\hline Household income ${ }^{3}$ & 2028 & 858 & 549 & 7000 & 1987 & 857 & 2107 & 854 \\
\hline Self-rated bad health & 0.42 & & 0 & 1 & 0.41 & & 0.45 & \\
\hline Married & 0.73 & & 0 & 1 & 0.71 & & 0.76 & \\
\hline Male & 0.50 & & 0 & 1 & 0.51 & & 0.47 & \\
\hline Unemployed ever before & 0.46 & & 0 & 1 & 0.45 & & 0.49 & \\
\hline Partnership dissolution & 0.05 & & 0 & 1 & 0.05 & & 0.06 & \\
\hline Number of children & 1.67 & 1.18 & 0 & 8 & 1.62 & 1.13 & 1.77 & 1.26 \\
\hline Affected by the reform & 0.35 & & 0 & 1 & 0 & 0 & 1 & 0 \\
\hline Person-year-observations & & & 4,669 & & 3,050 & & 1,619 & \\
\hline
\end{tabular}

Source: NEPS SC6 v.9.0.1, own calculations.

Notes: (1) Years of education are defined according to school leaving degree and reform status.

(2) Reported years in school are calculated from the education biography data. (3) Monthly net household income, equivalized with the square root of the number of household members.

\subsubsection{Results}

\section{Reform effects on track choice}

Since the reform targeted basic track students it would be straightforward to restrict the analysis on only those. It is though possible that students reacted to the reform by moving from a basic to an intermediate track school, because after all, the prolonging of compulsory schooling reduced the opportunity costs for the next higher school leaving degree. Prior to the reform the intermediate school leaving certificate required two more years of education than the basic school leaving certificate, and with the reform this difference was shortened to only one year.

As a first step I therefore test whether the reform affected track choice. Only if the reform had no influence on the students probability of choosing basic track schools, I could restrict the analysis to them, estimates would otherwise suffer from a selection bias (Angrist and Pischke 2009, p.64f). I thus estimated 4 linear probability models to examine if the reform had changed the probability of attending school (at 8th grade) in each of the four tracks, first for both genders together, then separately. 
Table 2.2: Endogeneity of track choice

\begin{tabular}{|c|c|c|c|c|}
\hline \multicolumn{5}{|c|}{ Probability of attending school in each of 4 tracks } \\
\hline & Basic & Intermediate & Academic & Other \\
\hline \multirow[t]{2}{*}{ Reform } & $-0.107 * *$ & $0.081 * *$ & 0.008 & 0.019 \\
\hline & $(0.046)$ & $(0.038)$ & $(0.040)$ & $(0.015)$ \\
\hline \multirow[t]{2}{*}{$\mathrm{N}($ track=1) } & 666 & 242 & 313 & 26 \\
\hline & \multicolumn{3}{|c|}{ Females } & \\
\hline \multirow[t]{2}{*}{ Reform } & -0.074 & 0.074 & -0.004 & 0.003 \\
\hline & $(0.063)$ & $(0.055)$ & $(0.051)$ & $(0.015)$ \\
\hline \multirow[t]{2}{*}{$\mathrm{N}($ track=1) } & 307 & 140 & 138 & 7 \\
\hline & \multicolumn{3}{|c|}{ Males } & \\
\hline \multirow[t]{2}{*}{ Reform } & $-0.102^{*}$ & $0.084 *$ & 0.038 & -0.020 \\
\hline & $(0.057)$ & $(0.044)$ & $(0.051)$ & $(0.019)$ \\
\hline $\mathrm{N}($ track=1) & 359 & 102 & 175 & 19 \\
\hline
\end{tabular}

Probability of attending school in basic/intermediate or academic track Basic and intermed. track

Academic track and other

\begin{tabular}{lrr}
\hline Reform & -0.009 & 0.009 \\
& $(0.041)$ & $(0.041)$ \\
$\mathrm{N}($ track $=1)$ & $(757)$ & 259 \\
\hline
\end{tabular}

Source: NEPS SC6 v.9.0.1, own calculations.

Notes: Significance levels * $0.10 * * 0.05 * * * 0.01$. Robust standard errors in parantheses. Further controls: Birth cohort, gender, age, age squared, state where respondents passed 8th grade, interaction between this state and birth cohort. $\mathrm{N}=1016$, estimation uses only one observation per person.

The observed pattern in the upper row of Table 2.2 indicates that indeed students reacted on the reform by choosing intermediate instead of basic track schools. ${ }^{20}$ The probability of attending academic track or other, rare types of schools in 8th grade is not affected by the reform. A second set of two estimations shows that the probability of attending school in basic and intermediate versus academic track schools is not affected by the reform, I thus can restrict the main analysis on the target sample of respondents who attended basic or intermediate track schools at 8th grade.

However, an analysis of endogeneity of track choice by gender reveals that only boys' track choice was affected by the reform. For women the probability of attending secondary school in basic or intermediate track was not altered by the reform.

${ }^{20}$ When I restrict the sample to cohorts of two years before and after the reform, this shift from basic to intermediate track is not significant and very small in magnitude. This is reasonable because most students do not switch from one secondary school track to another, they rather choose the intermediate track when they start secondary school. It thus took 3 years after implementation of the reform until this pattern could occur among 8 th graders. 


\section{Direct and indirect effects of education on life satisfaction}

Estimations of eq. (2.1) and (2.2) in a 2SLS procedure with individual random effects in the second stage reveals a negative causal effect of education on happiness (third column in Table 2.3). This result might be unexpected and counter-intuitive to the presupposition that education promotes human life in modern societies. The results is though partly in line with results from Avendano et al. (2017), who analyzed the long-run effect of an increase in minimum school leaving age in the UK on mental health outcomes. They found that the mandatory additional year increased the probability of mental illnesses. Mental health is not identical to life satisfaction, but both are concepts of subjective well-being and it is likely that mental health problems reduce overall life satisfaction. Dahmann and Schnitzlein (2019), the other study that addresses this question, found no effect on life satisfaction. They however used different data that do not allow to identify if someone was exposed to the reform as exactly as the NEPS data allow.

The association between education and life satisfaction in the random effects estimation in the second column in Table 2.3 is very small and insignificant. The reduced form, the regression of the outcome on only exogenous controls and the reform itself, shows the negative and significant effect on life satisfaction, which is the basis for the IV estimate. This estimate of the effect of one additional year of education is even larger, yet insignificant, because not all students, that were exposed to the reform, were compliers. Some would have chosen nine or more years of education even without the reform. For the same reason, the first stage coefficient, the mean increase in years of education due to the reform, is below unity, although the reform increased mandatory schooling by one year. The estimate is hence a local average treatment effect (LATE) (Angrist and Pischke 2009, pp. 151-158), which is the effect only on those who in absence of the reform would have left school after 8 years. F-statistics for the excluded instrument should exceed the value of 10, when the instrument is not weak Baum et al. (2007). For IV estimations with repeated observations per individual the Kleibergen-Paap Wald F statistic is more appropriate, since it is robust to violations of homoscedasticity. This F statistic exceeds 15 for our instrument and the instrumented variable. ${ }^{21}$

The analysis with the control sample (columns 4-6 in Table 2.3) reveals also a slightly positive effect of the prolonging of compulsory schooling on the years of education, but the Kleibergen-Paap F statistic is only 0.3, thus the reform cannot serve as an instrument for the control group. Moreover, the estimate from the reduced form shows that the reform had no effect on life satisfaction in the control group.

${ }^{21}$ In fact, the Kleibergen-Paap Wald F-statistic is not part of the routine for the random effects IV estimator. Since the instrument and the instrumented variable are constant over time, we refer to the estimate of the K-P F-statistic of the cross-sectional IV estimation with robust standard errors and on only one observation per person, which I run to estimate the effect of education on the number of children. 
Table 2.3: OLS, RE and RE-IV regression of life satisfaction on years of education

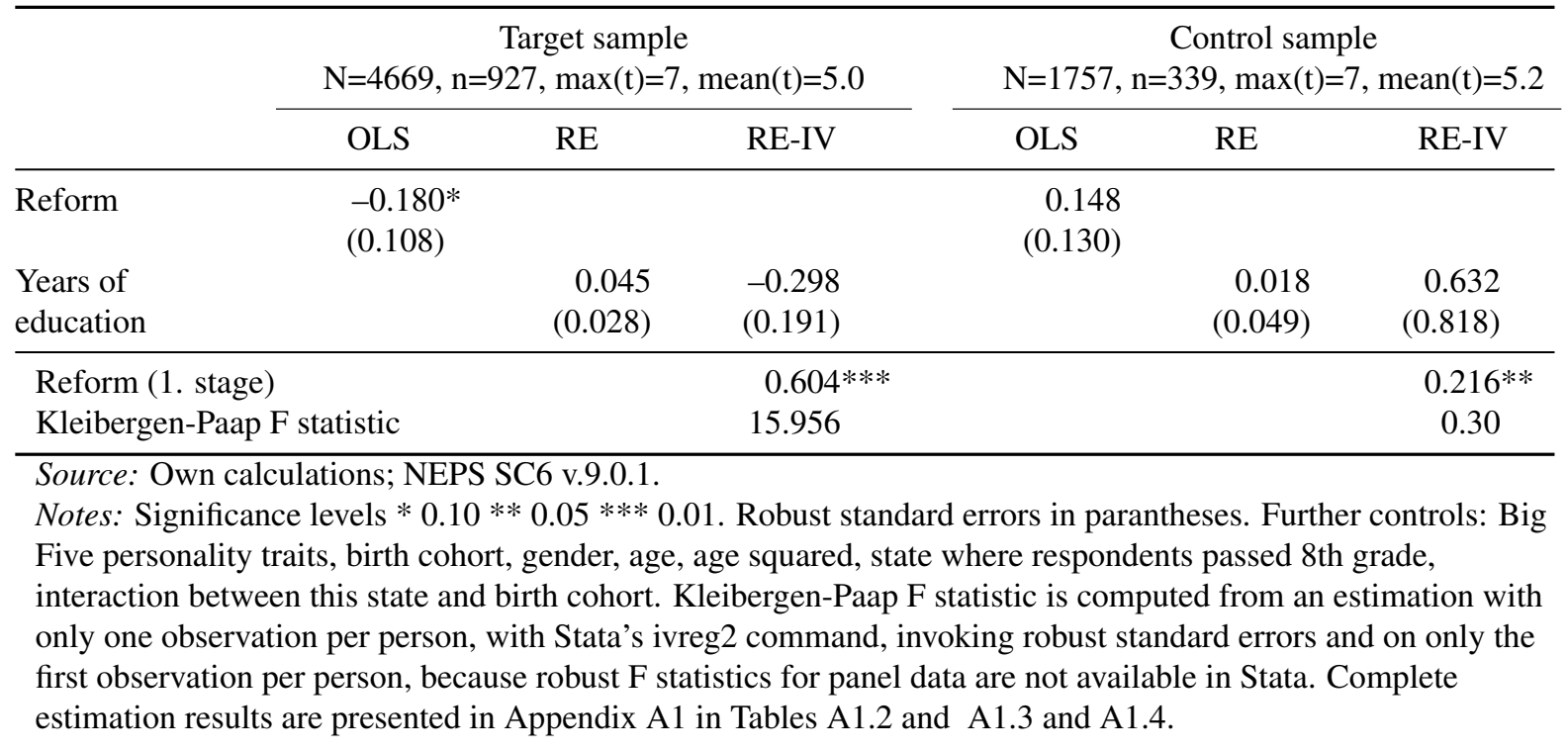

Including the mediating outcomes into the regression yields an estimate of the direct (residual) effect of education on life satisfaction. ${ }^{22}$ This direct effect (in Table 2.4) is quite similar to the overall effect of education on life satisfaction in Table 2.3.

Separate estimations of the effect of education on the mediating outcomes reveal that education obviously influences adult outcomes (see Table 2.4): Income increased by $13 \%$ for the additional year of education, the probability of partnership dissolution is reduced by $9 \%$-points. The effects of education on bad health is unexpected at first sight: the additional year of education increased the share of respondents who self-rated their health as poor. This finding contradicts to the results from Brunello et al. (2016) who found that education slightly (but only weakly significantly) reduces the prevalence of self-rated poor health. This however does not question my results, because Brunello et al. (2016) do not analyze data from Germany, and they estimate a European education-health gradient, which must not be the same within all countries. My result is partly in line with the results from Dursun and Cesur (2016), who found that the increase in education in Turkey had strong negative impact on satisfaction with health for men. Kemptner et al. (2011) and Dahmann and Schnitzlein (2019) found positive effects of education on objective measures for physical health but did not analyze the effect on self-rated health.

The absence of a significant effect of education on unemployment is in line with the findings of Cygan-Rehm (2017), who also found no effect on employment or eligibility for public transfers, which can be interpreted as indicators for unemployment.

${ }^{22}$ Concerns might arise because estimates of the reform effect on education in the first stages differ for different outcomes of the second stage, though first stages are structurally identical and independent of the second stage outcomes. Yet, for estimation a FGLS procedure is employed, with weights that refer to the error term variances of the second stage (StataCorp.LLC 2017, pp. 250). 
Table 2.4: RE-IV regression of life satisfaction on years of education and mediators, and of mediators on years of education

Respondents with basic and intermediate degree: 4669 person year observations of 927 individuals

\begin{tabular}{|c|c|c|c|c|c|c|}
\hline & $\begin{array}{c}\text { Life } \\
\text { satisfaction }\end{array}$ & $\begin{array}{c}\text { Bad } \\
\text { health }\end{array}$ & $\begin{array}{c}\text { Income, } \\
\text { log. }\end{array}$ & $\begin{array}{l}\text { N. of own } \\
\text { children }\end{array}$ & $\begin{array}{l}\text { Partnership } \\
\text { dissolution }\end{array}$ & $\begin{array}{c}\text { Un- } \\
\text { employed }\end{array}$ \\
\hline \multirow[t]{2}{*}{ Years of education } & $-0.320 *$ & $0.132 * *$ & $0.128 * *$ & 0.313 & $-0.091 * * *$ & 0.085 \\
\hline & $(0.181)$ & $(0.062)$ & $(0.051)$ & $(0.238)$ & $(0.024)$ & $(0.067)$ \\
\hline Bad health & $-0.358 * * *$ & & & & & \\
\hline \multirow{2}{*}{$\begin{array}{l}\text { Household income, } \\
\text { log. }\end{array}$} & $0.231 * *$ & & & & & \\
\hline & $(0.110)$ & & & & & \\
\hline \multirow[t]{2}{*}{ N. of own children } & -0.033 & & & & & \\
\hline & $(0.077)$ & & & & & \\
\hline \multirow{2}{*}{$\begin{array}{l}\text { Partnership } \\
\text { dissolution }\end{array}$} & 0.003 & & & & & \\
\hline & $(0.034)$ & & & & & \\
\hline \multirow{2}{*}{$\begin{array}{l}\text { Unemployed ever } \\
\text { before }\end{array}$} & 0.013 & & & & & \\
\hline & $(0.091)$ & & & & & \\
\hline \multirow[t]{2}{*}{ Reform (1. stage) } & $0.552 * * *$ & $0.605 * * *$ & $0.610 * * *$ & $0.520 * * *$ & $0.594 * * *$ & $0.626 * * *$ \\
\hline & $(0.051)$ & $(0.062)$ & $(0.054)$ & $(0.130)$ & $(0.056)$ & $(0.055)$ \\
\hline
\end{tabular}

Source: Own calculations; NEPS SC6 v.9.0.1.

Notes: Significance levels * $0.10 * * 0.05 * * * 0.01$. Robust standard errors in parantheses. Further controls: Birth cohort, gender, age, age squared, state where respondents passed 8th grade, interaction between this state and birth cohort, Big Five personality traits, Mundlak terms for income and health. Estimation of the effect of education on the number of own children was performed with the Stata's ivreg2 command, invoking robust standard errors, and on only the first observation per person. Complete estimation results are presented in Appendix A1 in Table A1.5. 


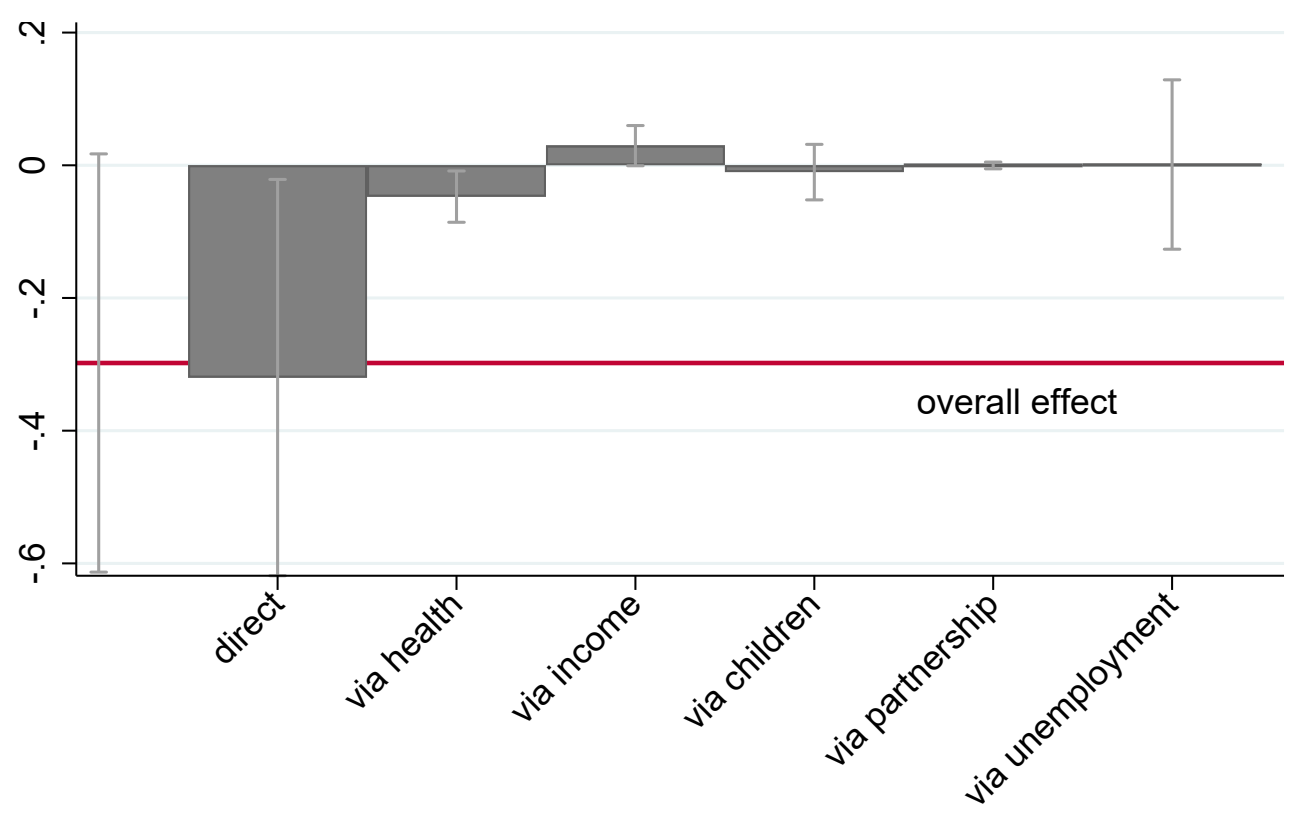

Figure 2.5: Overall, direct and indirect effects of education on life satisfaction

Source: NEPS SC6 v.9.0.1, own calculations.

Notes: Indirect effects and standard errors for indirect effects computed according to Sobel (1982).

Vertical grey lines depict $90 \%$ confidence intervals.

The estimates together show that education has indirect as well as direct effects on life satisfaction. Indirect effects with their standard errors are computed according to the "Product of coefficients" approach (Sobel 1982). The product of the estimated education effect on health with the estimated effect of health on happiness $-0.358 \cdot 0.132=-0.047$ is the indirect effect of education on life satisfaction, transmitted through self rated health. This effect is statistically significantly different from zero at the 5\%-level, because its standard error is 0.023 The additional year of education increases the probability that respondents rate their health poor. Poor health then has a negative effect on life satisfaction, so that the additional year of education reduces life satisfaction via health by -0.05 of eleven points. Though this effect is very small it is not offset by the indirect positive effect via income. The transmitted effect is small, the additional year of education increased life satisfaction via income by 0.03 of eleven points, with a standard error of 0.018. Even though the additional year of education reduced the risk of partnership dissolutions, this effect is not transmitted to life satisfaction. All other effects are substantially and statistically insignificant. Given that the indirect effects are so small, it is reasonable that the direct and the overall effect of education on life satisfaction are virtually identical.

Direct, indirect and overall effects from Table 2.4 are plotted together in Figure 2.5 where the red horizontal line indicates the overall effect of education on life satisfaction, i.e. the 
estimate in Table 2.3. The grey boxes visualize the mediated effects from Table 2.4. The light grey vertical lines depict the $90 \%$ confidence intervals. Mediation is obviously not important for the effect of education on life satisfaction.

\section{Gender-separate estimations}

To address possible effect heterogeneity, I run separate estimations for women and men. ${ }^{23}$

Results in Table 2.5 reveal indeed some heterogeneity. ${ }^{24}$ Life satisfaction of men was negatively affected by the mandatory prolonging of education, while the additional year of education had no effect on life satisfaction of women. The striking differences between the genders relate to self-rated bad health and the direct effect of education on life satisfaction. For males the additional year of education negatively affected their well-being in terms of self rated health and life satisfaction, although income was positively affected. The only significant effects that I found for women are the positive effect on income and the positive effect on partnership stability. Finally, the first stage coefficient of the reform effect on years of education is higher for males than for females.

Indirect effects for males and females are plotted in Figure 2.6. As before, the overall effect is plotted as the red line, with a vertical grey line for the $90 \%$ confidence interval, indirect effects with standard errors are computed according to Sobel (1982) and plotted as dark grey bars and light grey lines, respectively.

\subsection{Discussion and conclusion}

I use data on education, employment and family biographies and panel data on health, income and happiness to examine the direct and indirect long-run, causal effect of education on life satisfaction. To ensure exogenous variation in education I exploit a reform, which prolonged mandatory schooling from eight to nine years at different years in different German states between 1949 and 1968. Estimates show a negative causal effect of the additional year of education on life satisfaction, and that mediators transmit only very little of that effect. Although income and partnership stability are positively affected by the additional year of education this does not transmit to life satisfaction. Only a negative effect on male self-rated health transmits to life satisfaction, but this transmitted effect is small in comparison to the direct negative effect.

\footnotetext{
${ }^{23}$ The mediator "own children" is dropped for these subsample estimations because the Kleibergen-Paap F test indicates that instrument could be weak for the respective estimation. This could be due to the smaller number of observations because this estimation is run with only one observation per person, because neither education nor number of own children changes during the observation period.

${ }^{24}$ For the following estimations I tested the power of the instrument in a cross-section IV estimation on all observations per person, with standard errors clustered by individual. The Kleibergen-Paap F statistic is 13.31 for females and for males 17.27.
} 
Table 2.5: Gender-separated RE-IV regression of life satisfaction on years of education and mediators, and of mediators on years of education

\begin{tabular}{|c|c|c|c|c|c|c|}
\hline \multicolumn{7}{|c|}{ Females - 2358 person year observations of 459 individuals } \\
\hline & \multicolumn{2}{|c|}{ Life satisfaction } & Bad health & Income, log. & $\begin{array}{l}\text { Partnership } \\
\text { dissolution }\end{array}$ & $\begin{array}{l}\text { Un- } \\
\text { employed }\end{array}$ \\
\hline Years of education & $\begin{array}{l}-0.181 \\
(0.272)\end{array}$ & $\begin{array}{l}-0.269 \\
(0.280)\end{array}$ & $\begin{array}{r}0.067 \\
(0.083)\end{array}$ & $\begin{array}{c}0.137 * \\
(0.079)\end{array}$ & $\begin{array}{l}-0.081 * * * \\
(0.029)\end{array}$ & $\begin{array}{r}0.093 \\
(0.117)\end{array}$ \\
\hline Self-rated health & & $\begin{array}{l}-0.408 * * * \\
(0.082)\end{array}$ & & & & \\
\hline Household income, log & & $\begin{array}{c}0.257^{*} \\
(0.156)\end{array}$ & & & & \\
\hline Partnership dissolution & & $\begin{array}{r}0.206 \\
(0.137)\end{array}$ & & & & \\
\hline Unemployed ever before & & $\begin{array}{l}-0.052 \\
(0.114)\end{array}$ & & & & \\
\hline Reform (1. stage) & $\begin{array}{l}0.585 * * * \\
(0.068)\end{array}$ & $\begin{array}{l}0.526 * * * \\
(0.064)\end{array}$ & $\begin{array}{l}0.582^{* * * *} \\
(0.068)\end{array}$ & $\begin{array}{l}0.561 * * * \\
(0.070)\end{array}$ & $\begin{array}{l}0.600 * * * \\
(0.070)\end{array}$ & $\begin{array}{l}0.530 * * * \\
(0.074)\end{array}$ \\
\hline \multicolumn{7}{|c|}{ Males - 2311 person year observations of 469 individuals } \\
\hline & \multicolumn{2}{|c|}{ Life satisfaction } & Bad health & Income, log. & $\begin{array}{l}\text { Partnership } \\
\text { dissolution }\end{array}$ & $\begin{array}{l}\text { Un- } \\
\text { employed }\end{array}$ \\
\hline Years of education & $\begin{array}{l}-0.384 \\
(0.236)\end{array}$ & $\begin{array}{l}-0.343 * \\
(0.203)\end{array}$ & $\begin{array}{l}0.174 * * \\
(0.080)\end{array}$ & $\begin{array}{c}0.119 * \\
(0.064)\end{array}$ & $\begin{array}{l}-0.089 * * * \\
(0.030)\end{array}$ & $\begin{array}{r}0.064 \\
(0.083)\end{array}$ \\
\hline Bad health & & $\begin{array}{l}-0.308 * * * \\
(0.079)\end{array}$ & & & & \\
\hline Household income, log. & & $\begin{array}{r}0.207 \\
(0.152)\end{array}$ & & & & \\
\hline Partnership dissolution & & $\begin{array}{l}-0.195 * \\
(0.115)\end{array}$ & & & & \\
\hline Unemployed ever before & & $\begin{array}{l}-0.030 \\
(0.110)\end{array}$ & & & & \\
\hline Reform (1. stage) & $\begin{array}{l}0.706^{* * * *} \\
(0.078)\end{array}$ & $\begin{array}{l}0.668 * * * \\
(0.087)\end{array}$ & $\begin{array}{l}0.706^{* * * *} \\
(0.078)\end{array}$ & $\begin{array}{l}0.703 * * * \\
(0.079)\end{array}$ & $\begin{array}{l}0.710 * * * \\
(0.080)\end{array}$ & $\begin{array}{l}0.696^{* * * *} \\
(0.080)\end{array}$ \\
\hline
\end{tabular}

Source: NEPS SC6 v.9.0.1; own calculations.

Notes: Significance levels * $0.10 * * 0.05 * * * 0.01$. Robust standard errors. Further controls: Birth cohort, gender, age, age squared, state where respondents passed 8th grade, interaction between this state and birth cohort, Big Five personality traits, Mundlak terms for income and health. Complete estimation results are presented in Appendix A1 in Tables A1.6 and A1.7. 

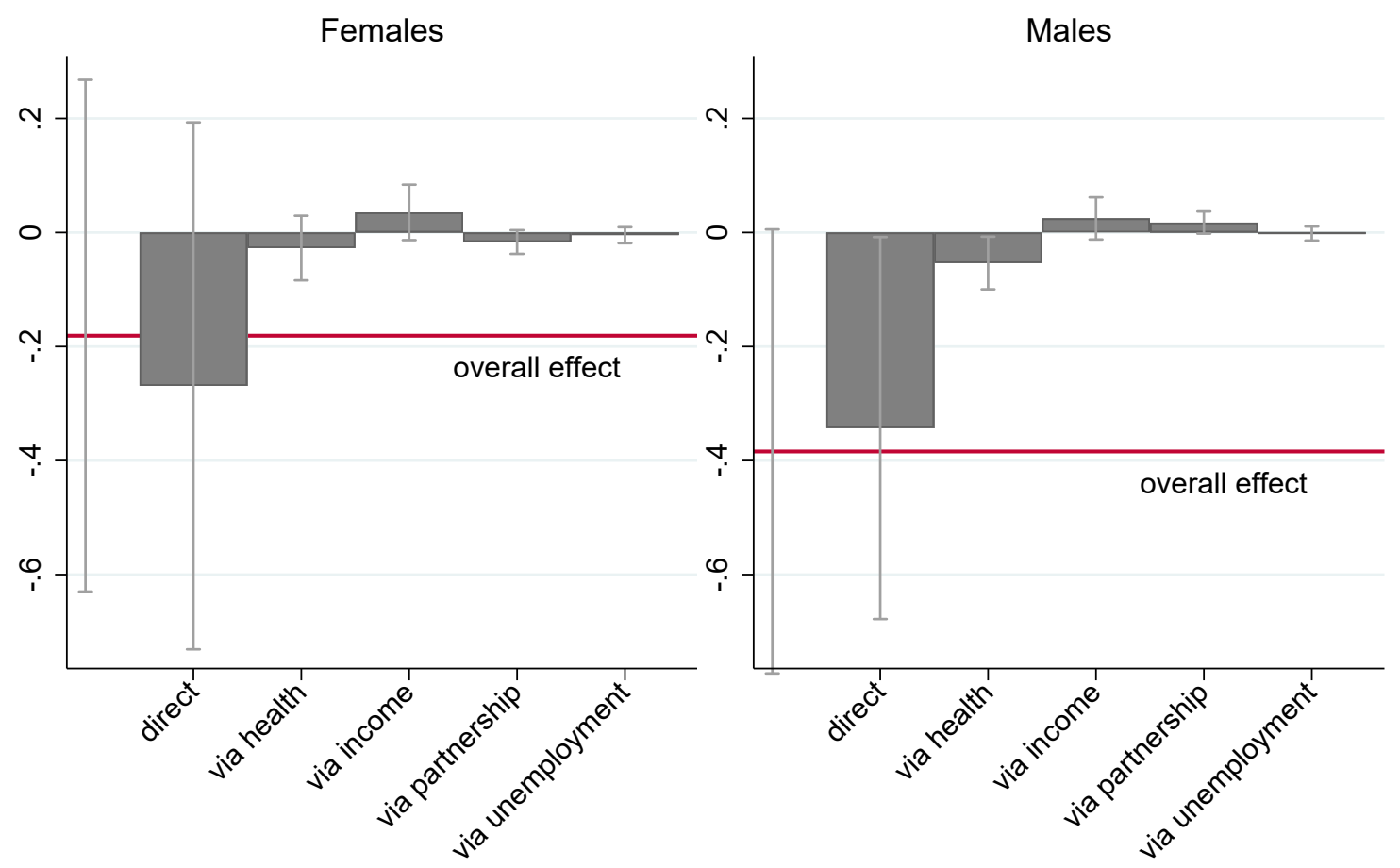

Figure 2.6: Overall, direct and indirect effects of education on life satisfaction

Source: NEPS SC6 v.9.0.1, own calculations.

Notes: Indirect effects and standard errors for indirect effects computed according to Sobel (1982). Vertical grey lines depict $90 \%$ confidence intervals. 
The question must be discussed how to interpret the negative estimate of the satisfaction effect of education. Is education really detrimental for life satisfaction? At least an additional, mandatory year in school had negative effects on life satisfaction. For the reform that I exploit in my analysis a natural c.p. condition applies: it was an additional year of education when the school leaving certificate was held constant. And that could be one argument against the global interpretation that education has a negative effect on life satisfaction. The reform-induced year of education came without a corresponding increase in instrumental or signaling value of education, i.e. access to better jobs or higher social prestige, that is attached to the school leaving certificate. After all, only duration-in-school effects remain or effects of the content that students learned in the additional year. Thus, one interpretation could be that education has only instrumental value, signaled by the school leaving certificate.

On the other hand, the reform-induced year of education was costly in terms of foregone opportunities: The unemployment rates in these years were lower than in the decade before and low in absolute terms, below one percent in the years 1961 to 1966, only in 1967 the rate was 2.1 and in 1968 1.5. (Table A1.1). The additional year in school came without relative improvement, because the graduates still hold the lowest possible school leaving certificate, but their labor market entry was postponed by one year. In circumstances where labor market entry were difficult the additional year could have been beneficial, in times with easy labor market entry this could have been seen as a disadvantage, especially in direct comparison to those cohorts that were just one year older but left school two years before. Thus, even if education had intrinsic value, it could be counterbalanced by high opportunity costs. Further analyses of the causal effects of education on life satisfaction could benefit from more elaborated distinctions between signaling, instrumental and intrinsic value of education. Other than Dahmann and Schnitzlein (2019) I could find the effect of opportunity costs and disappointment, because this is likely most pronounced in the cohorts directly following the reform, in comparison to the nearest cohorts prior to the reform. The fact that my identification is very precise - thanks to the precision of the data - revealed this negative effect of an additional year in school without any reward in terms of certificate.

That these effects of opportunity costs and dissapointment at the age of 15 last until respondents are at age 60 or even older is unexpected, yet supported by findings from Avendano et al. (2017), Courtin et al. (2019).

Why is the pattern less pronounced for women? At first because their education was less influenced by the reform. The first stage coefficient is smaller, and the unconditional distribution of school leaving certificates in the cohorts before and after the reform shows that female students did not alter their demand for education, while male students did. Their share of intermediate school leaving certificates increased with the reform. Ferrante (2009) showed in his analysis, that education in creative and prospering environments, which generally offer oppor- 
tunities, could boost individuals' aspirations faster than their realized opportunities. In such environments further education might lead to unfulfilled aspirations, hence disappointment and dissatisfaction. Thus men would have suffered more from unfulfilled aspirations, because they invested more in education. Second, females in these years were less attached to the labor market. Even if they entered the labor market after graduating from school, the overall female employment rate was still very low (see Table A1.1). Thus, the lost year in the labor market was less detrimental for women, because they anticipated their role as housekeeper and caregiver, aside the labor market.

This research thus yields insights about the long-run value of a mandatory investment without manifest short-run rewards for females but with short-run opportunity costs for males. It underlines how important circumstances, framing or antecedents are for subjective evaluation of events or situations. Referring back to the question about the value of education, the results presented here allow the interpretation that the additional year of education had no effect on life satisfaction if it was not costly in terms of opportunities. 


\section{Chapter 3}

\section{Satisfaction Data as a Means: Income Sharing Within Households}

This study has already been published under the title Income Sharing within Households: Evidence from Data on Financial Satisfaction in: Social Sciences (2016), 5(3):47, DOI: 10.3390/socsci5030047;

except for Figure 3.1 and the supplementary material in Appendix A2.

\subsection{Introduction}

One problem with the analyses of personal income distribution is that households are the unit of observation, while individuals are the unit of analysis. To address this problem, researchers typically calculate the equivalent household income and assign it to each individual, representing the amount of money this person would need to achieve the same level of welfare if he or she lived alone. A crucial assumption for these calculations is the equal sharing assumption, which states that all members of a household achieve the same level of welfare from the household income. ${ }^{1}$ Besides its theoretical relevance, Phipps and Burton (1995) impressively illustrate that the intra-household distribution of income influences the distribution of personal income in a society and, thereby, the extent and even more the structure of poverty, which is clearly an issue of policy relevance.

Sharing of household income has been analyzed by economists since the 1980s (for an overview, see Himmelweit et al. 2013), and different theoretical models have been used for the analyses: Bargaining models explain sharing outcomes according to bargaining power, which is determined by the amount of welfare each partner would lose in case of a disagreement (for

\footnotetext{
${ }^{1}$ This is also called the "income pooling hypothesis". I prefer the expression "equal sharing assumption", which is used, for example, by Jenkins (1991), Phipps and Burton (1995), since it is clearer in the context of the analyses of income distribution.
} 
example, Ott 1992, Lundberg and Pollak 1996). Similarly, but with a slightly different appearance, the resource theory of power explains bargaining power as compensation for contributions to the household's or the partner's welfare (Blood and Wolfe 1960). The collective model (Apps and Rees 1988, Chiappori 1988, 1992) is the most flexible and least demanding model in terms of assumptions about the behavior of household members: It only requires the assumption that household resources are allocated in a way so that it is impossible to make one partner better off without making the other one worse off. Hence, this model has been widely used as a tool for empirical analyses of the determinants of sharing within households.

Rejection of the equal sharing hypothesis has been obtained using a variety of data and different approaches, such that it is widely accepted. It appears that sharing resources within households is not independent of the household members' characteristics, such as age, education, employment level or earned income (Thomas 1993, Browning et al. 1994, Lundberg et al. 1997, Phipps and Burton 1998, Bourguignon et al. 1993).

Yet, most economic research of intra-household sharing does not consider gender issues systematically. Though research has found that gender norms, such as the male breadwinner ideology, shape the perception and valuation of men's and women's contributions to the household income (De Henau and Himmelweit 2013, Ahn et al. 2013, Deutsch et al. 2003), the interaction between gender breadwinning norms and determinants of income sharing is, to the best of my knowledge, not analyzed yet. Thus, the main contribution of this paper is the examination of sharing in different household employment situations. With this focus, deviation from gender breadwinning norms emerges as a reason for unequal sharing, which complements bargaining models, as well as the resource theory of power.

One major challenge in analyzing the intra-household sharing of income results from its unobservability. Most early research used expenditures for assignable goods to analyze intrahousehold sharing (Browning et al. 1994, Thomas 1993, Bourguignon et al. 1993, Lundberg et al. 1997, Hotchkiss 2005) and implicitly assumed that expenditure shares are representative of the individual's welfare. Other studies focus more on access to household resources (Pahl 1989, Woolley 2000), which facilitates partners' financial autonomy from each other.

From a welfare perspective, the aforementioned approaches suffer from the weak connection between the observed inequalities and the inequalities of the partners' welfare. For the analysis at hand, welfare is understood as "the contribution to our well-being from those goods and services that we can buy with money" (Van Praag and Frijters 1999, p. 427). Partners may spend more or less for private consumption; they may manage and control their finances with equal or with unequal access. The final distribution of the couple's welfare, however, may differ from these observable patterns, because the differential power between partners with regard to money operates even after and beyond the partners' responsibilities for, e.g., everyday purchases, savings or investments and because individuals' needs may be differently expensive. 
I therefore define sharing as equal, if both members of a given household achieve the same level of welfare from their use of the household income. The notion of equal sharing implies that sharing is independent of any factor that itself neither influences prices nor the household members' preferences. According to Browning et al. (1994), such factors are called distribution factors. This implication is used to formulate a testable hypothesis: partners share their income equally, i.e. independently. It must be rejected if any factor is found to influence the intrahousehold sharing of income. To this end, satisfaction differences are regressed on distribution factors and control variables.

The first question is therefore if partners' financial contributions to the household income influence the sharing of household resources. The second research question addresses how partners' respective financial contributions to household income influence the sharing of household resources, i.e., does the distribution factor affect both partners' financial satisfaction equally or asymmetrically? The third research question asks if partners' financial contributions to household income influence the sharing of household resources independently of the couple's working time arrangement.

\subsection{Background}

\subsubsection{Norms and Expectations Regarding Income Sharing}

Most couples pursue the ideal of togetherness in household finances and financial decisions (Bennett et al. 2012, Vogler 2005). In the sample for the analysis at hand, as well, $73 \%$ of couples report that they entirely pool their incomes, ${ }^{2}$ and $79 \%$ state that they make financial decisions together ${ }^{3}$. However, pooling incomes entirely and deciding about it together can be figures of speech that cover a variety of money management arrangements and conflicting tacit norms and expectations. Partnerships are understood as "based on love, sharing and equality, [where] all resources are shared equally regardless of who contributes what to the household. At the same time however, we also enter the labor market as individuals who [...] own the money we have earned, it is ours and we are seen as having a legitimate right to both more say over how money is used and more money for our own use." (Vogler 2005, p. 3).

This is especially true for women, who often perceive entitlement only to their own money as theirs to spend (Bennett et al. 2012) and who most often contribute smaller earnings to the household income, due to the gender pay gap and gendered labor market participation (Olivetti

\footnotetext{
2 This information exists in only four of the 12 years of data that I use, but of those, it was $73 \%$ of the couples who congruently answered at least once that they pool their entire incomes; and those who pool do this for most $(86 \%)$ of the time.

${ }^{3}$ This information exists in only four of the 12 years of data that I use; 79\% of the couples who answered congruently at least once that they make financial decisions together gave this answer in $71 \%$ of the years.
} 
and Petrongolo 2016). Men, in contrast, appear to have a less ambiguous notion of togetherness and also straightforward access the household income, while financial autonomy, on the other hand, is found to be threatening for them (Bennett et al. 2012, p. 104).

Still, many men and women tend to evaluate their own and their partner's income contribution according to the male breadwinner scheme, in the way that the men's income is the main income and the women's the less important surplus (De Henau and Himmelweit 2013, Ahn et al. 2013). This becomes obvious in a finding of Deutsch et al. (2003), who reported that child-care expenses are subtracted from the women's earnings before these are valued as a contribution to the household income.

\subsubsection{Empirical Findings about Income Sharing from Satisfaction Data}

The equal sharing hypothesis has already been tested and rejected by the use of data on financial satisfaction. Bütikofer and Gerfin (2017), for example, estimate the effect of female income share on sharing between men and women, and Alessie et al. (2006) did the same for the effect of the female hourly wage ratio. They interpreted significant interaction effects for the female income contribution, in couples as a distribution factor for income sharing, and found that a higher income contribution of the female relative to her partner both increases her and lowers his financial satisfaction.

In contrast to these approaches, Bonke and Browning (2009) and Kalugina et al. (2009) found an even more sensitive indicator for intra-household inequality, namely differences in self-rated economic well-being, which have the advantage of detecting the impact of the distribution factor on both partners simultaneously.

Bonke and Browning (2009) and Kalugina et al. (2009) confirm that the income share is a significant distribution factor. However, from a methodological point of view, both results suffer from not taking into consideration the fact that satisfaction data are not fully comparable between individuals. Though both analyses used panel data, they did not exploit the panel quality of the data to account for unobserved couple-specific heterogeneity. In addition, all of the aforementioned approaches did not consider that the valuation of each partner's contributions to the household resources may asymmetrically be influenced by gender norms.

Such asymmetries are the focus of Ahn et al. (2013) and De Henau and Himmelweit (2013). Ahn et al. (2013) used a person's own earned income share, with the aim of testing the procedural utility hypothesis ${ }^{4}$ and analyzing whether the person's earned income share differs in importance to financial satisfaction for women and men, i.e. to see whether the importance of relative income is gendered. They found that it is: the woman's financial satisfaction decreases with her labor income share for nearly $75 \%$ of women, while for $90 \%$ of men, financial satis-

\footnotetext{
${ }^{4}$ Is earned income worth more than income from other sources? Ahn et al. (2013) found that it is.
} 
faction increases with their share of their own labor income. The income share is therefore not a distribution factor for Spanish couples; they rather prefer a male breadwinner arrangement.

In contrast to previous studies, De Henau and Himmelweit (2013) did not analyze the asymmetric influence of income shares, but of each partners' employment status instead. They found that both partners value paid work higher than unpaid work, and that for both partners, the man's paid work is worth more than the woman's.

These are valuable insights into how asymmetric the valuation of contributions to household resources may be. Yet, both analyses (De Henau and Himmelweit 2013, Ahn et al. 2013) do not allow one to distinguish a direct satisfaction effect of paid work or earned income from its distribution effect, since absolute and relative employment statuses or earned income are not considered simultaneously, as is done in the subsequent analyses.

\subsubsection{Validity of Financial Satisfaction for Analyses of Intra-Household Sharing}

Financial satisfaction data provide a valid approach to intra-household sharing if it reflects an individual's welfare.

Using satisfaction data for intra-household sharing is supported by Van Praag and Ferrer-iCarbonell (2008). They conclude that gender different levels of satisfaction, which they found, indicate different " "psychological mechanisms' that translate the objective situation into subjectively perceived satisfactions" or differences in the objective situation of women and men (Van Praag and Ferrer-i-Carbonell 2008, p. 119). Here, such a different objective situation might be different access to household income, and the different psychological mechanisms might involve different entitlement to it.

One important caveat ${ }^{5}$ against using satisfaction data in the context of intra-household inequality is that individuals adapt to their circumstances and form their expectations accordingly (see, for example, (Stutzer 2004, Clark et al. 2008a)). Consequently, partners, who repeatedly experience that their expectation of equal income sharing is violated, might adapt their expectation and, hence, their valuation of the household income.

Burchardt (2014) and Clark et al. (2008a), however, found that adaptation works slowly and imperfectly. Therefore, changes in financial satisfaction associated with contemporaneous changes in circumstances should not be affected by slow adaptation. What is more, the direction of any bias is obvious: a distribution factor effect would be underestimated.

\footnotetext{
${ }^{5}$ Less critical caveats include the argument that financial satisfaction depends not only on the income (share), but also on needs, expectations and deviations thereof (for an overview, see (Stutzer 2004, Clark et al. 2008a, Ferrer-i-Carbonell 2013)), and may also be driven by individual's personality (Brickman and Campbell 1971, Magnus et al. 1993, Luhmann et al. 2011). These concerns are accounted for by controlling for a wide range of covariates and by using fixed effects estimation.
} 


\subsection{Theoretical Approach}

Assuming that income induces material well-being and that the welfare, individuals derive thereof, is expressed in financial satisfaction, reported financial satisfaction may be used to analyze the distribution of income within households.

To follow this path, assumptions about the linkage between income and welfare are necessary, which are part of standard micro-economic theory: individuals must be equally able to transform income into well-being; individuals must be subject to the same prices and need to be equally informed. This is unlikely to be the case in society as a whole, but these are reasonable assumptions for partners in one household. It is not necessary to assume that partners need the same amount of money to produce the same level of well-being, i.e., common or identical utility function, because it is not the distribution of amounts of money that is of interest, but the distribution of income-induced well-being between the partners.

Usually, equivalent incomes are computed as a representation of welfare, depending on household size and composition. It is straightforward to assume that financial satisfaction depends not exactly on equivalized income, but on how much welfare a person can actually draw out of their household's income, i.e., financial satisfaction depends on the welfare-effective income. $^{6}$

Actual welfare-effective income $\tilde{y}_{i h}$ will affect financial satisfaction, in particular when it is compared to expected welfare-effective income, $y_{i h}^{*}$, which is the level of welfare a partner expects. ${ }^{7}$ I assume that partners expect equal sharing in the sense of equal welfare levels $u_{i h}($. from the household income. ${ }^{8}$ Formally, the partners' expectation of equal sharing is expressed as:

$$
u_{m h}\left(y_{m h}^{*}\right)=u_{f h}\left(y_{f h}^{*}\right)
$$

If partners share their household income equally in terms of equal welfare, as expressed in Equation (3.1), and the assumption holds that they expect equal sharing, then there is no difference between actual and expected welfare-effective income $\left(\tilde{y}_{i h}-y_{i h}^{*}\right)$. The difference is

\footnotetext{
${ }^{6}$ For single households, this is the household income; for individuals in multi-person households, it is some share of the household income. Note that the sum of shares may exceed the household income because of the economies of scales of living together (Bütikofer and Gerfin 2017).

7 According to the idea of adaptation (Stutzer 2004), I assume that expectations about welfare levels are tailored towards the household's scope, i.e., expected welfare-effective income $y_{i h}^{*}$ is a function $0<f()<$.1 of total household income.

${ }^{8}$ This assumption is necessary because otherwise, only deviations from expected shares of income can be detected and not deviations from equal sharing. In the cultural context of present-day Germany, which is characterized by individualization (Beck 1987) and post-materialism (Inglehart 1997), this assumption is sound. However, research into the allocation of domestic work (for an overview, see Peuckert (2008)) and of income sharing (see Thomas (1993), Browning et al. (1994), Lundberg and Pollak (1996), Phipps and Burton (1998), Pahl (1989)) shows that reality often falls short of such expectations.
} 
positive if actual welfare-effective income is higher than expected and negative if expectations are higher.

$$
\left(\tilde{y}_{i h}-y_{i h}^{*}\right) \begin{cases}>0 & \text { more than expected } \\ =0 & \text { as much as expected } \\ <0 & \text { less than expected }\end{cases}
$$

Receiving more (less) than expected should have a positive (negative) effect on financial satisfaction. Financial satisfaction can therefore be explained as being dependent on the difference between actual and expected welfare-effective income:

$$
s_{i h}=\alpha_{i}+x_{i h}^{\prime} \beta_{i}+\delta\left(\tilde{y}_{i h}-y_{i h}^{*}\right)+\varepsilon_{i h},
$$

where $s_{i h}=$ individual financial satisfaction, $\alpha_{i}=$ gender-specific regression constant, $x_{i h}=$ vector with individual characteristics, $\beta_{i}=$ vector with gender-specific effects, $\delta=$ effect of intra-household sharing on financial satisfaction, $\varepsilon_{i h}=$ individual error term.

Equation (3.2) alone is insufficient to analyze the distribution of welfare among household partners; rather, income sharing can be examined by comparing partners' financial satisfaction.

If partners share their income equally (in terms of equal welfare levels; see Equation (3.1)), they should ceteris paribus be equally satisfied. If one partner can make use of more than the expected amount of income, he or she should report more financial satisfaction than his/her partner. ${ }^{9}$ It is hence the difference in reported satisfaction that provides information about the sharing of income among partners. For this reason, Equation (3.2) for the female partner is subtracted from Equation (3.2) for the male partner:

$$
\begin{aligned}
\Delta s_{h} & =s_{m h}-s_{f h} \\
& =\alpha_{m}-\alpha_{f}+x_{m h}^{\prime} \beta_{m}-x_{f h}^{\prime} \beta_{f}+\delta\left(\tilde{y}_{m h}-y_{m h}^{*}-\tilde{y}_{f h}+y_{f h}^{*}\right)+v_{h},
\end{aligned}
$$

where $v_{h}=\varepsilon_{m h}-\varepsilon_{f h}=$ household level error term.

Regarding the differences in reported satisfaction, the term containing the intra-household distribution of income is positive if the couple shares its income in favor of the man; it equals

\footnotetext{
${ }^{9}$ For this step, the assumptions that partners expect equal sharing in terms of equal welfare levels (cf. Equation (3.1)) and that expected welfare-effective income is a function of the household income are necessary.
} 
zero if they share equally; and it is negative if they share in favor of the woman.

$$
\left(\tilde{y}_{m h}-y_{m h}^{*}-\tilde{y}_{f h}+y_{f h}^{*}\right) \begin{cases}>0 & \text { Sharing in favor of the man } \\ =0 & \text { Equal sharing, i.e., }\left(\tilde{y}_{i h}=y_{i h}^{*}\right) \\ <0 & \text { Sharing in favor of the woman }\end{cases}
$$

Even after identifying income sharing as an influence on the partners' financial satisfaction, it still remains unobservable. However, income sharing can be seen as determined by the distribution factor, here the income ratio between the partners, i.e., $\left(\frac{z_{m h}}{z_{m h}+z_{f h}}\right) \cdot{ }^{10}$ Intra-household sharing of income is supposed to be some function $g($.$) of the distribution factor.$

Formally:

$$
\left(\tilde{y}_{m h}-y_{m h}^{*}-\tilde{y}_{f h}+y_{f h}^{*}\right)=g\left(\frac{z_{m h}}{z_{m h}+z_{f h}}\right) \text {, }
$$

where $z_{m h}=$ the male partner's own income and $z_{f h}=$ the female partner's own income.

Substituting Equation (3.4) in Equation (3.3) yields the initial theoretic model,

$$
\Delta s_{h}=\alpha_{m}-\alpha_{f}+x_{m h}^{\prime} \beta_{m}-x_{f h}^{\prime} \beta_{f}+\left(\frac{z_{m h}}{z_{m h}+z_{f h}}\right)^{\prime} \delta+v_{h}
$$

where: $\delta=$ the effect of the distribution factor (income ratio) on the satisfaction difference.

Fig. 3.1 roughly outlines the underlying relation between theoretical issues and observable facts, in order to facilitate understanding of the model.

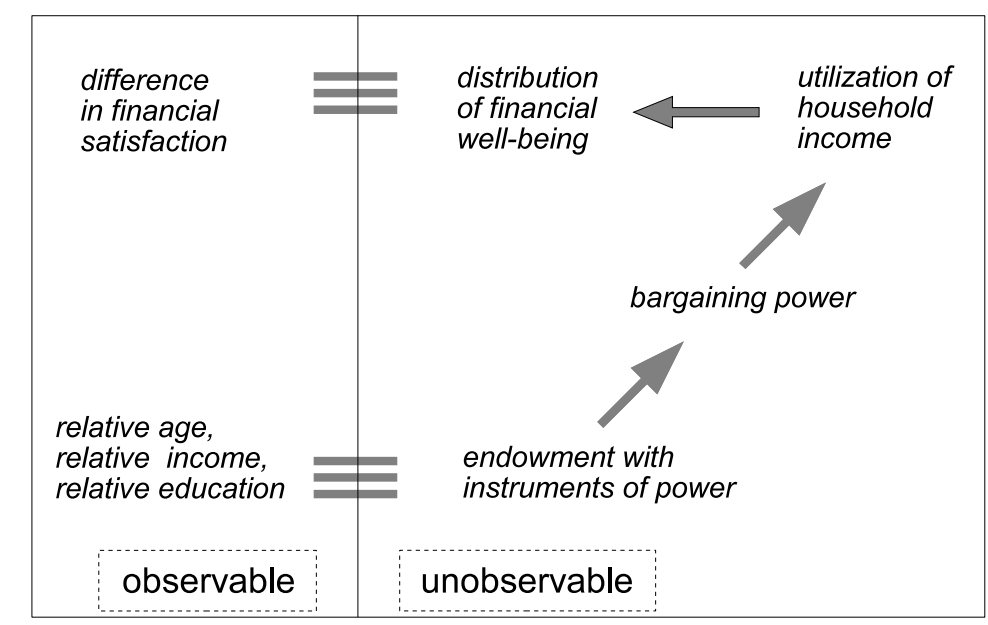

Figure 3.1: Overview

\footnotetext{
${ }^{10}$ This distribution factor can be derived from bargaining models, as well as from the resource theory of power.
} 
Estimates of this model will show whether couples share their household income equally or depending on the distribution factor. If the distribution factor significantly influences the satisfaction differences, the equal sharing hypothesis must be rejected.

The model in Equation (3.5) can be easily augmented with another distribution factor, namely the couple's ratio of working hours in the labor market. The comparison of the effects of both distribution factors will show whether household partners value the effort in terms of working hours or its outcome, the income contribution.

The income ratio is, however, not only a distribution factor and a source of power, but eventually is also a result of the couple's working time arrangement. This must be taken into account when analyzing the influence of the income ratio on sharing. Hence, the initial model is used for analyses in subsamples according to the household's employment situation, namely male breadwinner (once with women employed part-time and once with women not employed) and double full-time households. Women who are not employed tend to have very low income of their own, and thus, strict male breadwinner couples may not share according to the income ratio. Women who contribute to the household income, even though not with the same amount of employed work, often contribute with more unpaid work to the household resources, and thus, the influence of the income ratio may be smaller than for couples with both partners employed full-time.

Separate estimations for women and men will reveal whether the distribution factor affects both partners' satisfaction with household income in the same absolute amount (surely with the opposite sign). This will give some insight into the asymmetry of unequal sharing and show who needs to struggle for their entitlement to the household's income.

\subsection{Data and Empirical Specification}

Data are retrieved from the German Socio-Economic Panel SOEP. ${ }^{11}$ The SOEP is a longitudinal survey of persons in households in the Federal Republic of Germany, conducted annually by the German Institute for Economic Research (DIW), Berlin.

The analyses focus on couples living together, with or without children; couples living together with persons other than their own children and those with adult children who have significant income of their own, i.e., $25 \%$ of the equivalized income of the household, are excluded ${ }^{12}$, because these arrangements may imply that different distribution procedures take place. Further, distribution procedures may be different if household partners are retired; therefore, households are excluded when one of the partners reaches the age of 65 . Households are also dropped if

11 The data used in this publication were made available by the German Socio-Economic Panel Study (SOEP) at the German Institute for Economic Research (DIW), Berlin. For details, see Wagner et al. (2007), HaiskenDeNew and Frick (2005).

${ }^{12}$ This reduces the sample by about $5 \%$. 
Table 3.1: Sample mean and standard deviation of relevant variables

\begin{tabular}{|c|c|c|c|}
\hline Variable & Mean & $\mathrm{SD}^{1}$ & SD within ${ }^{2}$ \\
\hline Satisfaction difference & -0.137 & 1.573 & 1.207 \\
\hline Men's financial satisfaction & 6.347 & 2.131 & 1.154 \\
\hline $\begin{array}{l}\text { Women's financial } \\
\text { satisfaction }\end{array}$ & 6.484 & 2.159 & 1.176 \\
\hline Men's income & 3344.59 & 2582.31 & 1229.92 \\
\hline Women's income & 1406.11 & 1524.81 & 653.67 \\
\hline Income ratio & 0.705 & 0.244 & 0.112 \\
\hline Men's working hours & 35.98 & 19.45 & 9.584 \\
\hline Women's working hours & 20.24 & 18.21 & 8.579 \\
\hline Working hours ratio & 0.586 & 0.341 & 0.178 \\
\hline $\begin{array}{l}\text { Equivalized household } \\
\text { income }^{3}\end{array}$ & 2007.77 & 1160.37 & 586.36 \\
\hline Married & 0.893 & & \\
\hline Household without children & 0.377 & & \\
\hline $\begin{array}{l}\text { Children under age of } 6 \text { in } \\
\text { household }\end{array}$ & 0.211 & & \\
\hline $\begin{array}{l}\text { Male breadwinner } \\
\text { household }^{4}\end{array}$ & 0.512 & & \\
\hline Partners equally employed & 0.303 & & \\
\hline $\begin{array}{l}\text { Female breadwinner } \\
\text { household }^{5}\end{array}$ & 0.075 & & \\
\hline $\begin{array}{l}\text { Households with at least } \\
\text { one partner unemployed }\end{array}$ & 0.085 & & \\
\hline
\end{tabular}

Notes: ${ }^{1}$ Standard deviation. ${ }^{2}$ The within standard deviation describes the variation around the observation unit-specific mean. ${ }^{3}$ Equivalized income is the monthly net household income, deflated with the square root of the household size. ${ }^{4}$ The man is employed full-time, while the woman is part-time or not employed (though not unemployed); the man is working part-time, while the woman is not employed, though not unemployed. 5 The woman is employed full-time, while the man is part-time or not employed (though not unemployed); the woman is working part-time, while the man is not employed, though not unemployed.

Source: SOEP.v28, 2000-2011; 36783 couple-year observations, 7573 couples.

one of the partners leaves the household. I further exclude the top and bottom $1 \%$ of the distribution of satisfaction differences, since Guven (2012) showed that large satisfaction differences are predictors of divorce. ${ }^{13}$ Additionally, since Frick et al. (2006) have shown that answers, especially on income questions, are unreliable in a respondent's first year in the panel study, these observations are excluded from the analysis. Finally, all observations with missing values are deleted. Using the waves of 2000 up to 2011, an unbalanced sample of $n=7573$ couples $\left(\sum_{i=1}^{n} t_{i}=36783 \text { couple-year observations) is obtained (see Table } 3.1\right)^{14}$.

${ }^{13}$ Since satisfaction differences are discrete exactly $2.24 \%$ of observations are dropped, i.e. 1,372 of 61,238 .

14 Restricting the sample to observations without missing values in the relevant varialbles reduced sample size by 10269 observations, reducing the sample to couples with both partners younger than 65 further reduces samples size by 13,645 observations. 


\subsubsection{Differences in Financial Satisfaction and the Distribution Factor}

In the SOEP, financial satisfaction is assessed at the beginning of the questionnaire with the following questions:

How satisfied are you today with the following areas of your life? Please answer by using the following scale: 0 means 'totally unhappy', 10 means 'totally happy'.

How satisfied are you with your household income?

To determine the distribution of income among household partners, the partners' difference in financial satisfaction, male's minus female's, ranging from -5 up to 5 , is used as the dependent variable. ${ }^{15}$

Satisfaction differences are not a typical dependent variable, which is why a spike plot is presented here. Figure 3.2 shows the distribution of the dependent variable, the difference in financial satisfaction between partners and, for comparison, the normal distribution. The generally small difference between the couple's financial satisfaction is not surprising with regard to the findings of Van Praag and Ferrer-i-Carbonell (2004). The slight tendency towards the left end of the scale in Figure 3.2 indicates slightly higher values of financial satisfaction for women.

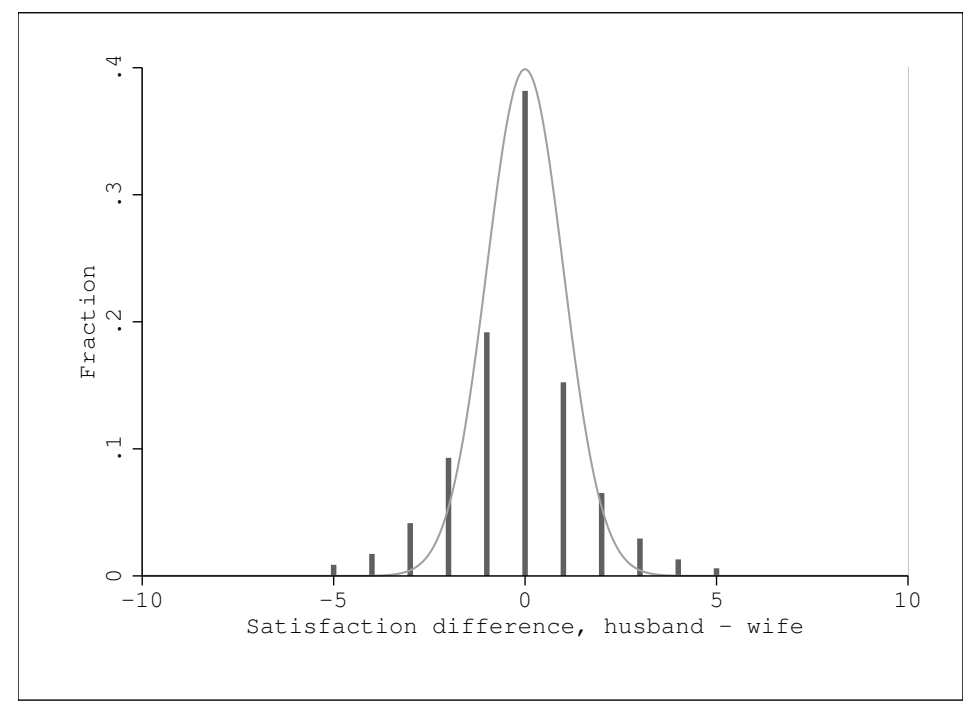

Figure 3.2: Within-couple differences in financial satisfaction.

Source: SOEP.v28, 2000-2011; 36783 couple-year observations, 7573 couples.

15 While this variable could theoretically range from -10 to 10 , its empirical range is -5 to 5 . 
The main explanatory variable is the ratio between the partners' individual income (monthly gross wage plus monthly incomes from any other source, ${ }^{16}$ where given in gross amounts), ranging from zero (man having no income) to one (woman having no income); see Equation (3.4).

Values of 0.5 for the distribution factor indicate that both partners bring in the same amount of money, either from employment or from other sources; values between zero and 0.5 indicate that the man's own income is less than the woman's; values between 0.5 and unity indicate that the man's own income exceeds the woman's.

As an additional distribution factor, the ratio of working hours is constructed in the same way, using information about the average hours each partner works per week (including overtime), with zero working hours for those who are not employed.

\subsubsection{Further Covariates}

Most partners differ with regard to attributes that are associated with financial satisfaction. Even household characteristics, which are necessarily the same for both partners, are differently associated with financial satisfaction for men and women. Thus, unequal answers to questions of satisfaction do not necessarily express unequal welfare. In order to examine the distribution of welfare between household partners, rather than satisfaction differences, it is hence necessary to control for these attributes.

Based on auxiliary fixed effects estimations of individual financial satisfaction, separated by gender, the following variables are identified as necessary controls for partners' different endowments with satisfaction-influencing characteristics: each partner's own income, self-rated health, a dummy variable indicating whether someone is unemployed at the time of the interview and actual working hours. Of the household characteristics, the presence of children (older than eleven years of age), living in an owned home, household income ${ }^{17}$ and household size have significantly different effects on women's and men's financial satisfaction.

Household income is adjusted to household size using the number of persons in log values as a further covariate (Schwarze 2003). Additional heterogeneity that is controlled for includes the presence of children in the household, living in an owned home, living in an urban area and the marital status of the partnership. Period effects are controlled for by including year binaries.

16 These include all monthly incomes at the time of the interview that do not depend on the household's structure or income, e.g., no means-tested transfers, but, for example, different sorts of unemployment benefits, child benefits and widows' pensions.

${ }^{17}$ Information about the household income is one partner's response to the question: "If you take a look at the total income from all members of the household: how high is the monthly household income today? Please state the net monthly income, which means after deductions for taxes and social security. Please include regular income such as pensions, housing allowance, child allowance, grants for higher education support payments, etc." 


\subsection{Estimation and Results}

Responses to satisfaction items are often handled as ordinally-scaled data. The same can be expected with satisfaction differences. Bonke and Browning (2009) and Kalugina et al. (2009) proceeded this way, collapsing the differences into broader categories and then using ordered probit estimation. However, once differences between scores of expressed satisfaction are used, a metric scale is implied. Furthermore, Ferrer-i-Carbonell and Frijters (2004) concluded that scaling (ordinal or cardinal) has less influence on the results of happiness regressions than the consideration of person fixed effects.

With regard to satisfaction differences and the income ratio between partners, fixed effects estimation helps to circumvent problems of endogeneity of the explanatory variable that arise if the partners' allocation of time to the labor market and, hence, their individual income, is shaped by the couple's idiosyncratic attitudes towards each partner's roles in the household. Fixed effects estimation also accounts for any other couple-specific time-constant heterogeneity, even if it is correlated to the explanatory variables.

The respective econometric model, based on Equation (3.3), can be written as:

$$
\Delta s_{h t}=\beta_{0}+x_{m h t}^{\prime} \beta_{m}-x_{f h t}^{\prime} \beta_{f}+x_{h t}^{\prime} \gamma+d_{h t}^{\prime} \delta+\eta_{h}+\varepsilon_{h t}
$$

Stochastic errors are kept in $\varepsilon_{h t} ; \eta_{h}$ denotes the couple-specific error term; the intercept $\beta_{0}=\alpha_{m}-\alpha_{f}$ contains the gender effect on financial satisfaction; and the vector $x_{h t}$ controls for the gender differences in the effects of some of the household characteristics, such as the household income and size. Lastly, $\delta$ captures the effect of the distribution factor, i.e., the income ratio, on the satisfaction difference between partners.

\subsubsection{Joint Estimates}

The first estimation in Table 3.2 clearly shows that the income ratio influences the satisfaction difference, even though own income is controlled for. The statistically significant coefficient shows that sharing is not independent and, thus, does not follow the equal sharing rule. This is in line with other work on this topic (e.g., Bonke and Browning (2009), Kalugina et al. (2009), Browning et al. (1994), Bourguignon et al. (1993)) and an answer to the first research question.

Moreover, the estimate shows that the satisfaction difference increases if the man contributes relatively more to the household income. That means that the relatively more a partner contributes to the household income, the relatively more he or she benefits from it.

The second specification in Table 3.2 takes an additional distribution factor into account to examine whether the effort to contribute income (in terms of working hours) or the income above the effort is the distribution factor, which explains sharing of the household income. 
The relative effort to bring income into the household can be captured with the parsimonious specification of the second model, though the effect of the working hours might be non-linear or dependent on who works relatively more, the man or the woman. Hence, a third specification with indicators for relative employment statuses is analyzed in the third model in Table 3.2.

For this specification, each partner's working hours are replaced by two binary variables indicating part-time employment and not being employed.

The reference category is full-time employment, since unemployment is already controlled for. The ratio of working hours is replaced by the three binary variables: the first one indicating whether allocation of work follows the male breadwinner scheme and the second indicating whether the woman works more than her partner. Couples are not classified as a male or female breadwinner couples if the partner is unemployed, because then, the asymmetric relative employment situation does not reveal a choice or preferences. Therefore, a third category becomes necessary for couples with one or both partners being unemployed. The reference group is thus couples where both partners are full-time, part-time or not employed.

Satisfaction differences are affected neither by the ratio of working hours nor by relative employment statuses. The effect of the income ratio, however, remains stable and does not decrease if the additional distribution factor in one and the other specification, (2) or (3), is considered. The same is true for most other covariates. Thus, the first question, if couples share their income according to the partners' financial contribution to the household income, is therefore answered: they do and even if the relative effort is controlled for. In other words, it is not the effort to contribute to the household's income, but the outcome of this effort that explains sharing.

Estimations of the partners' respective levels of financial satisfaction (Models 4 and 5 in Table 3.2) reveal that the income ratio influences women's financial satisfaction, though not men's, and that the ratio of working hours influences men's, but not women's financial satisfaction. Relative employment statuses in respective estimations (in Table A2.1 in Appendix A2) do not significantly influence either men's or women's levels of financial satisfaction and do not otherwise change the results.

A preliminary answer to the second research question is that unequal sharing is indeed asymmetric. 


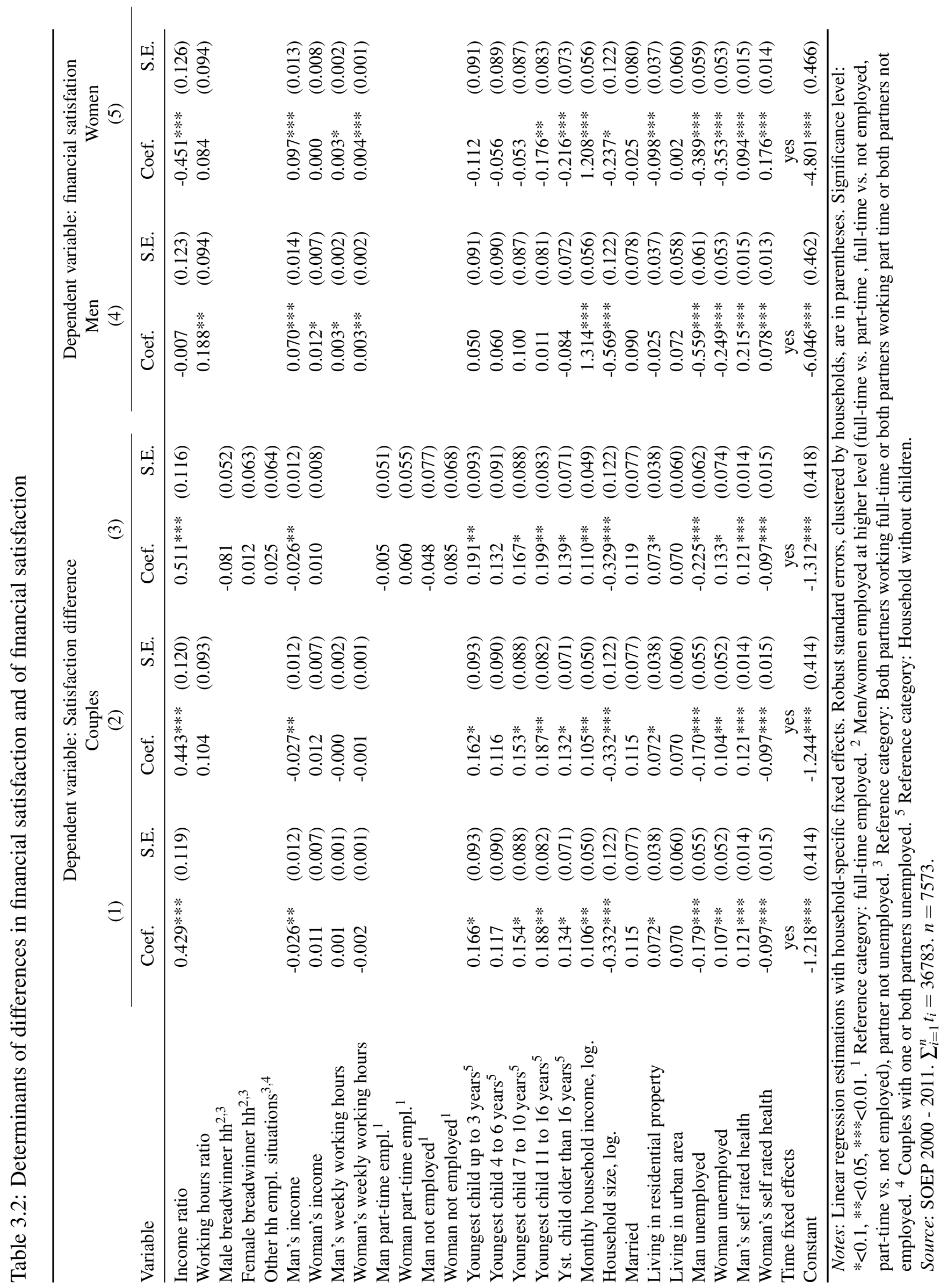




\subsubsection{Subsample Estimates}

Relative employment statuses are not found to be a distribution factor, yet these are circumstances in which sharing takes place and might be shaped.

Consequently, double full-time couples are the first subsample (column 1 in Table 3.3); male breadwinning households with part-time employed women are the second subsample (column 2 in Table 3.3); and finally, the same estimations are run for male breadwinning couples with women who are not employed (though not unemployed). ${ }^{18}$

Assignment to the subsamples is observation-wise, and therefore, two observations of one couple may fall into different subsamples, analogous to computing interaction effects, yet without imposing that all other effects are the same for different subsamples. Finally, the decision about subsample assignment depends (if not on statistical efficiency) on the understanding of the focus of the analysis. If generally stable personality traits and attitudes are in focus, casewise subsample assignment is appropriate. If the analysis focuses instead on behavior in contemporaneous reaction to circumstances, interaction effects or observation-wise assignment to subsamples are the more appropriate tools. One objection against observation-wise subsample assignment in the context of fixed-effects estimations concerns singletons, i.e., one-observationonly couples, which regularly come with this sort of assignment. Since these cannot be used for the fixed effects estimation, the corresponding interaction effects with the relative employment statuses and the income ratio, as well as with the man's and the woman's income are estimated using the whole sample. The same pattern as presented in Table 3.3 occurs; the results are available on request.

The model is the same as before, and again, the estimations rely only on the within variation. In Table 3.3, the estimates of $\delta$, which is the effect of the distribution factor on the satisfaction difference (see Equation (3.6)), are presented for each subsample. The same estimations are run for women and men separately to address asymmetries of the distribution factor effect. The subsample means of the distribution factor and the dependent variable are also reported.

The estimates in Table 3.3 show that couples' working time arrangement triggers the distribution factor effect. If women are not employed, while their partner is full-time or part-time employed, which is true for $19 \%$ of the observations, the income ratio is not a distribution factor for any of the partners. In the two other subsamples, i.e., in 54\% of the observations, couples are strongly affected by the distribution factor; satisfaction differences between those couples are not independent of the income ratio. The effect for double full-time couples is not significantly higher than for male breadwinner couples if the women is part-time employed. ${ }^{19}$

\footnotetext{
${ }^{18}$ Couples where both partners are part-time or not employed (but not unemployed) and female breadwinner couples are too few for corresponding estimations.

${ }^{19}$ The z-value for the difference of the effects is $z=\frac{\delta_{1}-\delta_{2}}{\sqrt{s e\left(\delta_{1}\right)^{2}+s e\left(\delta_{2}\right)^{2}}}=-1.19$.
} 
Focusing the asymmetry of unequal sharing in the subsamples reveals that in double fulltime couples, the woman's financial satisfaction is independent of the income ratio, in contrast to women who are part-time employed while their partner is full-time employed (column 2 in Table 3.3) and whose financial satisfaction is significantly associated with the income share. Men's financial satisfaction is independent of the income ratio as long as the male breadwinner scheme is met (columns 2 and 3 in Table 3.3). It depends on the income ratio when the partner is also full-time employed (column 1 in Table 3.3).

The second and the third research question should hence be answered together: unequal sharing is asymmetric and depending on the couples' working time arrangement. If male breadwinning with female part-time employment is practiced, unequal sharing is associated with the woman's valuation of the household income. If both partners are employed full-time, unequal sharing is associated with the man's valuation of the household income.

Table 3.3: Subsample estimates

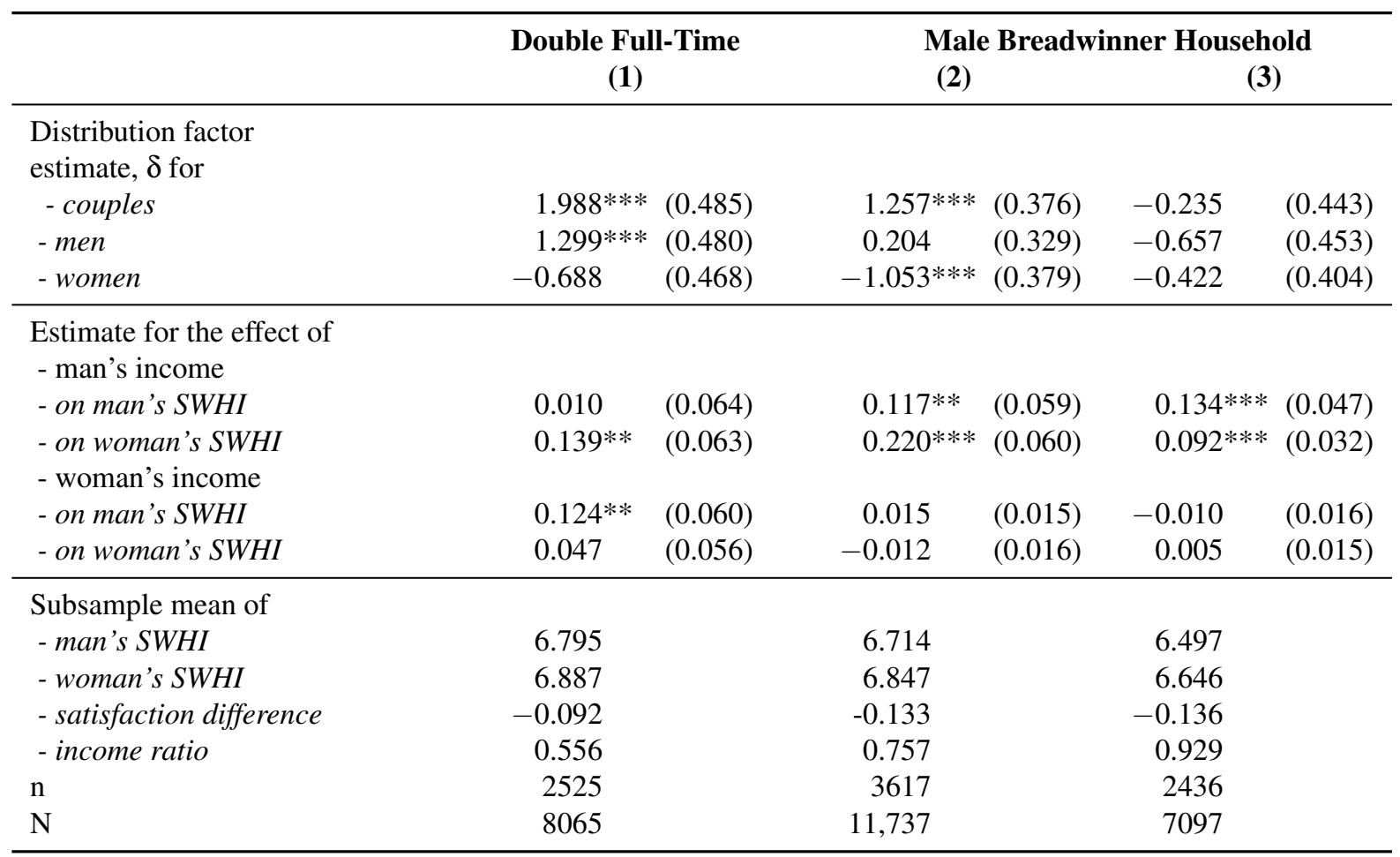

Notes: Linear regression estimations with individual-specific fixed effects; same specification as Model (2), (4) and (5) in Table 3.2. Robust standard errors, clustered by households, are in parentheses. Significance level: $*<$ $0.1, * *<0.05, * * *<0.01$. (1) Both partners full-time employed; (2) man full-time and women part-time employed; (3) man full- or part-time and women not employed. SWHI is satisfaction with household income. Source: SOEP.v28 , 2000-2011 


\subsubsection{Interpretation}

Strict male breadwinning couples do not share according to the income ratio, which is not surprising, since most of these women do not have their own income. However, the results here cannot indicate if women who are not employed enjoy equal and independent sharing. It is nevertheless possible that they obtain or perceive entitlement to the household income according to other contributions to the household's welfare, rather than independent entitlement.

If men are full-time employed and their partners at least part-time, sharing is associated with the couple's income ratio, meaning that it is not equal sharing. Whether unequal sharing is a matter of unequal access to the household income or of unequal entitlement cannot directly be answered. Yet, $73 \%$ of the couples report that they pool their incomes entirely, so unequal sharing might be more of a matter of unequal entitlement, rather than of unequal access to the household income.

Women in male breadwinner households obtain entitlement according to the income ratio if they are employed part-time (Table 3.3, column (2)). They enjoy independent entitlement to the household income, if they are employed full-time, like their partner.

Men need to be the breadwinner to enjoy independent entitlement to the household income. If the male breadwinning scheme is abandoned, men feel entitlement according to the income ratio.

These findings can be understood as gender-specific outcomes of one common pattern: The one who is perceived to contribute not enough enjoys entitlement to the household's income according to the share of income the person puts in. Contributing enough entitles one to freely access the household income. Gender roles come into play when each partner's contribution is assessed. The man contributes enough if he is the breadwinner, while she needs to contribute the same amount of employment to enjoy independent entitlement to the household income.

One ambiguity occurs with regard to the interplay of welfare with independent entitlement to the household income. For men, being the breadwinner is associated with independent entitlement to the household income, on the one hand, but not with relatively higher financial satisfaction, on the other. For women, the male breadwinning arrangement is associated with unequal income sharing, yet not with relatively lower financial satisfaction. The insignificant and even negative effect of male breadwinning on satisfaction differences in Model 3 in Table 3.2 suggests this interpretation. Since the woman's income in male breadwinner couples is seen as a contribution of minor importance (the effects of male and female income on each partner's satisfaction with household income in Table 3.3 show this), it is possible that it does not enter the pool of the household income, yet contributes to the woman's welfare because she can use it for her private purposes, though perhaps after bearing the costs for children, as Deutsch et al. (2003) found. As a result, the relatively higher their own income is, the relatively higher their welfare is compared to their partners'. The same does not apply to women who 
contribute a portion to the household income that is perceived to be relevant and which thus enters the pool of household income. If this were true, unequal entitlement would apply to less essential, private spending, associated with the notion that the private money is of minor importance for the other members of the household, because relevant parts of the income originate from other sources, namely the partner. In that case, earning the irrelevant surplus income may have a positive effect in that it opens up the possibility for financial privacy and autonomy. Corresponding findings about the perception of women's income contributions as irrelevant are reported in Bennett et al. (2012), Bennett (2013), yet not with the notion that underestimation of the women's financial contribution to the household income might be positive for her welfare.

\subsection{Concluding Remarks}

This study analyzes differences in financial satisfaction between household partners to examine welfare differences. If household partners share their household income following an equal sharing rule, the well-being from the household's income should be independent from any distribution factor.

The results clearly indicate that the equal sharing hypothesis has to be rejected, i.e., sharing is not independent of the male income ratio, the distribution factor. Further, results show that this is true only for couples where the woman is employed.

The main contribution of this paper is the extrapolation of the interplay of the male breadwinner norm and the asymmetry of unequal entitlement to the household income. Unequal sharing is asymmetric insofar as only one partner's entitlement to the household income depends on the distribution factor. The partner who is perceived to contribute inadequately to the household income is the one whose welfare depends on the income ratio. How much contribution is enough for independent entitlement to the household income is strongly gendered. Men need to be the breadwinner to freely access household income, and women need to contribute the same amount of employment as their partner to enjoy independent entitlement to the household income.

The finding that partners enjoy independent access to the household income, at least independent of the income ration, if they meet the gender-specific breadwinning norm might justify the forecast that equal income sharing will become more common if gender breadwinning norms equalize. 


\section{Chapter 4}

\section{Satisfaction as a Cause: Causality in the Income-Satisfaction-Link}

Susanne Elsas and Caspar Kaiser 


\subsection{Introduction}

In economic theory, the concept of utility is used to explain human behavior. It is standardly assumed that higher incomes generate higher levels of utility. Since utility is a theoretical concept, which is not directly observable, welfare and happiness economists equate utility with happiness and analyze self-reported data on satisfaction to test this assumption empirically (i.e. Easterlin 1995, Vendrik and Woltjer 2007, Layard et al. 2008, Carver and Grimes 2019). Typically the only causal pathway considered is that running from income to happiness. The reverse pathway, i.e. happiness causing income, is often neglected.

More recently however, evidence emerged that happiness promotes health, sociability, careers and productivity (De Neve et al. 2013) - all of which are causes and sources of earned income. Earned incomes, in turn, are one of the primary elements of a household's overall income (alongside e.g. government transfers or incomes from capital). These positive effects of happiness could transmit to overall household income, which means that overall household income could therefore potentially be influenced by happiness. Additionally, happiness may also increase equivalized household incomes via increasing the probability of household formation with a partner, which generates economies of scale compared to single households. It is thus likely that household income is also positively affected by happiness.

Since most people refer to equivalized household income when evaluating their income satisfaction (Schwarze 2003), it is reasonable that many studies use measures of equivalized household income when estimating the hedonic effects of income (e.g., Stutzer 2004, Boyce et al. 2010, Vendrik and Woltjer 2007, Jäntti et al. 2014). But, if greater happiness is a cause for greater household incomes, then estimates that do not account for this causal path will be biased upward. One aim of this study is therefore to explore the probable size of such a bias. We thus provide here the first (to our knowledge) simultaneous estimations of the bi-directional causal effects between equivalized income and happiness.

Our attempt at estimating the causal effect of happiness on equivalized household income is another substantive contribution which adds to the wider debate on the effects of happiness on socio-economic outcomes. 
Data for the analysis come from the German SOEP ${ }^{1}$ for the years 1985 to 2017 (273768 person-year-observations of 38,134 individuals). Self-reports on life satisfaction serve as measure for happiness, but estimations using financial satisfaction are provided too, since financial satisfaction is also a commonly used proxy for utility of income. Income is measured as annual equivalized household income. Identification relies on Lewbel instruments (Lewbel 2012), a method that exploits heteroscedasticity in the endogenous regressors to identify causal effects.

Our results indicate that income has no significant causal effect on life satisfaction, whereas satisfaction has only a weak effect on income. Standard estimates of the effect of income on satisfaction appear nevertheless to be biased upwards.

In the next section some related literature is discussed. The economic model, the identification strategy and the econometric model are explained in the third section. The fourth section describes the data. Since this is crucial for identification, that section also describes the patterns of heteroscedasticity in our key endogenous variables of interest. Results are presented in the fifth section. Two further sections present robustness checks and further estimations using financial satisfaction. A final section concludes.

\subsection{Related literature}

In economic theory and in the general public it is expected that income, ceteris paribus, generates utility and thereby raises satisfaction. Although this hypothesis has received general empirical support, the much debated Easterlin Paradox (Easterlin 1974, Stevenson and Wolfers 2008, Easterlin 2017, Kaiser and Vendrik 2019a), which notes that as countries grow richer over time, they do not grow happier, raises doubts about the utility of income hypothesis.

The debate about the importance of own income for life satisfaction never stopped completely (Hagerty and Veenhoven 2003, Easterlin 2005, Clark et al. 2008b, Kahneman and Deaton 2010, Boyce et al. 2010), but the majority agrees that income does matter, though perhaps only to a limited extent (Easterlin 1995, Oswald 1997, Diener and Oishi 2000, Frey and Stutzer 2002, Boyce et al. 2017).

\footnotetext{
${ }^{1}$ The German Socio-Economic Panel Study is an ongoing longitudinal study of German households. The SOEP began in 1984 with a sample of adult members from randomly selected households in West Germany. Since 1984, the SOEP has expanded to include East Germany and also added various subsamples to maintain a representative sample of the entire German population and to allow analyses of special groups in society, e.g affluent households, the migrant population or income-poor families.
} 
Very few previous studies, though, use methods that are explicitly able to identify causal effects of income on life satisfaction. Most of these studies find support for the hypothesis that income matters. At first, in a very innovative approach a significantly positive effect of income on life satisfaction was estimated exploiting exogenous income increases that occurred with the German reunification (Frijters et al. 2004). Yet, orderd logit estimations that account for individual-specific correlated unobserved heterogeneity were lateron found to be inconsistent estimators (Baetschmann et al. 2015). Some instrumental variable approaches yielded positive estimates, yet relevance and exogeneity of the instruments for income are not always straightforwardly established. This is, for example, the case if instruments are constructed from the share of respondents in the household showing their payslip to the interviewer ${ }^{2}$ and also when the parents' or spouse's education is used as an instrument. ${ }^{3}$ Exogeneity and relevance of industry- and occupation-wide variation in earnings, in contrast, are very well-established for instrumenting income in life satisfaction estimations, and are hence repeatedly used for this purpose: Luttmer (2005) analyzes the effect of spatial reference income, i.e. the mean income in the neigborhood, using US data. Vendrik (2013) and Kaiser (2018) use the same instruments, but German and British Data, and analyze if people adapt to income. All three studies did not focus the effect of own current income on life satisfaction, but all found strongly significant, positive and large effects of current income on life satisfaction. Vendrik (2013), though, mentions that the instruments they use are specially suitable to predict permanent income, rather than income of shorter periods.

In contrast to the aforementioned studies, Lachowska (2017) found large, significantly positive and robust effects of income on affect, but no statistically significant, nor robust effects on life satisfaction. She uses an instrument that she constructed from the economic stimulus tax

\footnotetext{
${ }^{2}$ Powdthavee (2010) used the share of respondents who showed their payslip to the interviewer, to predict household income. "The idea is that there is a direct correlation between the proportion of household members showing and not showing their payslip to the interviewer and that of household income as household income is bound to have been measured more accurately where the proportion of household member who showed payslip is high." (Powdthavee 2010, p. 81). This however explains precision of the income measure, but is no argument for a monotone effect on the amount of income, which would be needed for an instrumental variable estimation.

${ }^{3}$ Knight et al. (2009) also estimate significantly positive effects of income on life satisfaction in China. They used fathers and spouses education to instrument income in the life satisfaction equation. The usual statistical test are convincing, but only a weak argument is given that supports the generally untestable exogeneity assumption for the instrument: it is said that it was not likely that spouses or fathers education influences life satisfaction (except through income), because even own education is only weakly associated to life satisfaction in their OLS estimations with all covariates (Knight et al. 2009, p. 646). Findings for Germany indicate the contrary, i.e. that "[...] overall, family background and individual factors are of approximately equal importance for permanent life satisfaction." (Schnitzlein and Wunder 2016, p. 146)
} 
rebate that was implemented in the US in 2008, where timing of the payment was randomly assigned. This randomly assigned timing is the exogenous variation that she uses to identify the causal effect of a one-shot increase in income on life satisfaction.

A further study that analyzes the effects of short-run income shocks and long-term income changes bridges the gap between those who found large positive effects of income on life satisfaction (Luttmer 2005, Vendrik 2013, Kaiser 2018) and the result of Lachowska (2017), who found no effect: Using also German SOEP data Bayer and Juessen (2015) found that longterm changes in income have significant and sizable positive effects on life satisfaction, while short-term shocks have none. The authors identify the causal effects from lags and leads of the endogenous regressor. ${ }^{4}$

Psychologists, economists and common sense suspect that satisfaction or happiness also impact on income. Several recent studies in behavioral economics analyze (affective and evaluative) subjective well-being as a cause of various outcomes such as risk avoidance or delay gratification (for an overview, see: Lane 2017, De Neve et al. 2013), saving (Guven 2012), absenteeism (Bubonya et al. 2017), (un-)employment (Krause 2013, Kesavayuth and Zikos 2018), career progression (for an overview see: Walsh et al. 2018) or productivity (Oswald et al. 2015, Tenney et al. 2016, Bryson et al. 2017, Böckerman and Ilmakunnas 2012). All these outcomes predict income. Nevertheless, studies of the effect of satisfaction on income are rare and most often focus on earned income rather than equivalized household income. The first study on the effect of satisfaction on income appears to be by Graham et al. (2004). Using Russian panel data, they find that positive expectations and residual happiness are positively associated to future incomes. However, time lags can only identify unidirectional causal effects if no individual-specific unobserved heterogeneity is present that affects both dependent and any explanatory variable. De Neve and Oswald (2012) address this problem with siblings fixed effects; they estimate the effect of happiness at age 22 on future income at age 29 and find a positive effect. One other study investigates the causal effect of happiness on earnings (Mishra and Smyth 2014) using a relatively new method, the Lewbel (2012) instruments. They find a

\footnotetext{
${ }^{4}$ To pass the exogeneity requirement, the instruments must meet two conditions: The "No Foresight" condition which assumes that all deterministic components of income are captured in the exogenous controls that enter the first-stage regression. It holds whenever the individual has no better information on income growth in the next period than the econometrician. The second condition for the instrument to be exogenous is the "Short Memory" condition, which requires that, narrowly understood, change in assets neither responds to persistent shocks in the year before, nor to transitory shocks two years before (Bayer and Juessen 2015, pp. 166).
} 
positive effect of happiness on earnings for men. All these three, however, analyze earned income. This is the main income source for many people. However, these results cannot answer the question about effects of satisfaction on equivalized income. It could be that the effect of satisfaction on earnings attenuates when earnings are shared among household members. On the other hand, it is possible that household formation accelerates the effect of satisfaction on equivalized household income, which would not be picked up by estimation for earned income.

This would be a minor problem if many studies focusing the utility or welfare effect of income did not analyze the potential effect of equivalised household income (e.g., Stutzer 2004, Boyce et al. 2010, Vendrik and Woltjer 2007, Jäntti et al. 2014). For the purpose of welfare analyses and due to economies of scale, whereby incomes may be used more efficiently in larger households, it is appropriate in these settings to equivalize household incomes. And it is hence necessary to know if estimates of the hedonic effect of income are potentially overstated due to reverse causality that runs from happiness to equivalized household income.

\subsection{Model and identification}

To identify causal effects, researchers often exploit time lags, based on the idea that causes precede results. However, if individual-specific time-invariant unobservable or unobserved characteristics influence income and happiness, the time-lag method could falsely indicate a causal relation due to confounding. Such problems may be partially cured with fixed effects, like individual or family fixed effects. Nevertheless estimates still suffer from time-varying unobserved heterogeneity, and only the limited variation around fixed effects can be used for identification.

An arguably more elaborate approach applies external instruments, which affect only one of income or happiness directly, while the second is only indirectly affected via the first. Convincing instruments, especially for satisfaction, are usually hard to find. Guven (2012), who analyzed the effect of happiness on savings and consumption behavior found a convincing instrument for happiness: unexpected sunshine. Sunshine sufficiently influences happiness, so that the instrument is strong enough to identify sizable effects of happiness on savings behavior. Yet these might be be restricted to those whose satisfaction answers are driven to a larger extent by moods, affect and sunshine. As for income, an unforeseen tax rebate as used by Lachowska (2017) may be a particularly clean instrument, but is not available in the German case. 
As an alternative approach, internal instruments can be constructed from the data, as Lewbel (2012) shows. This method can be applied when no valid external instruments are available and is already used in empirical economics. ${ }^{5}$ In the following we explain how Lewbel's (2012) method can be applied to identify causal effects in the income happiness link.

\subsubsection{Model}

It is well-established that utility - measured in levels of stated satisfaction - depends positively on personal incomes. Nevertheless, there remains a long-standing controversy over the degree to which satisfaction depends on income. We join this debate with the question:

RQ1: Does satisfaction depend on income?

One might approach answering RQ1 by estimating a regression of the form:

$$
s_{i t}=\gamma_{1} \ln \left(y_{i t}\right)+X^{\prime}{ }_{i t} \beta_{1}+\alpha_{i}+\varepsilon_{1 i t}
$$

Here, $s_{i t}$ denotes satisfaction of individual $i$ at time $t . X$ is a vector of $J$ exogenous controls, $\alpha_{i}$ is an individual fixed effect, and $\varepsilon_{1 i t}$ is an ideosyncratic error. We avoid estimating $\alpha_{1 i}$, by demeaning $^{6}(4.1)$ :

$$
\dot{s}_{i t}=\gamma_{1} \ln \left(y_{i t}\right)+\dot{X}^{\prime}{ }_{i t} \beta_{1}+\varepsilon_{1 i t}
$$

Here, $\dot{s}_{i t}=s_{i t}-\bar{s}_{i}$, and similar for $\ln \left(y_{i t}\right)$ and each $j$ th variable $\dot{x}_{j i t}$ of the $J$ variables in $\dot{X}_{i t}$.

Although demeaning captures all time-invariant unobserved determinants that might confound the relationship between $s_{i t}$ and $\ln \left(y_{i t}\right)$, there are further issues which could cause inaccuracies in answers obtained from estimating (4.2): First, respondents might find it difficult to accurately report their incomes. There may therefore be measurement error in income, causing estimates from (4.2) to be biased towards zero. Second, there may be further unobserved time-varying determinants of stated satisfaction that could act as confounders. Third, incomes may depend on satisfaction. Although this third possibility has been considered, most previous

\footnotetext{
5384 citations are mentioned on the publishers website, 647 at google scholar and 256 in the web of science (as of August 08, 2019)

${ }^{6}$ We do not manually demean, but use Stata's 'xtreg, fe vce(cluster)' command.
} 
studies purely focused on earned income. Focusing earned income serves more to understand how satisfaction causes income. Our attempt however is to explore if equivalized income is also influenced by satisfaction. To the best of our knowledge this possibility has until now not been evaluated in a joint analysis with RQ1. We therefore ask:

RQ2: Does equivalized income depend on satisfaction?

A natural approach to answering this question is to estimate a regression that is analogous in form to (4.2):

$$
\ln \left(y_{i t}\right)=\gamma_{2} \dot{s}_{i t}+\dot{X}^{\prime}{ }_{i t} \beta_{2}+\varepsilon_{2 i t}
$$

However, if the true values of $\gamma_{1}$ and $\gamma_{2}$ are indeed different from zero, OLS estimates of (4.2) and (4.3) will be biased due to simultaneity of $\gamma_{1}$ and $\gamma_{2}$. One aim of this study is to gauge how large the impact of such simultaneity is.

\subsubsection{Identification}

A standard approach to circumvent these problems would be to find suitable instruments for both satisfaction and income. Although such instruments potentially exist (see Section 4.2), we here explore the use of an alternative strategy where instruments are constructed from a readily available subset of the observed exogenous variables in $\dot{X}$. This approach, developed by Lewbel (2012), can be summarized as follows.

To construct instruments for $\ln \left(y_{i t}\right)$ in equation (4.2), we run the following auxiliary regression in the first step: ${ }^{7}$

$$
\ln (y)_{i t}=\dot{Z}^{\prime}{ }_{i t} \delta_{1}+\mathrm{v}_{1 i t}
$$

Where $\dot{Z}$ is a subset of $K$ variables in $\dot{X}$ that satisfy the exogeneity assumption. We can then use the residuals $\hat{v}_{1 i t}$ and sample-centered values of each variable $\dot{z}_{k}$ in $\dot{Z}$ to calculate $K$ instruments

\footnotetext{
${ }^{7}$ Actually we did not conduct the estimatation step by step, we use the Stata-ado 'xtivreg2h' by Baum and Schaffer (2012).
} 
for $\ln \left(y_{i t}\right)$ in the second step:

$$
\text { yinst }_{k i t}=\left(\dot{z}_{k i t}-\overline{\dot{z}}_{k}\right) \hat{v}_{1 i t}
$$

Instruments for $\dot{s}_{i t}$ to be used in equation (4.3) are constructed analogously. We first run:

$$
\dot{s}_{i t}=\dot{Z}^{\prime}{ }_{i t} \delta_{2}+v_{2 i t}
$$

We then calculate $K$ instruments for $\dot{s}_{i t}$ as given by:

$$
\operatorname{sinst}_{k i t}=\left(\dot{z}_{k i t}-\overline{\dot{z}}_{k}\right) \hat{v}_{2 i t}
$$

These instruments are then - as in conventional instrumental variable estimations - used to predict the endogenous regressors in the structural equations, (4.2) and (4.3).

The intuition of this identification strategy follows from linear regression mechanics: Residuals are by construction exogenous to the the right-hand-side variables. If satisfaction, the outcome of the structural equation (4.2), is independent of the residuals of the auxiliary income regression given in Eq. (4.4), and if the variables in $Z$ are exogenous in the structural equation, then the instruments are exogenous. In that case, the instruments affect the outcome only via the endogenous regressor. To be relevant, the instrument must affect the endogenous regressor. If residuals are heteroscedastic, they contain (information about) the variation of the outcome variable, which makes the instruments relevant.

Thus our instruments are constructed from observed variables, all of which are assumed to be exogenous. Since we heavily rely on these, we only consider few variables as sufficiently exogenous to be included in $Z$, i.e. age, age $e^{2}$ wave $e^{2}$, and $w a v e^{3}$. In our main estimations we set $Z=X$.

However, as this is a very unusual specification, we run robustness regressions in which we augment our set of variables in $X$ to also include more standard demographic controls. See Section 4.4 for a list and description. We then compare two specifications. Our baseline specifications only include age and wave (and powers thereof) as controls, and instruments for income and satisfaction are constructed on the basis of these controls. Our robustness specification then adds demographic variables as further controls, but continues to construct instruments solely on 
the basis of age and wave (and powers thereof), in which case, $Z$ is a proper subset of $X$. Next to our informal comparison of these specifications, we also always report results from Hansen $\mathrm{J}$ test on overidentifying restrictions to evaluate the exogeneity of all instruments, the constructed and all controls.

As noted in Lewbel (2012) and Baum and Lewbel (2019), for each instrument yinst $_{k}$ to be valid, we require that $\operatorname{Cov}\left(z_{k}, \varepsilon_{1} \varepsilon_{2}\right)=0$ and $\operatorname{Cov}\left(z_{k}, \varepsilon_{1}^{2}\right) \neq 0 .{ }^{8}$ The former assumption is satisfied if the errors $\varepsilon_{1}$ and $\varepsilon_{2}$ are independent of each other. This is the case when income and satisfaction are endogenous in each other because of a common factor, i.e. aspirations or wellbeing. The latter requirement simply implies heteroscedasticity in the auxiliary regression of (4.4) and (4.6). We therefore report Breusch-Pagan heteroscedasticity test results in Table 4.2.

The relevance of an instrument constructed from a particular variable $x_{k}$ depends on the strength of heteroscedasticity with respect to $x_{k}$, we therefore inspect in the next section observed heteroscedasticity patterns with estimates with statistical tests and residual plots that should be indicative of how locally restricted our estimates are.

Estimations are run with the Stata-ado ivreg2h, which was written by Baum and Schaffer (2012) calling the GMM estimator and using clustered standard errors, since we use several observations per person.

\subsection{Data}

Data come from the German Socio-Economic Panel Study (SOEP), version 34, for years 19842017 (doi:10.5684/soep.v34). We restrict the sample to individuals of age 18 to 60 who live in private households. Each individual's first observation is dropped, because Frick et al. (2006) found that the quality of income information is significantly lower in these observations. Observations with extreme values for equivalized household income (outer $2 \%$ of the distribution in each survey year) are also excluded because these are prone to measurement error (Layard et al. 2008).

The first endogenous variable is the annual post government household income in the year before the survey. Incomes are deflated to the baseline year 2005 and equivalized with the

\footnotetext{
${ }^{8}$ Similarly, for each instrument sinst $t_{k}$ to be valid we require that $\operatorname{Cov}\left(x_{k}, \varepsilon_{1} \varepsilon_{2}\right)=0$ and $\operatorname{Cov}\left(x_{k}, \varepsilon_{2}^{2}\right) \neq 0$
} 
square root of the household size, which is very close to the OECD equivalence scale from Hagenaars et al. (1994) and used in recent OECD publications (OECD 2008, 2011). ${ }^{9}$

Our second endogenous variable is life satisfaction, measured on a 11-point Lickert-type scale, with higher values indicating higher satisfaction. Analogue analyses are run with financial satisfaction. Since we use income in the year before the survey, we also use satisfaction in the year before the survey, because with satisfaction data collected a few months later than the income measure, RQ2 could not be analyzed properly.

Exogenous controls are age, age squared, survey wave squared and cubed. ${ }^{10}$ In our baseline specification we use less controls than studies on life satisfaction usually use. To ease comparison with other known estimates, we add specifications with commonly used controls; these are: reference income ${ }^{11}$ education, marital status, children in the household (yes/no), region of residence (East/West Germany), being unemployed at the time of the interview, home ownership and health, approximated with hospital overnight stays (yes/no) in the previous year. Since most women give birth in a hospital, hospital overnight stays for women do not necessarily indicate health problems. To account for this, we include an interaction term for women who answered that they stayed in hospital overnight in the year before and who live in a household with children not older than one year. ${ }^{12}$ Sample descriptives are presented in Table 4.1.

Since identification relies on heteroscedasticity related to the exogenous control variables, we present estimates of the association between exogenous controls and the squared residuals of (4.4) and (4.6) in Table 4.2. There we also present statistics on the Breusch-Pagan test for heteroscedasticity.

The last two rows in Table 4.2 show the $\chi^{2}$ test statistics and corresponding p-values for the Breusch-Pagan-Test, indicating that heteroscedasticity is present in all endogenous variables.

\footnotetext{
${ }^{9}$ We also ran all estimations with the unequivalized household income. This slightly changed the size of the coefficients but not the interpretation. Results are reported in the appendix A3.2.

${ }^{10}$ For convenience age and squared survey wave are divided by 10 , squared age and cubed wave are divided by 100 , to avoid significant zeroes.

${ }^{11}$ Reference income is the mean income of all individuals within an moving age range of 5 years younger and 5 years older, living in the same state (Bundesland), in households of the same size (top-coded at 5 persons per household), and with similar highest level of education

${ }^{12}$ Hospital overnight stay is not measured in the years 1990 and 1993. To avoid large data losses, we inserted random numbers, generated from a binomial distribution with the the same success probability as the observed variable.
} 
Table 4.1: Sample descriptives

\begin{tabular}{lrrrr}
\hline & Mean & $\begin{array}{r}\text { Std. } \\
\text { Dev. }\end{array}$ & Min & Max \\
\hline Life satisfaction & 7.009 & 1.733 & 0 & 10 \\
Income & 37587 & 18686 & 120 & 802920 \\
Financial satisfaction & 6.335 & 2.209 & 0 & 10 \\
Age & 41.641 & 10.812 & 20 & 60 \\
Female & 0.523 & 0.499 & 0 & 1 \\
Years of education & 12.047 & 2.680 & 7 & 18 \\
Hospital overnight stay & 0.102 & 0.303 & 0 & 1 \\
Gave birth & 0.015 & 0.121 & 0 & 1 \\
Married & 0.476 & 0.499 & 0 & 1 \\
Children in household & 0.662 & 0.473 & 0 & 1 \\
Living in East Germany & 0.199 & 0.399 & 0 & 1 \\
Unemployed & 0.067 & 0.250 & 0 & 1 \\
Home owner & 0.484 & 0.500 & 0 & 1 \\
\hline
\end{tabular}

Source: SOEP v34, own calculations. 273,768 person year observations of 38134 individuals.

Notes: Hospital overnight stay for 261,782 person year observations, and 11986 imputed random numbers. Income is post-government household income, not equivalized.

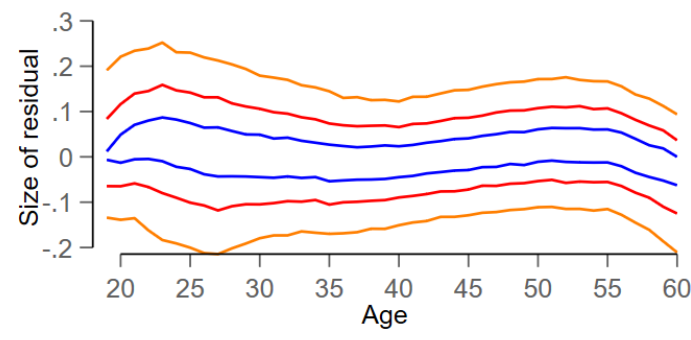

Percentiles of the distribution of residuals - 40th\&60th - 30th\&70th - 20th\&80th

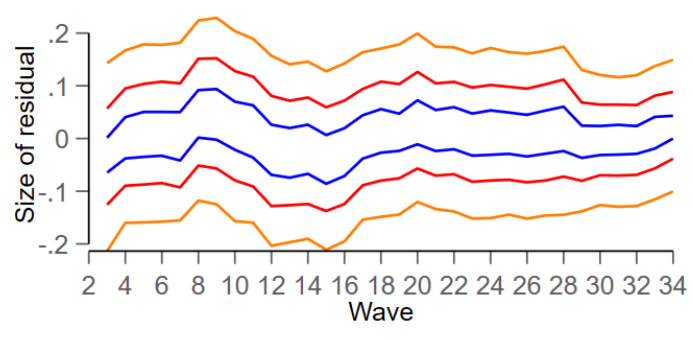

Percentiles of the distribution of residuals - 40th\&60th - 30th\&70th - 20th\&80th

Figure 4.1: Age- and wave-related heteroscedasticity in income

Source: SOEP v34, own calculations. 337031 person year observations of 46945 individuals.

Notes: Residuals from fixed effects regressions of income on age, age ${ }^{2}$, wave ${ }^{2}$ and wave ${ }^{3}$ 
Table 4.2: Squared residuals of endogenous regressors and exogenous controls

\begin{tabular}{lccc}
\hline & $v_{1 i t}^{2}$ & $v_{2 i t}^{2}$ & $v_{3 i t}^{2}$ \\
& (Equiv. income) & (Life satisfaction) & (Fin. satisfaction) \\
\hline Age & $-0.017^{* * *}$ & $-0.169^{* * *}$ & $0.025^{* * *}$ \\
Age, sq. & $(0.000)$ & $(0.007)$ & $(0.005)$ \\
& $0.010^{* * *}$ & $0.099^{* * *}$ & $0.021^{* * *}$ \\
Wave, sq. & $(0.000)$ & $(0.008)$ & $(0.006)$ \\
& $-0.005^{* * *}$ & $-0.083^{* * *}$ & $-0.036^{* * *}$ \\
Wave, cub. & $(0.000)$ & $(0.004)$ & $(0.003)$ \\
& $0.001^{* * *}$ & $0.016^{* * *}$ & $0.008^{* * *}$ \\
Constant & $(0.000)$ & $(0.001)$ & $(0.001)$ \\
& $0.135^{* * *}$ & $2.783^{* * *}$ & $1.276^{* * *}$ \\
\hline Chi squared & $(0.001)$ & $(0.028)$ & $(0.021)$ \\
Prob> Chi squared & 4630 & 2087 & 447 \\
\hline
\end{tabular}

Source: SOEP v34, own calculations. 337031 person year observations of 46945 individuals.

Notes: Significance levels $* 0.10 * * 0.05 * * * 0.01$. Cluster-robust standard errors in parentheses. Dependent variables are squared residuals from fixed effects regressions, exogenous variables are within transformed.

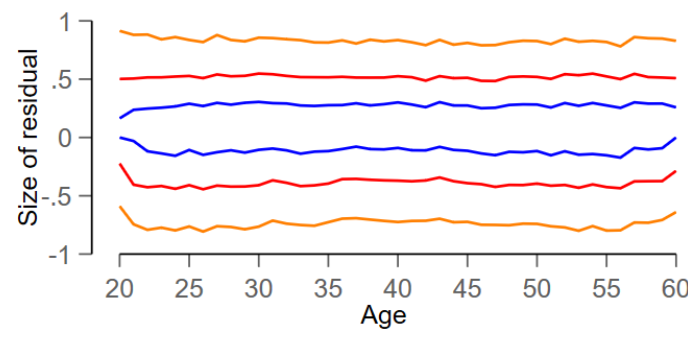

Percentiles of the distribution of residuals - 40th\&60th - 30th\&70th - 20th\&80th

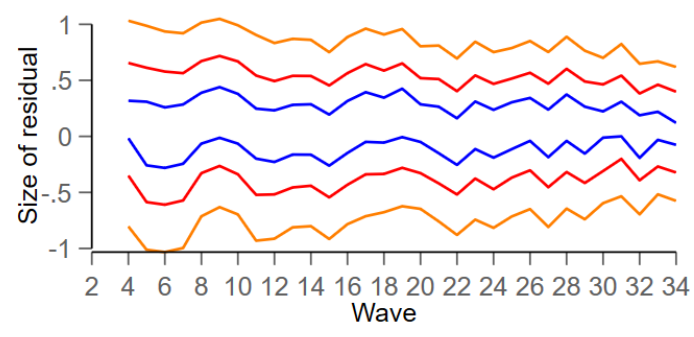

Percentiles of the distribution of residuals - 40th\&60th - 30th\&70th - 20th\&80th

Figure 4.2: Age- and wave-related heteroscedasticity in life satisfaction

Source: SOEP v34, own calculations. 337031 person year observations of 46945 individuals.

Notes: Residuals from fixed effects regressions of life satisfaction on age, age ${ }^{2}$, wave ${ }^{2}$ and wave ${ }^{3}$ 
Figure 4.1 and Figure 4.2 are plots of the distribution of residuals that are used to construct the instruments for income and life satisfaction. ${ }^{13}$ The plots underline the message of the Breusch-Pagan test in Table 4.2. The distribution of the residuals of income narrows over the survey years and respondents' age. The distribution of the residuals of life satisfaction also narrows over the survey years and reveals a slight tendency to narrow in the respondents' middle ages. Heteroskedasticity in financial satisfaction follows a similar pattern, the plots theron are presented in Appendix A3 Figure A3.1. It thus appears as though our exogenous controls and squared residuals are sufficiently associated to allow for identification based on Lewbel's instruments.

\subsection{Results}

Results are presented in the same order as the model equations are discussed. Some notes apply to all results: To avoid problems of weak instruments, we follow Baum et al. (2007), who suggest the rule of thumb of Staiger and Stock (1997). This means, we trust only estimates with F-statistics $>10$. Since the estimations rely on multiple observations per person, the Wald F- statistics based on the reduced rank test of Kleibergen and Paap (2006) are valid test statistics, because they are robust to non-i.i.d. errors. These F values are displayed as "K-P F-Statistic" for each IV estimation in the bottom of the tables. Test statistics for the Hansen $\mathbf{J}$ test of overidentifying restrictions, which tests the null that the instruments are exogeous, are reported under each IV estimation. ${ }^{14}$ In the bottom line of most estimation tables a $\mathrm{z}$-score is reportet, which indicates that the estimates from the IV procedure significantly differ from the conventional fixed effects estimates if it exceeds 1.96.

To construct the instruments, we use a very sparse set of exogenous controls to assure that the exogeneity assumption of the instruments can be met. We are strict with the exogeneity requirement towards the controls, because the internal instruments are constructed from the exogenous controls. If controls were used that might be endogenous in life satisfaction, the instruments that are constructed from these variables cannot satisfy the exogeneity assumption. Controls then are: age, age squared, survey wave squared, wave cubed. The estimation

\footnotetext{
${ }^{13}$ Demeanded income and life satisfaction were regressed on demeaned exogenous controls, i.e. age, age ${ }^{2}, w^{2} e^{2}$ and wave ${ }^{3}$.

${ }^{14}$ For the Hansen $\mathrm{J}$ test, it is thus a successfull result if $\chi^{2}$ indicates that the null is not rejected.
} 
procedure though allows to specify $Z$ as a subset of $X$ and we make use of this option and can therefore present, for comparison, results that rely on an augmented set of controls, described in Section 4.4; instruments, again, are constructed only from the exogenous controls listed before.

The complete estimation results are to be found in the appendix A2.

\subsubsection{RQ1: Income causing satisfaction}

The answer to RQ1 is provided in Table 4.3, and it obviously depends on the method. In a conventional fixed effects estimation we can confirm that increasing incomes are associated with increased life satisfaction with a reasonalbe effect size. The estimates from the IV approach though, show no effect of income on life satisfaction.

Table 4.3: FE-IV and FE estimations of RQ1: Utility of equivalized household income

\begin{tabular}{lccrrc}
\hline & \multicolumn{2}{c}{ I } & & \multicolumn{2}{c}{ II } \\
\cline { 2 - 3 } \cline { 5 - 6 } & IV-FE & FE & & IV-FE & FE \\
\hline Income, log. & 0.051 & $0.355^{* * * *}$ & & -0.006 & $0.367^{* * *}$ \\
& $(0.073)$ & $(0.013)$ & & $(0.108)$ & $(0.015)$ \\
Demographic & no & no & & yes & yes \\
controls & & & & & \\
\hline K-P F-Statistic & 267 & & & 172 & \\
Hansen J & 5.545 & & & 5.983 & \\
Prob>Chi sq. & 0.1360 & & & 0.1125 & \\
Z-score & -4.102 & & & -3.408 & \\
\hline
\end{tabular}

Source: SOEP v34, own calculations. 273,768 person year observations of 38,134 individuals.

Notes: Significance levels $* 0.10 * * 0.05 * * * 0.01$. Cluster-robust standard errors in parentheses. All estimations include age, age ${ }^{2}$, survey wave ${ }^{2}$ and survey wave ${ }^{3}$.

The most standard fixed effects regression result is presented in the last column of Table 4.3. This is a fixed effects estimate of the association between income and life satisfaction, when adding a large set of demographic controls (including health and marital status, education, (un-)employment, region of residence, children, home ownership and reference income). This specification is thus closer to previous studies. The penultimate column shows results, from the comparable estimation, where the same demographic control variables are included, but the internal instrumental variables approach is used. The instruments are exclusively constructed from the exogenous controls (age, age squared and survey wave squared and cubed), but not 
from the demographic controls. First and second column present results from the most sparse models, with only age and wave (and its powers); where in the first column identification comes from the internal instruments and in the second column the corresponding straightforward fixed effects estimates are presented.

In general, the patterns in the estimations with and without further controls are similar: The effects found through IV-estimations are zero while the FE-estimates are significantly positive. The z-sores indicate that the estimates from the two identification strategies differ significantly. Including further demographic controls does not meaningfully change the estimates: even though the sign reverses, the IV estimates are statistically insignificant with and without further demographic controls, the z-score to compare these coefficients is 0.437 (not given in the table), indicating that the difference between the estimates is not statistically significant. The conventional fixed effects estimates with and without further demographic controls are also not significantly different from each other. This similarity in the patterns suggests that the exogeneity assumption (i.e. that the product of first and second stage errors is uncorrelated to the exogeneous controls) is not seriously violated due to omitted variables - at least not due to the demographic controls that we considered. The Hansen J test, which is statistically insignificant at the $10 \%$ level underlines this by also suggesting no violations to exogeneity.

\subsubsection{RQ2: Satisfaction causing income}

The preceding results showed that usual fixed effects estimations may overstate the effect of income on life satisfaction. One possible reason for this finding could be reverse causality: life satisfaction might cause income, as asked in RQ2.

Estimates in Table 4.4 support this hypothesis only weakly. Higher life satisfaction might cause higher equivalized income, but significance is only weak and disappears when further control variables are included in the estimation. Again, the coefficients of the conventional fixed effects estimations are significantly positive. These, however, may be biased due to any of the reasons mentioned in Section 4.3.1. Covariates ${ }^{15}$ again, do not significantly change the results for the conventional fixed effects estimates, and change only the significance test for the IV-FE estimation. According to the test statistics, the IV estimation is trustworthy; Instruments

\footnotetext{
${ }^{15}$ The set of demographic covariates in the estimations for RQ2 is the same as for RQ1 except for giving birth
} and reference income, these are not included in the estimations for Table 4.4. 
Table 4.4: FE-IV and FE estimations of RQ2: Life satisfaction causing household income

\begin{tabular}{lccccc}
\hline & \multicolumn{2}{c}{$\mathrm{I}$} & & \multicolumn{2}{c}{ II } \\
\cline { 2 - 3 } \cline { 5 - 6 } & IV-FE & FE & & IV-FE & FE \\
\hline Life satisfaction & $0.011^{*}$ & $0.016^{* * *}$ & & 0.010 & $0.014^{* * *}$ \\
& $(0.006)$ & $(0.001)$ & & $(0.006)$ & $(0.001)$ \\
Demographic & no & no & & yes & yes \\
controls & & & & 158 & \\
\hline K-P F-Statistic & 158 & & & 0.745 & \\
Hansen J & 2.663 & & & 0.8626 & \\
Prob>Chi sq. & 0.4466 & & & -0.723 & \\
Z-score & -0.741 & & & & \\
\hline
\end{tabular}

Source: SOEP v34, own calculations. 273,768 person year observations of 38,134 individuals.

Notes: Significance levels $* 0.10 * * 0.05 * * * 0.01$. Cluster-robust standard errors in parentheses. All estimations include age, age ${ }^{2}$, survey wave ${ }^{2}$ and survey wave ${ }^{3}$.

are not weak and the model is not misspecified, which could be interpreted as all instruments being exogenous.

The weak indication for a causal effect from life satisfaction on income matches the results for RQ1 that higher incomes do not cause greater life satisfaction although the association is significantly positive, The conventional fixed effects estimator could overstate the hedonic effect of income due to reverse causality.

\subsubsection{Robustness check}

One objection against the presented estimates might result from the fact the in three of four IV estimations we found only small or zero and insignificant effects, while the corresponding conventional fixed effects estimator found larger and significant effects. One might therefore suspect that the Lewbel IV estimator is not suitable for either the discrete scale of the satisfaction data or not capable of detecting small significant effects due to the reduced power which is common in IV estimations and even more so when only within variation of the data is used. To address this concern we run the same regressions on simulated data. On top of the SOEP data, 
we simulated a random variable with similar distribution as reported income, and panel data structure. ${ }^{16}$

Table 4.5: Re-estimations of $\mathrm{H} 1$ and $\mathrm{H} 2$ : For simulated random income and manipulated satisfaction depending on simulated income

\begin{tabular}{lccrr}
\hline & \multicolumn{2}{c}{ RQ1 } & \multicolumn{2}{c}{ RQ2 } \\
& IV FE & FE & IV FE & FE \\
\hline Sim.Income & $0.218^{* * *}$ & $0.238^{* * *}$ & & \\
Sim.Satisf. & $(0.076)$ & $(0.026)$ & & \\
& & & 0.004 & $0.003^{* * *}$ \\
& & $0.004)$ & $(0.000)$ \\
\hline K-P F-Statistic & 266 & 158 & \\
Hansen J & 1.4 & 8.8 & \\
Prob>Chi sq. & 0.7132 & 0.0325 & \\
Z-score & -0.252 & 0.279 & \\
\hline
\end{tabular}

Source: SOEP v34, own calculations. 273,768 person year observations of 38,134 individuals.

Notes: Significance levels * $0.10 * * 0.05 * * * 0.01$. Cluster-robust standard errors in parentheses. All estimations include age, age ${ }^{2}$, survey wave ${ }^{2}$ and survey wave ${ }^{3}$.

We then manipulated the satisfaction data such that it depended on the simulated income data, but preserved its scaling and distribution. We thus obtain a simulated income measure, which is completely exogenous, but correlated within individuals over time. We then manipulated the satisfaction data such that it depends on the simulated income data, but preserves its scaling and distribution. ${ }^{17}$

That is, we have a simulated income measure, which is completely exogenous, uncorrelated between individuals but correlated within. And we have satisfaction data that to some extent depend on this exogenous simulated income. Hence in a re-estimation of RQ1 and RQ2 we would expect that the conventional fixed effects estimator finds positive effects in both directions and that the IV-FE estimator finds only a positive effect for RQ1, i.e. the effect of simulated income on manipulated satisfaction.

\footnotetext{
16 Stata program code for the simulated income data is given in the Appendix A3.

${ }^{17}$ Stata program code for the manipulated satisfaction data is given in the Appendix A3.
} 
Results of re-estimations of $\mathrm{H} 1$ and $\mathrm{H} 2$ in Table 4.5 show the expected pattern, supported by statistical tests. This may increase our confidence that the zero effects presented in Sections 4.5 indeed represent the nonexistence of causal effects in the link between income and satisfaction in the underlying population.

\subsubsection{Re-estimation of $\mathrm{H} 1$ and $\mathrm{H} 2$ for financial satisfaction}

One may believe that financial satisfaction (instead of overall life satisfaction) is a better proxy for economic welfare. Studies that investigate the link between financial satisfaction and income are e.g. Schwarze (2003), D’Ambrosio and Frick (2012), Ng and Diener (2014), Frijters et al. (2015), Guardiola and Guillen-Royo (2015), Elsas (2016), Brown and Gray (2016), Bütikofer and Gerfin (2017). To connect to this strand of the literature we also run our main estimations using financial satisfaction.

Table 4.6: FE-IV and FE estimations of RQ1: Income causing financial satisfaction

\begin{tabular}{lccccc}
\hline & \multicolumn{2}{c}{$\mathrm{I}$} & & \multicolumn{2}{c}{$\mathrm{II}$} \\
\cline { 2 - 4 } \cline { 5 - 6 } & IV-FE & FE & & IV-FE & FE \\
\hline Income, log. & $0.917 * * *$ & $0.949^{* * * *}$ & & $1.167 * * *$ & $1.122^{* * *}$ \\
& $(0.096)$ & $(0.018)$ & & $(0.138)$ & $(0.020)$ \\
Demographic & no & no & & yes & yes \\
controls & & & & 172 & \\
\hline K-P F-Statistic & 267 & & & 22.534 & \\
Hansen J & 17.311 & & & 0.0001 & \\
Prob>Chi sq. & 0.0006 & & & 0.321 & \\
Z-score & -0.327 & & & & \\
\hline
\end{tabular}

Source: SOEP v34, own calculations. 273,768 person year observations of 38,134 individuals.

Notes: Significance levels $* 0.10 * * 0.05 * * * 0.01$. Cluster-robust standard errors in parentheses. All estimations include age, age ${ }^{2}$, survey wave ${ }^{2}$ and survey wave ${ }^{3}$.

According to the results in Table 4.6 we cannot conclude that the effect of income on financial satisfaction is overstated with conventional FE estimation, because the z-score does not exceed 1.96. The p-value of the Hansen $\mathrm{J}$ test, however, indicates specification problems, either with the instruments or the exogenous controls. Future analyses should address this problem. 
The estimated effect of financial satisfaction on income is shown in Table 4.7. This effect is larger than the effect of life satisfaction on income. Again, though, the Hansen J test indicates specification issues, either with the instruments or the exogenous controls.

Table 4.7: FE-IV and FE estimations of RQ2: Financial satisfaction causing equivalized income

\begin{tabular}{lccccc}
\hline & \multicolumn{2}{c}{ I } & & \multicolumn{2}{c}{ II } \\
\cline { 2 - 3 } \cline { 5 - 6 } & IV- & FE & & IV- & FE \\
& FE & & & FE & \\
\hline Fin. satisfaction & $0.035^{* * *}$ & $0.028^{* * *}$ & & $0.031^{* * *}$ & $0.026^{* * *}$ \\
& $(0.004)$ & $(0.001)$ & & $(0.004)$ & $(0.001)$ \\
Demographic & no & no & & yes & yes \\
controls & & & & & \\
K-P F-Statistic & 266 & & & 32.727 & \\
Hansen J & 32.585 & & & 0.0000 & \\
Prob>Chi sq. & 0.0000 & & & & \\
\hline
\end{tabular}

Source: SOEP v34, own calculations. 273,768 person year observations of 38,134 individuals.

Notes: Significance levels $* 0.10 * * 0.05 * * * 0.01$. Cluster-robust standard errors in parentheses. All estimations include age, age ${ }^{2}$, survey wave ${ }^{2}$ and survey wave ${ }^{3}$. Dependent variable is net equivalized household income.

\subsection{Conclusion}

This study intended to explore simultaneity in the income-happiness link and to what extent this might bias standard estimates of the hedonic effect of income. In that sense our analysis is methodological, since we are not primarily interested in the precise mechanisms that could generate the simultaneity. Our conclusions are both promising and disappointing.

They are disappointing because using Lewbel instruments, we find no significant causal effect from income on life satisfaction but weak indication for a causal effect of life satisfaction on income. The zero effect of equivalized income on life satisfaction is unexpected and in contradiction to most findings in this area of research. We are, nevertheless, cautiously optimistic that our zero effects are not a problem due to the estimator or our application of it, for two reasons: First, most studies in this field do not properly identify causal effects, but estimate 
merely associations under consideration of covariates and individual level fixed effects. Among those studies that use convincing methods, results indicate that long-term changes in income have significant and sizable effects on life satisfaction (Vendrik 2013, Bayer and Juessen 2015) while short-term shocks do not effect life satisfaction (Bayer and Juessen 2015, Lachowska 2017). Second, in a simulation, where satisfaction data was manipulated so that it depends on a simulated random, but income-like variable, the estimator that we use, found the simulated effect. The small and only weakly significant effect of life satisfaction on equivalized household income indicates that life satisfaction influences also equivalized household income, albeit only mildly. Based on our results we have to consider that the effect of income on life satisfaction could be overstated in conventional fixed effects estimations. This might, according to our results, be due to reverse causality from satisfaction to income.

The present analysis is promising because Lewbel's (2012) internal instruments passed the weak instruments tests in every specification, Hansen's $\mathbf{J}$ test indicates that the estimator is applicable at least for the analysis of the effect of income on life satisfaction and reverse. This is encouraging good news for empirical research on satisfaction. The method appears capable of identifying potential causal effects between life satisfaction and it's correlates and therewith enables filling a still existing gap in empirical happiness research. 


\section{Appendices}

\section{A1 Supplementary material for Chapter 2}

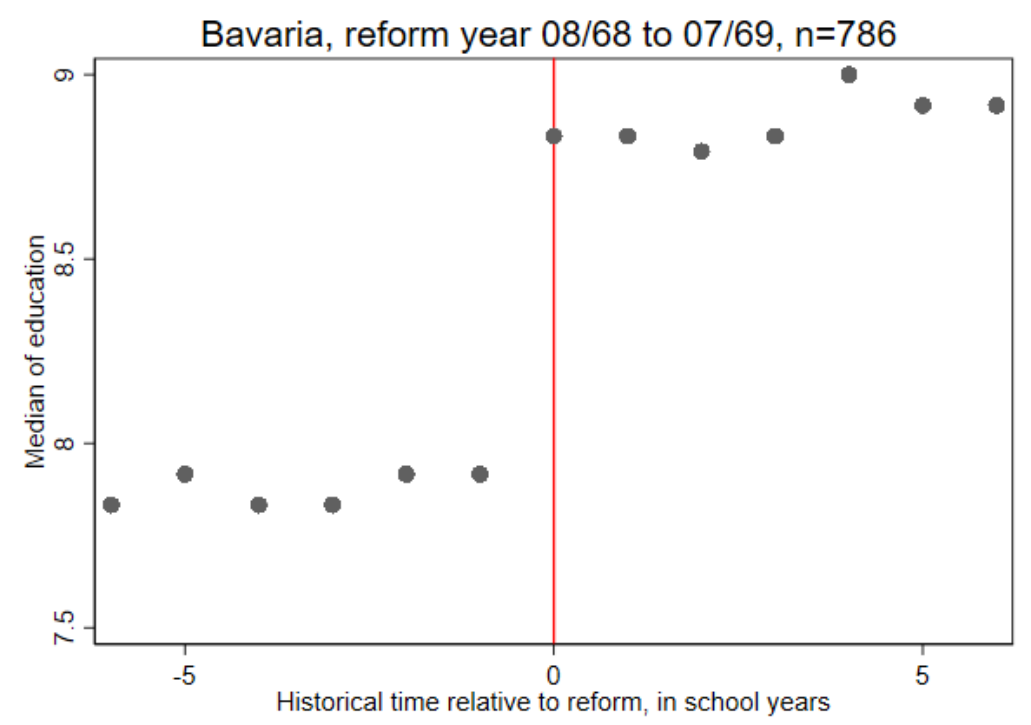

Figure A1.1: Median duration of schooling before and after the reform, target group in Bavaria

Source: Own calculations; NEPS SC6 v9.0.1 
Table A1.1: National unemployment and employment rates

\begin{tabular}{lcccccc}
\hline & \multicolumn{3}{c}{ Unemployment rate } & & \multicolumn{2}{c}{ Employment rate } \\
\cline { 2 - 3 } Year & All & Males & Females & & Males & Females \\
\hline 1950 & 11.0 & 10.8 & 11.5 & &. &. \\
1951 & 10.4 & 9.8 & 12.2 & &. &. \\
1952 & 9.5 & 8.8 & 11.0 & &. &. \\
1953 & 8.4 & 7.9 & 9.4 & &. &. \\
1954 & 7.6 & 7.2 & 8.6 & &. &. \\
1955 & 5.6 & 5.0 & 7.0 & &. &. \\
1956 & 4.4 & 4.0 & 5.4 & &. &. \\
1957 & 3.7 & 3.4 & 4.3 & & 90.6 & 46.1 \\
1958 & 3.7 & 3.7 & 3.8 & & 90.4 & 46.5 \\
1959 & 2.6 & 2.5 & 2.6 & & 90.1 & 46.6 \\
1960 & 1.3 & 1.3 & 1.3 & & 90.3 & 47.2 \\
1961 & 0.8 & 0.8 & 0.8 & & 90.6 & 47.2 \\
1962 & 0.7 & 0.7 & 0.7 & & 90.6 & 46.7 \\
$1963^{(1)}$ & 0.8 & 0.9 & 0.7 & & 90.4 & 46.7 \\
1964 & 0.8 & 0.8 & 0.7 & & 89.9 & 46.6 \\
$1965^{(2)}$ & 0.7 & 0.7 & 0.5 & & 89.7 & 46.8 \\
$1966^{(3)}$ & 0.7 & 0.8 & 0.6 & & 89.8 & 46.6 \\
1967 & 2.1 & 2.4 & 1.7 & & 87.9 & 45.1 \\
1968 & 1.5 & 1.7 & 1.2 & & 88.2 & 45.1 \\
$1969^{(4)}$ & 0.9 & 0.9 & 0.8 & & 88.3 & 45.5 \\
1970 & 0.7 & 0.7 & 0.8 & & 87.7 & 45.9 \\
\hline
\end{tabular}

Source: columns 2-4: iab (2019) and columns 5-6: Destatis (2019)

Note: Labor market entry of the first cohort after 9 years of compulsory schooling in (1) Lower Saxony, and urban municipalities in Hesse, (2) Baden Wuerttemberg, (3) Rhineland Palatinate, rural Hesse, Saarland and North Rhine Westphalia and (4) Bavaria. 


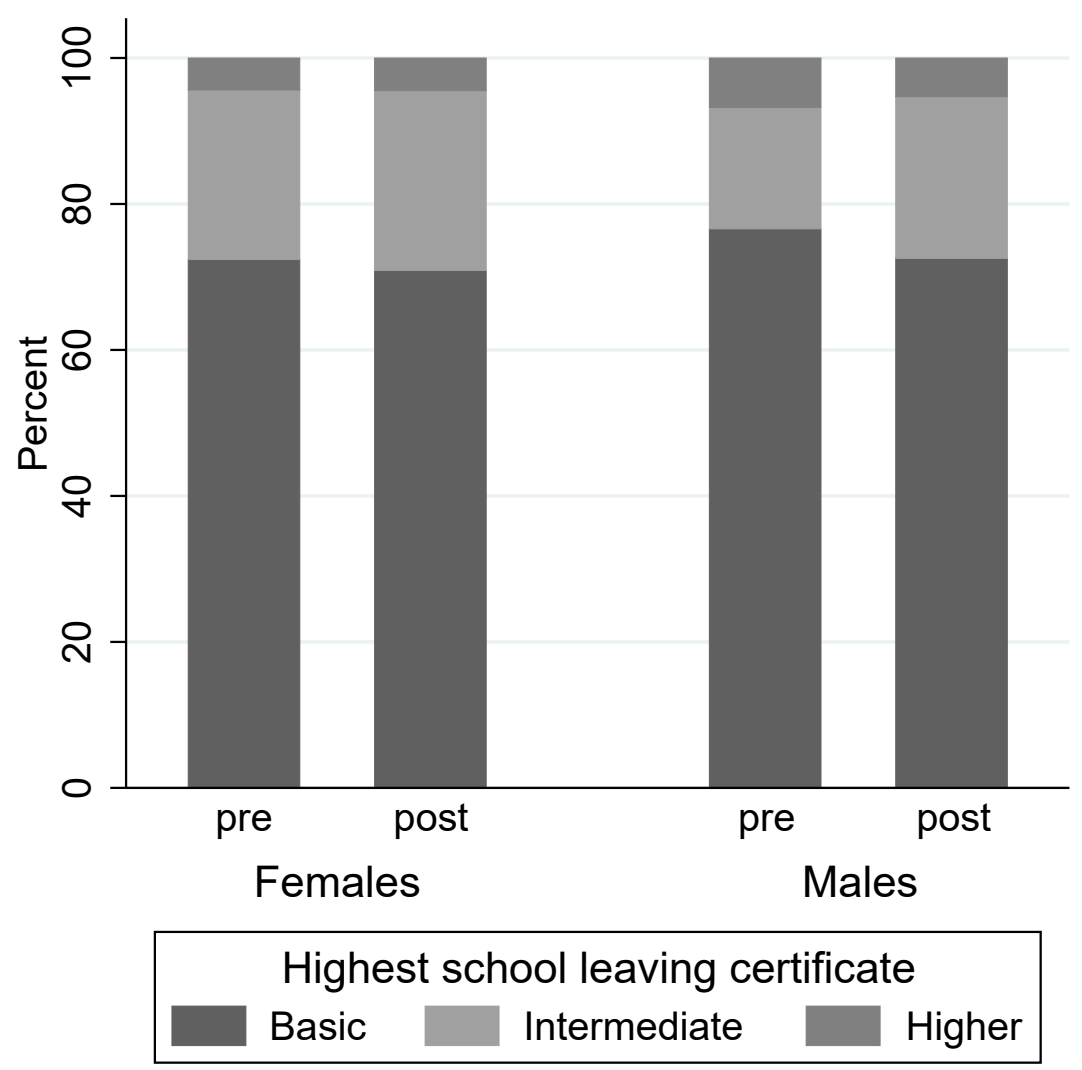

Figure A1.2: Education distribution in the target sample, by gender and reform status

Source: Own calculations; NEPS SC6 v9.0.1

Note: Highest school leaving certificate, might stem from later life education.

\section{A1.1 Complete estimation results}


Table A1.2: OLS, RE and RE-IV regression of life satisfaction on years of education - target sample

\begin{tabular}{|c|c|c|c|c|}
\hline & OLS & RE & RE-IV & RE-IV \\
\hline Reform & $\begin{array}{l}-0.180^{*} \\
(0.108)\end{array}$ & & & \\
\hline Years of schooling & & $\begin{array}{r}0.045 \\
(0.028)\end{array}$ & $\begin{array}{l}-0.308 \\
(0.196)\end{array}$ & $\begin{array}{l}-0.298 \\
(0.191)\end{array}$ \\
\hline Big 5: Extraversion & $\begin{array}{l}0.191 \text { *** } \\
(0.041)\end{array}$ & $\begin{array}{l}0.193^{* * * *} \\
(0.041)\end{array}$ & & $\begin{array}{l}0.184 * * * \\
(0.043)\end{array}$ \\
\hline Big 5: Agreeableness & $\begin{array}{r}0.071 \\
(0.056)\end{array}$ & $\begin{array}{r}0.067 \\
(0.056)\end{array}$ & & $\begin{array}{r}0.078 \\
(0.060)\end{array}$ \\
\hline Big 5: Conscientiousness & $\begin{array}{r}0.051 \\
(0.051)\end{array}$ & $\begin{array}{r}0.058 \\
(0.051)\end{array}$ & & $\begin{array}{r}0.021 \\
(0.055)\end{array}$ \\
\hline Big 5: Neuroticism & $\begin{array}{l}-0.213 * * * \\
(0.043)\end{array}$ & $\begin{array}{l}-0.211 * * * \\
(0.043)\end{array}$ & & $\begin{array}{l}-0.227 * * * \\
(0.045)\end{array}$ \\
\hline Male & $\begin{array}{l}-0.046 \\
(0.084)\end{array}$ & $\begin{array}{l}-0.034 \\
(0.083)\end{array}$ & $\begin{array}{l}-0.037 \\
(0.091)\end{array}$ & $\begin{array}{l}-0.065 \\
(0.091)\end{array}$ \\
\hline Age & $\begin{array}{r}0.257 \\
(0.260)\end{array}$ & $\begin{array}{r}0.285 \\
(0.258)\end{array}$ & $\begin{array}{r}0.271 \\
(0.262)\end{array}$ & $\begin{array}{r}0.253 \\
(0.261)\end{array}$ \\
\hline Age. squared & $\begin{array}{l}-0.002 \\
(0.002)\end{array}$ & $\begin{array}{l}-0.002 \\
(0.002)\end{array}$ & $\begin{array}{l}-0.002 \\
(0.002)\end{array}$ & $\begin{array}{l}-0.002 \\
(0.002)\end{array}$ \\
\hline Born before 1951 & $\begin{array}{r}0.048 \\
(0.161)\end{array}$ & $\begin{array}{r}0.164 \\
(0.154)\end{array}$ & $\begin{array}{l}-0.077 \\
(0.236)\end{array}$ & $\begin{array}{l}-0.103 \\
(0.227)\end{array}$ \\
\hline Lower Saxony & $\begin{array}{r}0.401 \\
(0.260)\end{array}$ & $\begin{array}{r}0.298 \\
(0.253)\end{array}$ & $\begin{array}{c}0.476^{*} \\
(0.288)\end{array}$ & $\begin{array}{r}0.433 \\
(0.303)\end{array}$ \\
\hline Hesse & $\begin{array}{r}0.064 \\
(0.228)\end{array}$ & $\begin{array}{r}0.051 \\
(0.231)\end{array}$ & $\begin{array}{r}0.043 \\
(0.247)\end{array}$ & $\begin{array}{r}0.016 \\
(0.236)\end{array}$ \\
\hline Rhineland-Palatinate & $\begin{array}{l}-0.020 \\
(0.199)\end{array}$ & $\begin{array}{r}0.009 \\
(0.200)\end{array}$ & $\begin{array}{l}-0.125 \\
(0.244)\end{array}$ & $\begin{array}{l}-0.139 \\
(0.224)\end{array}$ \\
\hline Baden-Wuerttemberg & $\begin{array}{l}-0.050 \\
(0.178)\end{array}$ & $\begin{array}{l}-0.080 \\
(0.181)\end{array}$ & $\begin{array}{c}-0.134 \\
(0.193)\end{array}$ & $\begin{array}{l}-0.068 \\
(0.189)\end{array}$ \\
\hline Bavaria & $\begin{array}{r}0.116 \\
(0.139)\end{array}$ & $\begin{array}{r}0.164 \\
(0.137)\end{array}$ & $\begin{array}{c}-0.008 \\
(0.171)\end{array}$ & $\begin{array}{r}0.044 \\
(0.165)\end{array}$ \\
\hline Saarland & $\begin{array}{l}-0.260 \\
(0.321)\end{array}$ & $\begin{array}{l}-0.297 \\
(0.312)\end{array}$ & $\begin{array}{l}-0.414 \\
(0.335)\end{array}$ & $\begin{array}{l}-0.368 \\
(0.354)\end{array}$ \\
\hline Born before $1951 \times$ Lower Saxony & $\begin{array}{c}-0.354 \\
(0.298)\end{array}$ & $\begin{array}{c}-0.370 \\
(0.297)\end{array}$ & $\begin{array}{l}-0.352 \\
(0.333)\end{array}$ & $\begin{array}{l}-0.298 \\
(0.343)\end{array}$ \\
\hline Born before $1951 \times$ Hesse & $\begin{array}{r}0.076 \\
(0.315)\end{array}$ & $\begin{array}{r}0.060 \\
(0.319)\end{array}$ & $\begin{array}{r}0.184 \\
(0.376)\end{array}$ & $\begin{array}{r}0.306 \\
(0.362)\end{array}$ \\
\hline Born before $1951 \times$ Rhineland-Palatinate & $\begin{array}{r}0.142 \\
(0.319)\end{array}$ & $\begin{array}{r}0.115 \\
(0.320)\end{array}$ & $\begin{array}{r}0.269 \\
(0.353)\end{array}$ & $\begin{array}{r}0.248 \\
(0.344)\end{array}$ \\
\hline Born before $1951 \times$ Baden-Wuerttemberg & $\begin{array}{r}0.005 \\
(0.255)\end{array}$ & $\begin{array}{r}0.030 \\
(0.257)\end{array}$ & $\begin{array}{r}0.148 \\
(0.278)\end{array}$ & $\begin{array}{r}0.045 \\
(0.271)\end{array}$ \\
\hline Born before $1951 \times$ Bavaria & $\begin{array}{l}-0.255 \\
(0.286)\end{array}$ & $\begin{array}{l}-0.307 \\
(0.281)\end{array}$ & $\begin{array}{c}-0.184 \\
(0.356)\end{array}$ & $\begin{array}{l}-0.136 \\
(0.342)\end{array}$ \\
\hline Born before $1951 \times$ Saarland & $\begin{array}{l}-0.225 \\
(0.524)\end{array}$ & $\begin{array}{c}-0.189 \\
(0.518)\end{array}$ & $\begin{array}{l}-0.085 \\
(0.571)\end{array}$ & $\begin{array}{c}-0.118 \\
(0.561)\end{array}$ \\
\hline Constant & $\begin{array}{l}-0.786 \\
(8.031)\end{array}$ & $\begin{array}{l}-2.333 \\
(7.951)\end{array}$ & $\begin{array}{r}2.229 \\
(8.648)\end{array}$ & $\begin{array}{r}2.300 \\
(8.602)\end{array}$ \\
\hline
\end{tabular}

Source: Own calculations; NEPS SC6 v.9.0.1.

Notes: 4669 person-year observations of 927 individuals. Significance levels $* 0.10 * * 0.05 * * * 0.01$; robust standard errors. Big 5 item "openness" is excluded because auxilliary IV estimations show an influence of education on openness. 
Table A1.3: OLS, RE and RE-IV regression of life satisfaction on years of education - control sample

\begin{tabular}{|c|c|c|c|c|}
\hline & OLS & RE & RE-IV & RE-IV \\
\hline Reform & $\begin{array}{r}0.148 \\
(0.130)\end{array}$ & & & \\
\hline Years of schooling & & $\begin{array}{r}0.018 \\
(0.049)\end{array}$ & $\begin{array}{r}0.363 \\
(0.709)\end{array}$ & $\begin{array}{r}0.632 \\
(0.818)\end{array}$ \\
\hline Big 5: Extraversion & $\begin{array}{r}0.065 \\
(0.056)\end{array}$ & $\begin{array}{r}0.064 \\
(0.056)\end{array}$ & & $\begin{array}{r}0.015 \\
(0.102)\end{array}$ \\
\hline Big 5: Agreeableness & $\begin{array}{r}0.119 \\
(0.086)\end{array}$ & $\begin{array}{r}0.114 \\
(0.086)\end{array}$ & & $\begin{array}{r}0.046 \\
(0.125)\end{array}$ \\
\hline Big 5: Conscientiousness & $\begin{array}{l}0.249 * * * \\
(0.074)\end{array}$ & $\begin{array}{l}0.242 * * * \\
(0.074)\end{array}$ & & $\begin{array}{l}0.310^{* *} \\
(0.127)\end{array}$ \\
\hline Big 5: Neuroticism & $\begin{array}{l}-0.257 * * * \\
(0.082)\end{array}$ & $\begin{array}{l}-0.258 * * * \\
(0.083)\end{array}$ & & $\begin{array}{l}-0.163 \\
(0.126)\end{array}$ \\
\hline Male & $\begin{array}{l}-0.043 \\
(0.119)\end{array}$ & $\begin{array}{l}-0.050 \\
(0.120)\end{array}$ & $\begin{array}{r}0.009 \\
(0.132)\end{array}$ & $\begin{array}{l}-0.025 \\
(0.158)\end{array}$ \\
\hline Age & $\begin{array}{l}0.690^{* *} \\
(0.348)\end{array}$ & $\begin{array}{c}0.670^{*} \\
(0.347)\end{array}$ & $\begin{array}{l}0.835 * * \\
(0.365)\end{array}$ & $\begin{array}{l}0.856 * * \\
(0.358)\end{array}$ \\
\hline Age. squared & $\begin{array}{l}-0.006^{* *} \\
(0.003)\end{array}$ & $\begin{array}{l}-0.006 * \\
(0.003)\end{array}$ & $\begin{array}{l}-0.007 * * \\
(0.003)\end{array}$ & $\begin{array}{l}-0.007 * * \\
(0.003)\end{array}$ \\
\hline Born before 1951 & $\begin{array}{r}0.238 \\
(0.227)\end{array}$ & $\begin{array}{r}0.171 \\
(0.214)\end{array}$ & $\begin{array}{r}0.306 \\
(0.335)\end{array}$ & $\begin{array}{r}0.338 \\
(0.373)\end{array}$ \\
\hline Lower Saxony & $\begin{array}{l}0.531 \text { *** } \\
(0.169)\end{array}$ & $\begin{array}{l}0.588^{* * * *} \\
(0.159)\end{array}$ & $\begin{array}{c}0.867 * \\
(0.480)\end{array}$ & $\begin{array}{r}0.197 \\
(0.605)\end{array}$ \\
\hline Hesse & $\begin{array}{l}-0.142 \\
(0.335)\end{array}$ & $\begin{array}{l}-0.106 \\
(0.334)\end{array}$ & $\begin{array}{r}0.074 \\
(0.507)\end{array}$ & $\begin{array}{r}0.187 \\
(0.566)\end{array}$ \\
\hline Rhineland-Palatinate & $\begin{array}{l}-0.207 \\
(0.255)\end{array}$ & $\begin{array}{l}-0.223 \\
(0.254)\end{array}$ & $\begin{array}{l}-0.365 \\
(0.303)\end{array}$ & $\begin{array}{l}-0.404 \\
(0.332)\end{array}$ \\
\hline Baden-Wuerttemberg & $\begin{array}{l}-0.137 \\
(0.205)\end{array}$ & $\begin{array}{l}-0.126 \\
(0.206)\end{array}$ & $\begin{array}{l}-0.100 \\
(0.230)\end{array}$ & $\begin{array}{l}-0.151 \\
(0.271)\end{array}$ \\
\hline Bavaria & $\begin{array}{r}0.063 \\
(0.185)\end{array}$ & $\begin{array}{r}0.043 \\
(0.180)\end{array}$ & $\begin{array}{r}0.074 \\
(0.227)\end{array}$ & $\begin{array}{r}0.138 \\
(0.272)\end{array}$ \\
\hline Saarland & $\begin{array}{l}-0.952 * * \\
(0.378)\end{array}$ & $\begin{array}{l}-0.959 * * \\
(0.397)\end{array}$ & $\begin{array}{l}-1.393^{* *} \\
(0.670)\end{array}$ & $\begin{array}{l}-1.531 * * \\
(0.708)\end{array}$ \\
\hline Born before $1951 \times$ Lower Saxony & $\begin{array}{l}-0.378 \\
(0.260)\end{array}$ & $\begin{array}{l}-0.362 \\
(0.262)\end{array}$ & $\begin{array}{l}-0.725^{*} \\
(0.421)\end{array}$ & $\begin{array}{l}-0.120 \\
(0.539)\end{array}$ \\
\hline Born before $1951 \times$ Hesse & $\begin{array}{c}0.708^{*} \\
(0.424)\end{array}$ & $\begin{array}{c}0.715^{*} \\
(0.430)\end{array}$ & $\begin{array}{r}0.455 \\
(0.623)\end{array}$ & $\begin{array}{r}0.750 \\
(0.830)\end{array}$ \\
\hline Born before $1951 \times$ Rhineland-Palatinate & $\begin{array}{r}0.351 \\
(0.406)\end{array}$ & $\begin{array}{r}0.362 \\
(0.402)\end{array}$ & $\begin{array}{r}0.435 \\
(0.418)\end{array}$ & $\begin{array}{r}0.447 \\
(0.432)\end{array}$ \\
\hline Born before $1951 \times$ Baden-Wuerttemberg & $\begin{array}{r}0.349 \\
(0.326)\end{array}$ & $\begin{array}{r}0.334 \\
(0.328)\end{array}$ & $\begin{array}{r}0.179 \\
(0.395)\end{array}$ & $\begin{array}{r}0.280 \\
(0.450)\end{array}$ \\
\hline Born before $1951 \times$ Bavaria & $\begin{array}{l}-0.323 \\
(0.432)\end{array}$ & $\begin{array}{l}-0.308 \\
(0.429)\end{array}$ & $\begin{array}{l}-0.310 \\
(0.523)\end{array}$ & $\begin{array}{l}-0.443 \\
(0.566)\end{array}$ \\
\hline Born before $1951 \times$ Saarland & $\begin{array}{l}-0.900^{*} \\
(0.468)\end{array}$ & $\begin{array}{l}-0.907 * \\
(0.484)\end{array}$ & $\begin{array}{l}-0.625 \\
(0.715)\end{array}$ & $\begin{array}{l}-0.875 \\
(0.653)\end{array}$ \\
\hline Constant & $\begin{array}{l}-14.276 \\
(10.597)\end{array}$ & $\begin{array}{l}-13.661 \\
(10.620)\end{array}$ & $\begin{array}{l}-21.994 \\
(14.598)\end{array}$ & $\begin{array}{l}-26.975^{*} \\
(15.133)\end{array}$ \\
\hline
\end{tabular}

Source: Own calculations; NEPS SC6 v.9.0.1.

Notes: Significance levels * $0.10 * * 0.05 * * * 0.01$; robust standard errors. 1757 person year observations of 339 individuals. Big 5 item "openness" is excluded because auxilliary IV estimations show an influence of education on openness. 
Table A1.4: First stage regression of years of education on reform

\begin{tabular}{|c|c|c|c|c|}
\hline \multirow[b]{2}{*}{ Reform } & \multicolumn{2}{|c|}{ Target sample } & \multicolumn{2}{|c|}{ Control sample } \\
\hline & $0.604 * * *$ & $(0.053)$ & $0.216^{* *}$ & 0.095 \\
\hline Big 5: Extraversion & -0.022 & $(0.018)$ & -0.005 & 0.011 \\
\hline Big 5: Agreeableness & 0.023 & $(0.028)$ & 0.015 & 0.015 \\
\hline Big 5: Conscientiousness & $-0.100 * * *$ & $(0.023)$ & 0.009 & 0.012 \\
\hline Big 5: Neuroticism & $-0.049 * * *$ & $(0.018)$ & -0.002 & 0.011 \\
\hline Male & -0.063 & $(0.041)$ & -0.014 & 0.077 \\
\hline Age & 0.005 & $(0.087)$ & 0.002 & 0.035 \\
\hline Age, squared & -0.000 & $(0.001)$ & -0.000 & 0.000 \\
\hline Born before 1951 & $-0.508 * * *$ & $(0.083)$ & -0.123 & 0.144 \\
\hline Lower Saxony & 0.096 & $(0.177)$ & $0.587 * * *$ & 0.086 \\
\hline Hesse & -0.159 & $(0.103)$ & $-0.501 * *$ & 0.218 \\
\hline Rhineland-Palatinate & $-0.398 * * *$ & $(0.103)$ & $0.243 * *$ & 0.125 \\
\hline Baden-Wuerttemberg & -0.057 & $(0.095)$ & -0.012 & 0.150 \\
\hline Bavaria & $-0.232 * * *$ & $(0.071)$ & -0.095 & 0.133 \\
\hline Saarland & $-0.357 * * *$ & $(0.138)$ & $0.700 * * *$ & 0.073 \\
\hline Born before $1951 \times$ Lower Saxony & 0.207 & $(0.191)$ & $-0.452 * * *$ & 0.168 \\
\hline Born before $1951 \times$ Hesse & $0.776 * * *$ & $(0.162)$ & -0.100 & 0.435 \\
\hline Born before $1951 \times$ Rhineland-Palatinate & $0.349 *$ & $(0.181)$ & -0.108 & 0.243 \\
\hline Born before $1951 \times$ Baden-Wuerttemberg & 0.125 & $(0.131)$ & 0.115 & 0.224 \\
\hline Born before $1951 \times$ Bavaria & $0.396 * * *$ & $(0.145)$ & 0.199 & 0.236 \\
\hline Born before $1951 \times$ Saarland & $0.350 *$ & $(0.207)$ & $0.240 *$ & 0.137 \\
\hline Constant & $9.776 * * *$ & $(2.690)$ & $12.070^{* * *}$ & 1.091 \\
\hline Kleibergen-Paap F-statistic & 15.56 & & 0.32 & \\
\hline Prob $>$ Chi sq. & 0.0001 & & 0.5689 & \\
\hline Observations & 4,669 & & 1,757 & \\
\hline Individuals & 927 & & 339 & \\
\hline
\end{tabular}

Source: Own calculations; NEPS SC6 v.9.0.1.

Notes: Significance levels $* 0.10 * * 0.05 * * * 0.01$; robust standard errors. Big 5 item "openness" is excluded because auxilliary IV estimations show an influence of education on openness. 


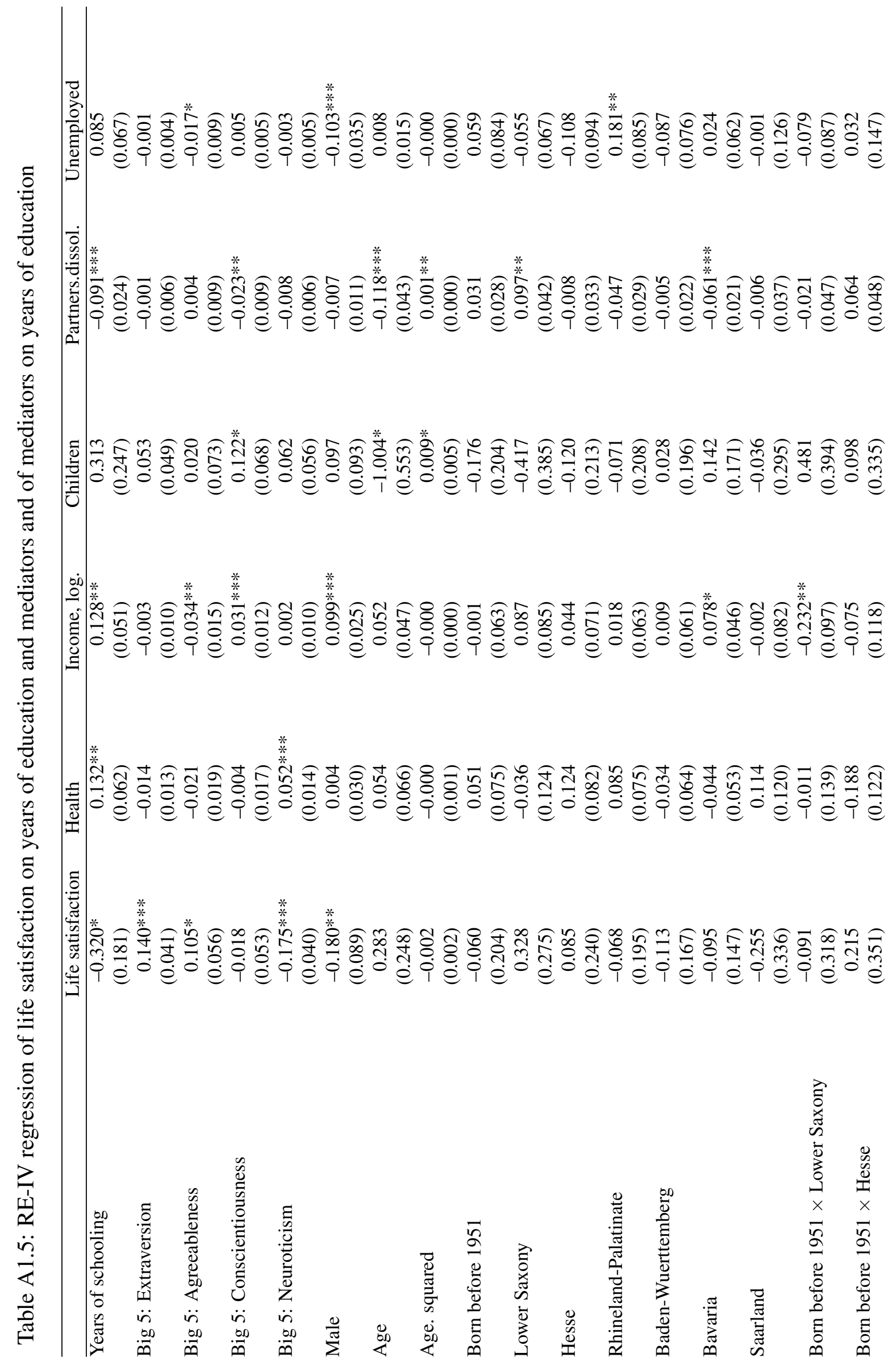




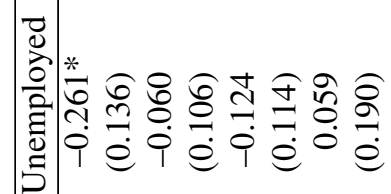

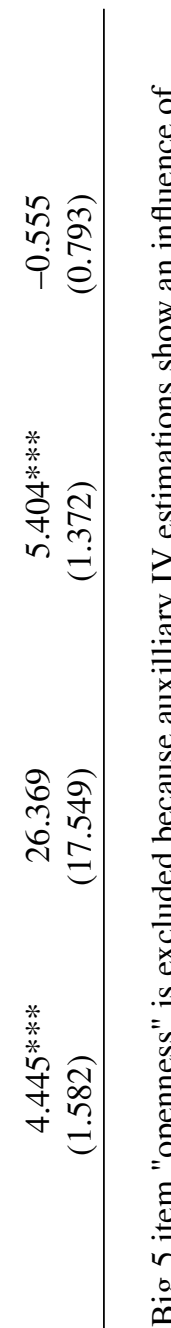

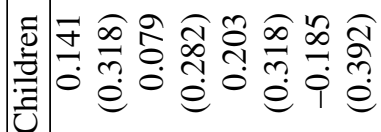

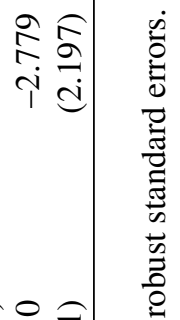

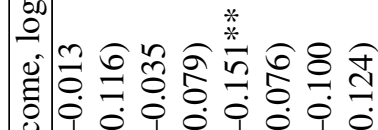

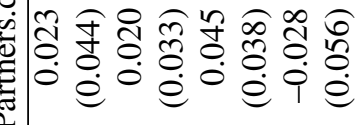

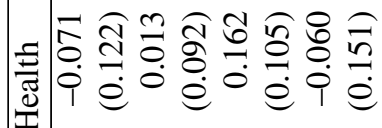

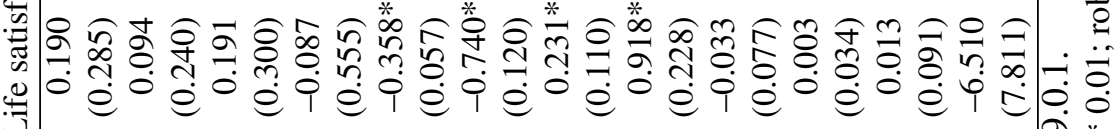

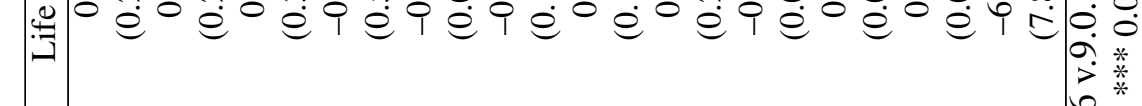

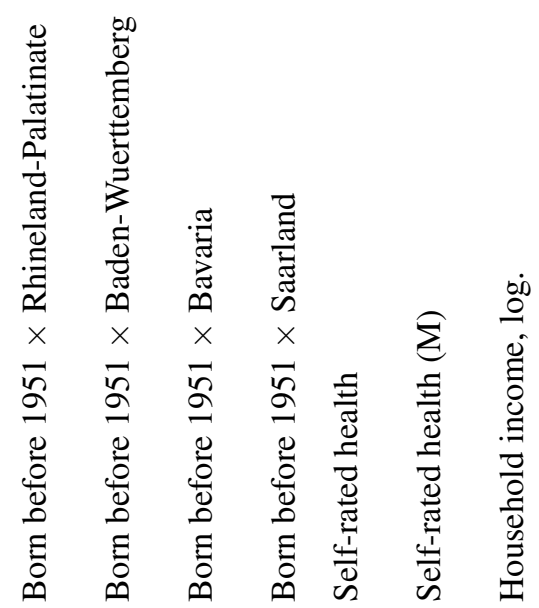

ن

经 *

Z这 $\stackrel{*}{\circ}$

官

:

$\frac{\pi}{\vec{z}} \frac{\mathrm{z}}{\mathrm{d}}$ 


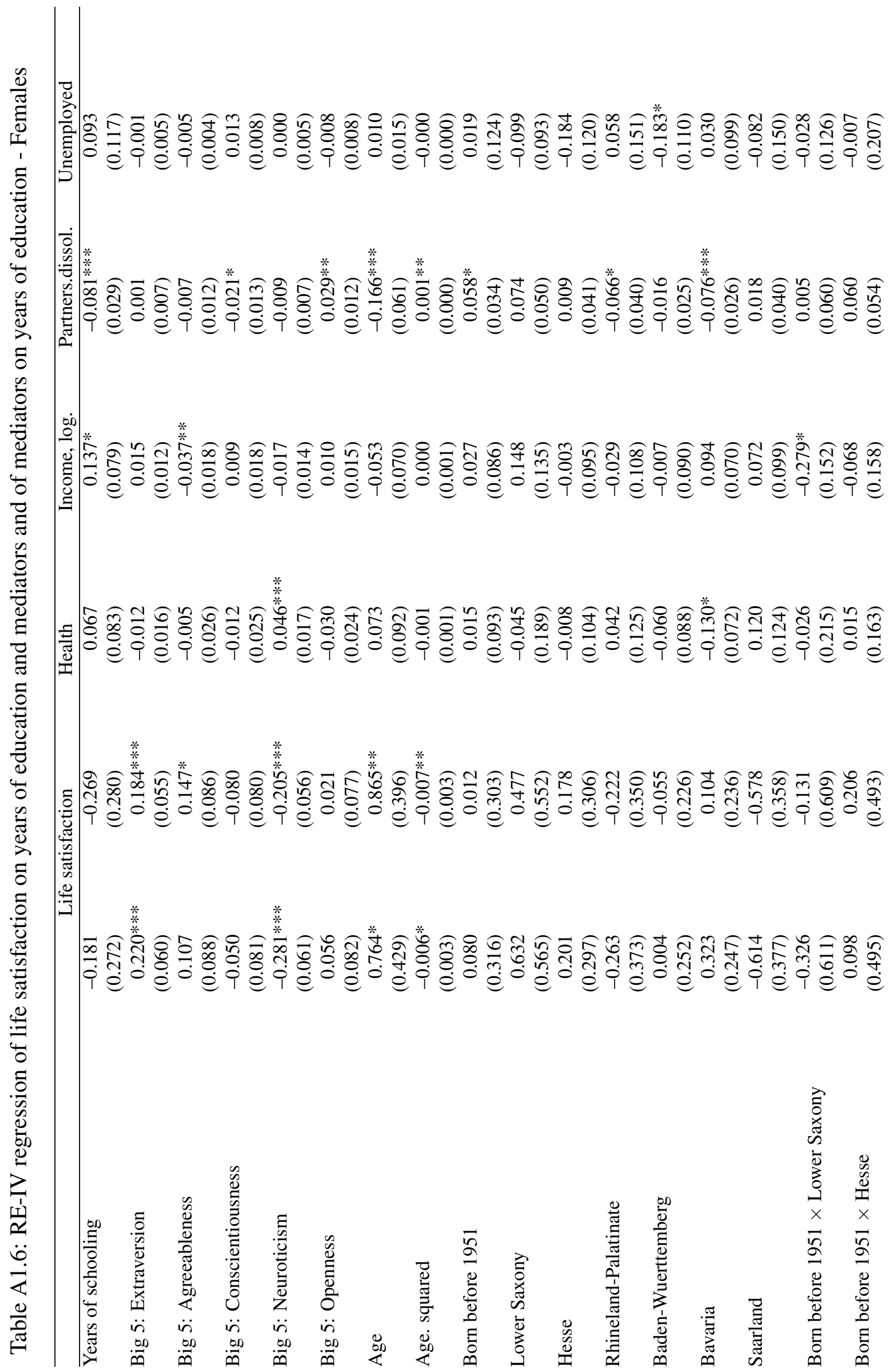




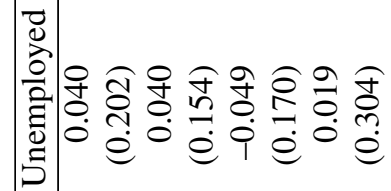

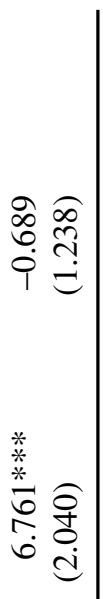

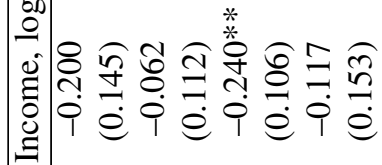

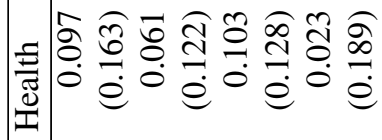

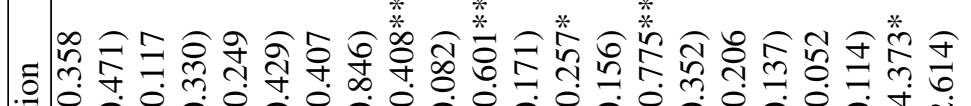

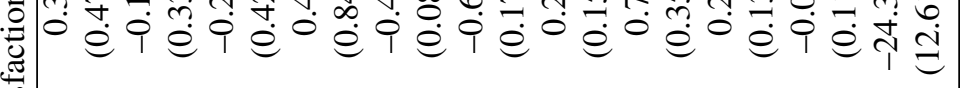




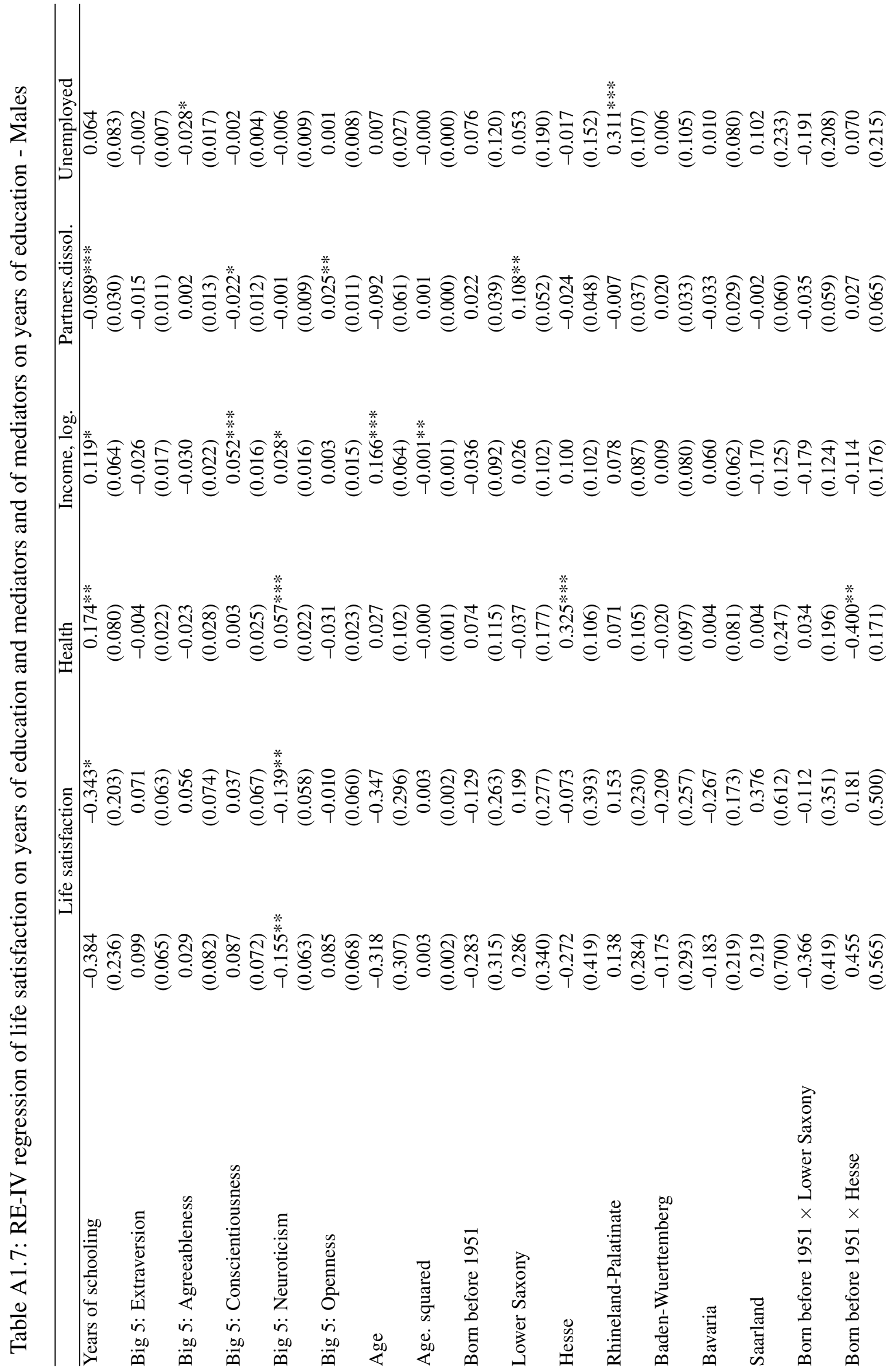




\section{With years in school instead of years of education}

NEPS data not only contain the highest degree of the respondents but also spell data on timing and duration of education. From these data I constructed a measure of duration in school until the respondent first left school for longer than 6 months. Results or a re-estimation for this measure of education are presented in Table A1.8. The pattern is similar: no effect of the association between duration in school and life satisfaction (column (I) shows the straightforward random effects estimate). The overall causal effect of the additional year of education on life satisfaction (IV estimate in column (II)) is slightly smaller in magnitude, though not statistically significant. This is reasonable because this measure also counts repeated classes, short school years and time in school that did not yield any degree. Compared to the content of education or the school leaving certificate, these variations in time are though less relevant for most aspects in life, as for example labor market access and outcomes or affiliation to a social class. Nevertheless, the overall pattern is the same: income and partnership stability are positively affected by the additional year of education and the negative effect on health and the negative direct effect of education on life satisfaction are also found with the duration-in-school measure.

\section{Without individuals from states that implemented the reform successively}

The implementation of the reform was a challenge for several reasons, one reason was the increased demand for teachers while at the same time many teachers where dismissed for state building reasons. ${ }^{1}$ To address this problem, several states implemented the reform successively. In Hesse the succession followed the rural/urban distinction and the data therefore allowed to assign the respondents' reform status. For Lower Saxony and Saarland however, only the final date is known when the reform was fully implemented. For the purpose of a further robustness check I therefore excluded respondents who attended 8th grade in one of both states.

Results hereon are presented in Table A1.9

\footnotetext{
${ }^{1}$ Many teachers were dismissed in the aftermath of World War II because of their membership in the NSDAP and connected organization.
} 


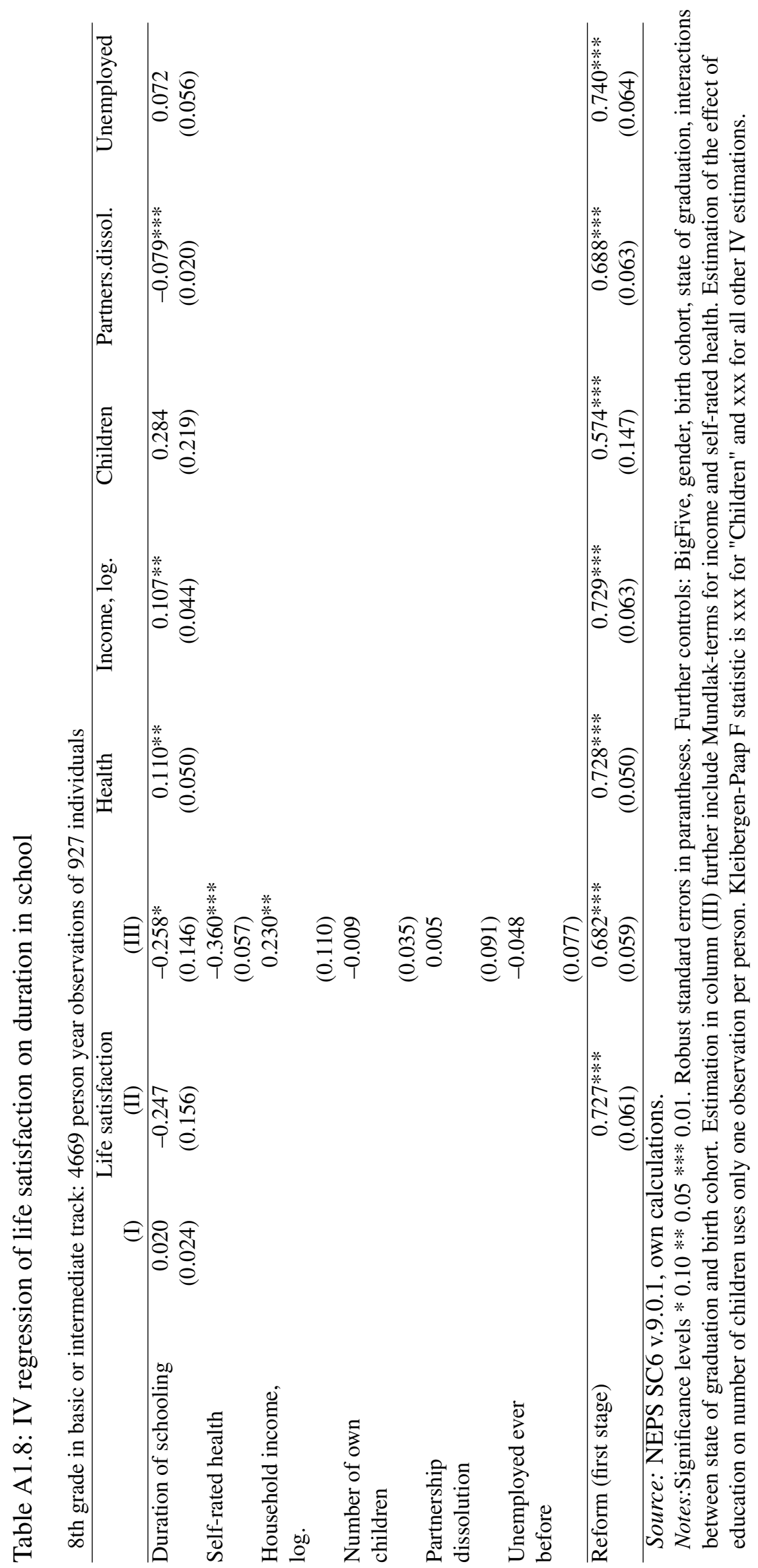




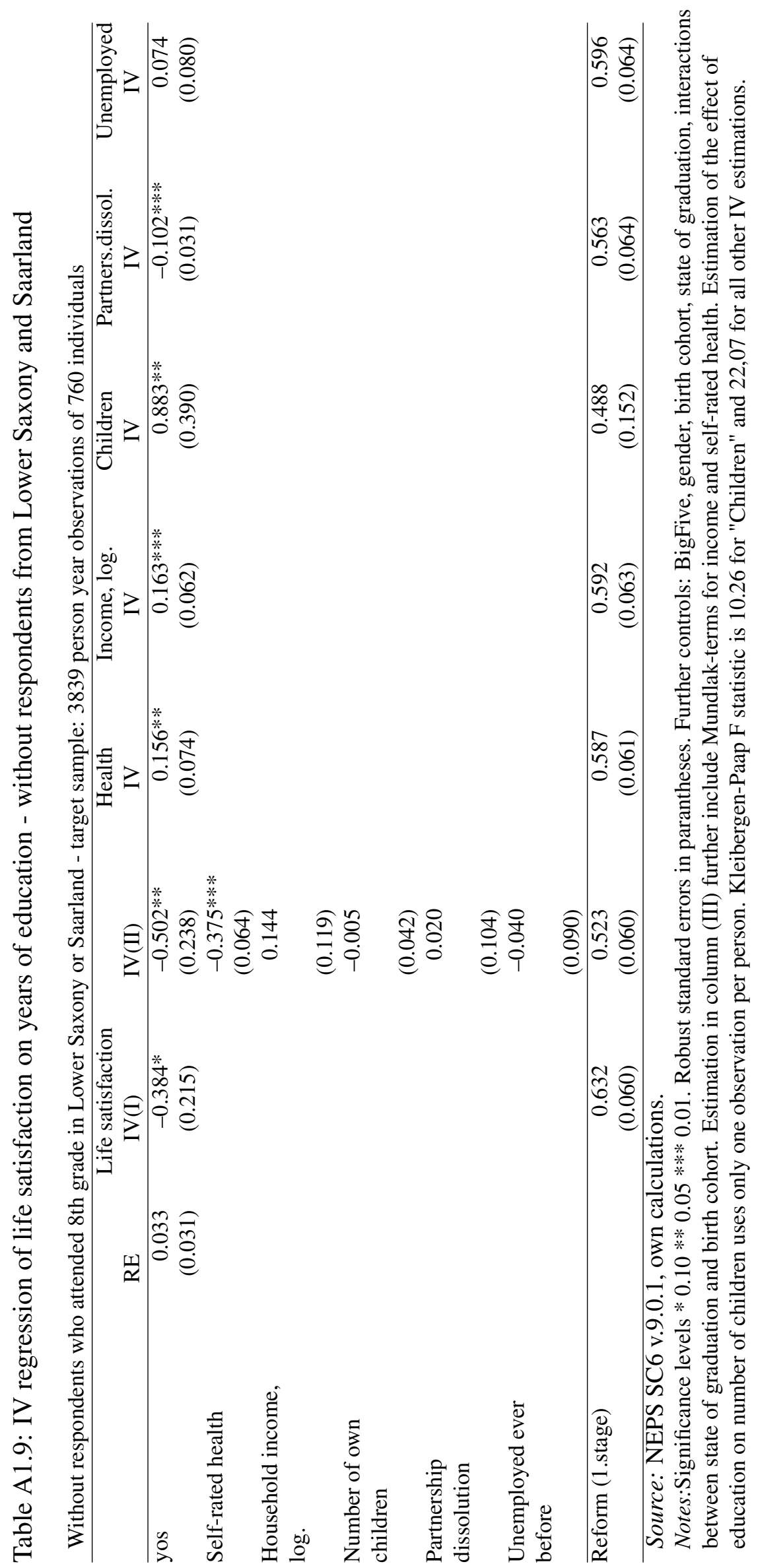




\section{A2 Supplementary material for Chapter 3}

\section{A2.1 Income pooling as a prerequisite for income sharing}

The analysis on income sharing in couples revealed that couples do not share their household income independently of their contribution to this income. Doubts may arise if this result is driven by couples who live together but do not pool their income. In a study with nearly the same setup I analyzed this prerequisite and then restricted the income sharing regression to couples who reported to pool their incomes (Elsas 2013). Results of this research indicated that systematic satisfaction differences are attenuated in income pooling couples, but still present. 


\section{A2.2 Relative employment status as distribution factor}

Table A2.1: Financial satisfaction and relative employment status as distribution factor

Distribution factor: relative employment status, instead of working hours.

\begin{tabular}{|c|c|c|c|c|}
\hline \multirow[b]{2}{*}{ Income ratio } & \multicolumn{2}{|c|}{ Men's satisfaction } & \multicolumn{2}{|c|}{ Women's satisfaction } \\
\hline & -0.003 & $(0.122)$ & $-0.514 * * *$ & $(0.125)$ \\
\hline Man's income & $0.077 * * *$ & $(0.014)$ & $0.103 * * *$ & $(0.013)$ \\
\hline Woman's income & $0.014^{*}$ & $(0.007)$ & 0.004 & $(0.008)$ \\
\hline Man unemployed & $-0.809 * * *$ & $(0.069)$ & $-0.584 * * *$ & $(0.066)$ \\
\hline Woman unemployed & $-0.338 * * *$ & $(0.083)$ & $-0.471 * * *$ & $(0.077)$ \\
\hline Man not working & $-0.144 *$ & $(0.081)$ & -0.097 & $(0.083)$ \\
\hline Woman not working & -0.043 & $(0.066)$ & $-0.129 *$ & $(0.069)$ \\
\hline Man working part-time & $-0.090 *$ & $(0.048)$ & $-0.084 *$ & $(0.050)$ \\
\hline Woman working part-time & -0.069 & $(0.053)$ & $-0.129 * *$ & $(0.055)$ \\
\hline $\begin{array}{l}\text { Male breadwinner household, } \\
\text { woman not unemployed }\end{array}$ & 0.001 & $(0.051)$ & 0.082 & $(0.052)$ \\
\hline Residual employment situations & 0.039 & $(0.070)$ & 0.026 & $(0.065)$ \\
\hline $\begin{array}{l}\text { Female breadwinner } \\
\text { household,man not unemployed } \\
\text { Reference category: equal } \\
\text { empoyment level }\end{array}$ & -0.048 & $(0.062)$ & -0.073 & $(0.061)$ \\
\hline Monthly household income, log. & $1.337 * * *$ & $(0.056)$ & $1.227 * * *$ & $(0.056)$ \\
\hline Household size, log. & $-0.581 * * *$ & $(0.122)$ & $-0.252 * *$ & $(0.122)$ \\
\hline $\begin{array}{l}\text { Reference category: household } \\
\text { without children }\end{array}$ & 0.057 & $(0.090)$ & -0.134 & $(0.091)$ \\
\hline Youngest child up to 6 years & 0.070 & $(0.090)$ & -0.063 & $(0.090)$ \\
\hline Youngest child up to 10 years & 0.111 & $(0.087)$ & -0.057 & $(0.087)$ \\
\hline Youngest child up to 16 years & 0.024 & $(0.081)$ & $-0.175 * *$ & $(0.083)$ \\
\hline Youngest child at least 16 years & -0.070 & $(0.072)$ & $-0.209 * * *$ & $(0.073)$ \\
\hline Man's self-rated health & $0.215 * * *$ & $(0.015)$ & $0.094 * * *$ & $(0.015)$ \\
\hline Woman's self-rated health & $0.079 * * *$ & $(0.013)$ & $0.176 * * *$ & $(0.014)$ \\
\hline Married & 0.092 & $(0.077)$ & -0.027 & $(0.080)$ \\
\hline Living in residential property & -0.023 & $(0.037)$ & $-0.096 * *$ & $(0.037)$ \\
\hline Living in urban area & 0.074 & $(0.058)$ & 0.004 & $(0.060)$ \\
\hline Survey year 2001 & $0.067 * *$ & $(0.032)$ & 0.024 & $(0.032)$ \\
\hline Survey year 2002 & $0.858 * * *$ & $(0.046)$ & $0.748 * * *$ & $(0.046)$ \\
\hline Survey year 2003 & $0.725 * * *$ & $(0.046)$ & $0.586 * * *$ & $(0.047)$ \\
\hline Survey year 2004 & $0.588 * * *$ & $(0.047)$ & $0.521 * * *$ & $(0.048)$ \\
\hline Survey year 2005 & $0.586 * * *$ & $(0.051)$ & $0.451 * * *$ & $(0.051)$ \\
\hline Survey year 2006 & $0.578 * * *$ & $(0.049)$ & $0.486 * * *$ & $(0.050)$ \\
\hline Survey year 2007 & $0.577 * * *$ & $(0.050)$ & $0.497 * * *$ & $(0.050)$ \\
\hline Survey year 2008 & $0.591 * * *$ & $(0.051)$ & $0.527 * * *$ & $(0.051)$ \\
\hline Survey year 2009 & $0.605 * * *$ & $(0.051)$ & $0.583 * * *$ & $(0.051)$ \\
\hline Survey year 2010 & $0.635 * * *$ & $(0.052)$ & $0.551 * * *$ & $(0.052)$ \\
\hline Survey year 2011 & $0.704 * * *$ & $(0.053)$ & $0.657 * * *$ & $(0.052)$ \\
\hline Constant & $-5.949 * * *$ & $(0.466)$ & $-4.637 * * *$ & $(0.469)$ \\
\hline $\mathrm{N}$ & 36783 & & 36783 & \\
\hline
\end{tabular}

Notes: Linear regression estimations with individual-specific fixed effects. Robust standard errors, clustered by individuals, are in parentheses. Significance level: $*<0.1, * *<0.05, * * *<0.01$.

Source: SOEP 2000 - 2011. 


\section{A2.3 Determinants of differences in financial satisfaction and of financial satisfaction in three subsamples}

Table A2.2: Differences in financial satisfaction and financial satisfaction in strict male breadwinning couples

Strict male breadwinning: woman not in the labor force, man working full-time or part-time

\begin{tabular}{|c|c|c|c|c|c|c|}
\hline \multicolumn{3}{|c|}{ Within-Couple satisfaction differences } & \multicolumn{2}{|c|}{ Men's satisfaction } & \multicolumn{2}{|c|}{ Women's satisfaction } \\
\hline Income ratio & -0.235 & $(0.443)$ & -0.657 & $(0.453)$ & -0.422 & $(0.404)$ \\
\hline Man's income & 0.042 & $(0.039)$ & $0.134 * * *$ & $(0.047)$ & $0.092 * * *$ & $(0.032)$ \\
\hline Woman's income & -0.015 & $(0.016)$ & -0.010 & $(0.016)$ & 0.005 & $(0.015)$ \\
\hline Monthly household income, log. & $0.316^{* * *}$ & $(0.106)$ & $0.947 * * *$ & $(0.120)$ & $0.631 * * *$ & $(0.109)$ \\
\hline Household size, log. & -0.154 & $(0.222)$ & -0.318 & $(0.194)$ & -0.164 & $(0.218)$ \\
\hline \multicolumn{7}{|l|}{$\begin{array}{l}\text { Reference category: household } \\
\text { without children }\end{array}$} \\
\hline Youngest child up to 6 years & -0.033 & $(0.075)$ & -0.017 & $(0.075)$ & 0.016 & $(0.080)$ \\
\hline Youngest child up to 10 years & -0.053 & $(0.089)$ & 0.066 & $(0.090)$ & 0.118 & $(0.095)$ \\
\hline Youngest child up to 16 years & -0.004 & $(0.108)$ & 0.021 & $(0.107)$ & 0.026 & $(0.110)$ \\
\hline Youngest child at least 16 years & 0.040 & $(0.120)$ & -0.178 & $(0.119)$ & $-0.218 *$ & $(0.118)$ \\
\hline Man's self-rated health & $0.115 * * *$ & $(0.036)$ & $0.176 * * *$ & $(0.034)$ & $0.061^{*}$ & $(0.035)$ \\
\hline Woman's self-rated health & $-0.065^{*}$ & $(0.039)$ & $0.081 * *$ & $(0.033)$ & $0.146^{* * *}$ & $(0.037)$ \\
\hline Man unemployed & -0.119 & $(0.176)$ & $-0.623 * * *$ & $(0.197)$ & $-0.504 * * *$ & $(0.192)$ \\
\hline Woman unemployed & & & . & & . & \\
\hline Man's weekly working hours & -0.001 & $(0.004)$ & $0.006 *$ & $(0.003)$ & $0.007 * *$ & $(0.003)$ \\
\hline Woman's weekly working hours & -0.002 & $(0.006)$ & 0.000 & $(0.006)$ & 0.002 & $(0.007)$ \\
\hline Working hours ratio & 0.054 & $(0.194)$ & 0.052 & $(0.195)$ & -0.002 & $(0.193)$ \\
\hline Living in residential property & -0.025 & $(0.085)$ & -0.004 & $(0.086)$ & 0.021 & $(0.091)$ \\
\hline Living in urban area & 0.032 & $(0.144)$ & 0.144 & $(0.164)$ & 0.111 & $(0.167)$ \\
\hline Survey year 2001 & -0.052 & $(0.076)$ & 0.077 & $(0.066)$ & $0.129 *$ & $(0.072)$ \\
\hline Survey year 2002 & $0.212 * *$ & $(0.105)$ & $0.575^{* * *}$ & $(0.103)$ & $0.364 * * *$ & $(0.101)$ \\
\hline Survey year 2003 & 0.161 & $(0.108)$ & $0.558 * * *$ & $(0.102)$ & $0.397 * * *$ & $(0.105)$ \\
\hline Survey year 2004 & $0.183^{*}$ & $(0.107)$ & $0.451 * * *$ & $(0.103)$ & $0.268 * *$ & $(0.108)$ \\
\hline Survey year 2005 & 0.135 & $(0.119)$ & $0.423 * * *$ & $(0.115)$ & $0.289 * *$ & $(0.118)$ \\
\hline Survey year 2006 & $0.194 *$ & $(0.108)$ & $0.388 * * *$ & $(0.108)$ & $0.194 *$ & $(0.111)$ \\
\hline Survey year 2007 & 0.175 & $(0.116)$ & $0.401 * * *$ & $(0.109)$ & $0.226 * *$ & $(0.115)$ \\
\hline Survey year 2008 & 0.082 & $(0.121)$ & $0.444 * * *$ & $(0.113)$ & $0.362 * * *$ & $(0.121)$ \\
\hline Survey year 2009 & 0.103 & $(0.122)$ & $0.340 * * *$ & $(0.116)$ & $0.238 * *$ & $(0.121)$ \\
\hline Survey year 2010 & 0.136 & $(0.122)$ & $0.386 * * *$ & $(0.123)$ & $0.250 * *$ & $(0.125)$ \\
\hline Survey year 2011 & $0.247^{*}$ & $(0.126)$ & $0.575 * * *$ & $(0.118)$ & $0.328 * * *$ & $(0.125)$ \\
\hline Constant & $-2.892 * * *$ & $(0.971)$ & $-2.729 * * *$ & $(1.034)$ & 0.163 & $(1.009)$ \\
\hline$\overline{\mathrm{N}}$ & 7097 & & 7097 & & 7097 & \\
\hline
\end{tabular}

Notes: Linear regression estimations with household-specific fixed effects. Robust standard errors, clustered by households, are in parentheses. Significance level: $*<0.1, * *<0.05, * * *<0.01$.

Source: SOEP 2000 - 2011. 
Table A2.3: Differences in financial satisfaction and financial satisfaction in mild male breadwinning couples

Mild male breadwinning: woman working part-time, man working full-time

\begin{tabular}{|c|c|c|c|c|c|c|}
\hline \multicolumn{3}{|c|}{ Within-Couple satisfaction differences } & \multicolumn{2}{|c|}{ Men's satisfaction } & \multicolumn{2}{|c|}{ Women's satisfaction } \\
\hline Income ratio & $1.257 * * *$ & $(0.376)$ & 0.204 & $(0.329)$ & $-1.053 * * *$ & $(0.379)$ \\
\hline Man's income & $-0.103 * *$ & $(0.049)$ & $0.117 * *$ & $(0.059)$ & $0.220 * * *$ & $(0.060)$ \\
\hline Woman's income & 0.027 & $(0.018)$ & 0.015 & $(0.015)$ & -0.012 & $(0.016)$ \\
\hline Monthly household income, log. & 0.046 & $(0.105)$ & $0.988 * * *$ & $(0.101)$ & $0.942 * * *$ & $(0.105)$ \\
\hline Household size, log. & -0.151 & $(0.170)$ & -0.234 & $(0.153)$ & -0.083 & $(0.157)$ \\
\hline \multicolumn{7}{|l|}{$\begin{array}{l}\text { Reference category: household } \\
\text { without children }\end{array}$} \\
\hline Youngest child up to 6 years & -0.077 & $(0.069)$ & 0.017 & $(0.057)$ & 0.094 & $(0.065)$ \\
\hline Youngest child up to 10 years & 0.002 & $(0.074)$ & 0.016 & $(0.067)$ & 0.014 & $(0.074)$ \\
\hline Youngest child up to 16 years & 0.017 & $(0.084)$ & -0.120 & $(0.076)$ & $-0.136 *$ & $(0.080)$ \\
\hline Youngest child at least 16 years & 0.031 & $(0.089)$ & $-0.204 * *$ & $(0.087)$ & $-0.235 * * *$ & $(0.085)$ \\
\hline Man's self-rated health & $0.094 * * *$ & $(0.026)$ & $0.172 * * *$ & $(0.026)$ & $0.079 * * *$ & $(0.026)$ \\
\hline Woman's self-rated health & $-0.069 * *$ & $(0.027)$ & $0.081 * * *$ & $(0.024)$ & $0.151 * * *$ & $(0.024)$ \\
\hline Man unemployed & 0.263 & $(0.266)$ & -0.284 & $(0.298)$ & $-0.548 * *$ & $(0.275)$ \\
\hline \multicolumn{7}{|l|}{ Woman unemployed } \\
\hline Man's weekly working hours & -0.001 & $(0.004)$ & 0.002 & $(0.004)$ & 0.003 & $(0.004)$ \\
\hline Woman's weekly working hours & $0.013 * *$ & $(0.005)$ & $0.014 * * *$ & $(0.005)$ & 0.001 & $(0.005)$ \\
\hline Working hours ratio & $0.732 * *$ & $(0.368)$ & 0.539 & $(0.400)$ & -0.193 & $(0.409)$ \\
\hline Living in residential property & 0.084 & $(0.072)$ & -0.049 & $(0.067)$ & $-0.133 *$ & $(0.069)$ \\
\hline Living in urban area & -0.010 & $(0.113)$ & 0.031 & $(0.096)$ & 0.040 & $(0.110)$ \\
\hline Survey year 2001 & 0.039 & $(0.074)$ & $0.123^{*}$ & $(0.064)$ & 0.084 & $(0.065)$ \\
\hline Survey year 2002 & -0.015 & $(0.098)$ & $0.655 * * *$ & $(0.089)$ & $0.670 * * *$ & $(0.093)$ \\
\hline Survey year 2003 & 0.106 & $(0.094)$ & $0.596 * * *$ & $(0.086)$ & $0.490 * * *$ & $(0.090)$ \\
\hline Survey year 2004 & -0.025 & $(0.096)$ & $0.435 * * *$ & $(0.088)$ & $0.460 * * *$ & $(0.093)$ \\
\hline Survey year 2005 & 0.026 & $(0.104)$ & $0.414 * * *$ & $(0.096)$ & $0.388 * * *$ & $(0.100)$ \\
\hline Survey year 2006 & 0.015 & $(0.097)$ & $0.415 * * *$ & $(0.087)$ & $0.400 * * *$ & $(0.093)$ \\
\hline Survey year 2007 & -0.046 & $(0.099)$ & $0.356 * * *$ & $(0.088)$ & $0.401 * * *$ & $(0.091)$ \\
\hline Survey year 2008 & -0.061 & $(0.100)$ & $0.428 * * *$ & $(0.089)$ & $0.489 * * *$ & $(0.092)$ \\
\hline Survey year 2009 & -0.138 & $(0.100)$ & $0.496 * * *$ & $(0.086)$ & $0.633 * * *$ & $(0.090)$ \\
\hline Survey year 2010 & -0.077 & $(0.098)$ & $0.511 * * *$ & $(0.089)$ & $0.588 * * *$ & $(0.091)$ \\
\hline Survey year 2011 & -0.079 & $(0.102)$ & $0.563 * * *$ & $(0.093)$ & $0.642 * * *$ & $(0.092)$ \\
\hline Constant & -1.471 & $(0.909)$ & $-4.251 * * *$ & $(0.878)$ & $-2.780 * * *$ & $(0.925)$ \\
\hline $\mathrm{N}$ & 11737 & & 11737 & & 11737 & \\
\hline
\end{tabular}

Notes: Linear regression estimations with household-specific fixed effects. Robust standard errors, clustered by households, are in parentheses. Significance level: $*<0.1, * *<0.05, * * *<0.01$.

Source: SOEP 2000 - 2011. 
Table A2.4: Differences in financial satisfaction and financial satisfaction in double full-time couples

Double full-time: Both partners of a couple are full-time employed

\begin{tabular}{|c|c|c|c|c|c|c|}
\hline \multirow{2}{*}{ Income ratio } & \multicolumn{2}{|c|}{ sfaction differences } & \multicolumn{2}{|c|}{ Men's satisfaction } & \multicolumn{2}{|c|}{ Women's satisfaction } \\
\hline & $1.988 * * *$ & $(0.485)$ & $1.299 * * *$ & $(0.480)$ & -0.688 & $(0.468)$ \\
\hline Man's income & $-0.128 * *$ & $(0.063)$ & 0.010 & $(0.064)$ & $0.139 * *$ & $(0.063)$ \\
\hline Woman's income & 0.077 & $(0.055)$ & $0.124 * *$ & $(0.060)$ & 0.047 & $(0.056)$ \\
\hline Monthly household income, log. & 0.057 & $(0.129)$ & $0.960 * * *$ & $(0.124)$ & $0.903 * * *$ & $(0.127)$ \\
\hline Household size, log. & -0.397 & $(0.280)$ & $-0.609 * *$ & $(0.265)$ & -0.212 & $(0.241)$ \\
\hline \multicolumn{7}{|l|}{$\begin{array}{l}\text { Reference category: household } \\
\text { without children }\end{array}$} \\
\hline Youngest child up to 6 years & 0.262 & $(0.169)$ & 0.144 & $(0.167)$ & -0.118 & $(0.158)$ \\
\hline Youngest child up to 10 years & 0.158 & $(0.183)$ & -0.040 & $(0.155)$ & -0.198 & $(0.160)$ \\
\hline Youngest child up to 16 years & $0.338 * *$ & $(0.172)$ & 0.167 & $(0.155)$ & -0.170 & $(0.159)$ \\
\hline Youngest child at least 16 years & 0.170 & $(0.155)$ & 0.120 & $(0.141)$ & -0.049 & $(0.141)$ \\
\hline Man's self-rated health & $0.126 * * *$ & $(0.034)$ & $0.255 * * *$ & $(0.033)$ & $0.130 * * *$ & $(0.031)$ \\
\hline Woman's self-rated health & $-0.084 * *$ & $(0.034)$ & $0.076 * * *$ & $(0.029)$ & $0.160 * * *$ & $(0.030)$ \\
\hline Man unemployed & . & & . & & . & \\
\hline Woman unemployed & & & . & & & \\
\hline Man's weekly working hours & 0.009 & $(0.007)$ & $0.015 * *$ & $(0.007)$ & 0.006 & $(0.007)$ \\
\hline Woman's weekly working hours & -0.005 & $(0.008)$ & -0.011 & $(0.007)$ & -0.006 & $(0.007)$ \\
\hline Working hours ratio & -0.664 & $(0.839)$ & $-1.420^{*}$ & $(0.769)$ & -0.755 & $(0.787)$ \\
\hline Living in residential property & 0.076 & $(0.085)$ & 0.043 & $(0.075)$ & -0.033 & $(0.078)$ \\
\hline Living in urban area & 0.216 & $(0.144)$ & 0.084 & $(0.124)$ & -0.131 & $(0.120)$ \\
\hline Survey year 2001 & 0.058 & $(0.081)$ & 0.064 & $(0.073)$ & 0.007 & $(0.071)$ \\
\hline Survey year 2002 & 0.021 & $(0.112)$ & $0.668 * * *$ & $(0.106)$ & $0.647 * * *$ & $(0.105)$ \\
\hline Survey year 2003 & 0.118 & $(0.111)$ & $0.572 * * *$ & $(0.105)$ & $0.454 * * *$ & $(0.105)$ \\
\hline Survey year 2004 & 0.103 & $(0.111)$ & $0.539 * * *$ & $(0.107)$ & $0.436 * * *$ & $(0.107)$ \\
\hline Survey year 2005 & $0.214^{*}$ & $(0.120)$ & $0.652 * * *$ & $(0.113)$ & $0.438 * * *$ & $(0.112)$ \\
\hline Survey year 2006 & 0.136 & $(0.117)$ & $0.503 * * *$ & $(0.108)$ & $0.367 * * *$ & $(0.112)$ \\
\hline Survey year 2007 & 0.148 & $(0.113)$ & $0.558 * * *$ & $(0.111)$ & $0.410 * * *$ & $(0.109)$ \\
\hline Survey year 2008 & 0.138 & $(0.112)$ & $0.515 * * *$ & $(0.112)$ & $0.377 * * *$ & $(0.110)$ \\
\hline Survey year 2009 & 0.118 & $(0.114)$ & $0.589 * * *$ & $(0.114)$ & $0.471 * * *$ & $(0.113)$ \\
\hline Survey year 2010 & 0.161 & $(0.113)$ & $0.659 * * *$ & $(0.111)$ & $0.498 * * *$ & $(0.111)$ \\
\hline Survey year 2011 & 0.132 & $(0.118)$ & $0.766 * * *$ & $(0.114)$ & $0.634 * * *$ & $(0.113)$ \\
\hline Constant & -1.235 & (1.198) & $-3.608 * * *$ & (1.190) & $-2.373 * *$ & (1.198) \\
\hline$\overline{\mathrm{N}}$ & 8065 & & 8065 & & 8065 & \\
\hline
\end{tabular}

Notes: Linear regression estimations with household-specific fixed effects. Robust standard errors, clustered by households, are in parentheses. Significance level: $*<0.1, * *<0.05, * * *<0.01$.

Source: SOEP 2000 - 2011. 
The above presented estimations included 4614 observations where the man reported being unemployed at the time of the interview. This is the case because the assignment of couples to subsamples is based on the couples' working time arrangement, which refer to the employment level in the year before the interview. Only the double full time couples are defined as not being unemployed at the time of the interview, and women in male breadwinning couples. For males in male breadwinning couples, yet, being unemployed at the time of the interview is possible. There are thus couples in the above estimations that were male breadwinning couples in the year before the interview, but should drop out of that category because the man was unemployed at the time of the interview. Additional estimations, which are restricted to couples where the man was not unemployed at the time of the interview, are therefore presented in the following three tables A2.5 - A2.7.

Table A2.5: Differences in financial satisfaction and financial satisfaction in strict male breadwinning couples -2

Strict male breadwinning 1: woman not in the labor force, man working full-time or part-time

\begin{tabular}{|c|c|c|c|c|c|c|}
\hline \multicolumn{3}{|c|}{ Within-Couple satisfaction differences } & \multicolumn{2}{|c|}{ Men's satisfaction } & \multicolumn{2}{|c|}{ Women's satisfaction } \\
\hline Income ratio & 0.360 & $(0.553)$ & 0.228 & $(0.546)$ & -0.133 & $(0.587)$ \\
\hline Man's income & 0.002 & $(0.047)$ & $0.194 * * *$ & $(0.065)$ & $0.192 * * *$ & $(0.053)$ \\
\hline Woman's income & -0.002 & $(0.017)$ & 0.012 & $(0.017)$ & 0.014 & $(0.017)$ \\
\hline Monthly household income, log. & $0.381 * * *$ & $(0.110)$ & $0.984 * * *$ & $(0.115)$ & $0.603 * * *$ & $(0.111)$ \\
\hline Household size, log. & -0.197 & $(0.230)$ & $-0.381 *$ & $(0.200)$ & -0.183 & $(0.223)$ \\
\hline \multicolumn{7}{|l|}{$\begin{array}{l}\text { Reference category: household } \\
\text { without children }\end{array}$} \\
\hline Youngest child up to 6 years & -0.006 & $(0.075)$ & 0.027 & $(0.074)$ & 0.033 & $(0.079)$ \\
\hline Youngest child up to 10 years & -0.017 & $(0.090)$ & 0.098 & $(0.090)$ & 0.115 & $(0.096)$ \\
\hline Youngest child up to 16 years & 0.036 & $(0.109)$ & 0.036 & $(0.104)$ & 0.000 & $(0.110)$ \\
\hline Youngest child at least 16 years & 0.106 & $(0.125)$ & -0.108 & $(0.120)$ & $-0.214^{*}$ & $(0.122)$ \\
\hline Man's self-rated health & $0.110 * * *$ & $(0.036)$ & $0.182 * * *$ & $(0.034)$ & $0.072 * *$ & $(0.036)$ \\
\hline Woman's self-rated health & $-0.071 *$ & $(0.040)$ & $0.084 * * *$ & $(0.032)$ & $0.155^{* * *}$ & $(0.038)$ \\
\hline Living in residential property & -0.015 & $(0.087)$ & -0.014 & $(0.085)$ & 0.001 & $(0.092)$ \\
\hline Living in urban area & 0.034 & $(0.144)$ & 0.149 & $(0.149)$ & 0.115 & $(0.164)$ \\
\hline Survey year 2001 & -0.038 & $(0.077)$ & 0.076 & $(0.065)$ & 0.113 & $(0.073)$ \\
\hline Survey year 2002 & $0.217 * *$ & $(0.107)$ & $0.586^{* * *}$ & $(0.103)$ & $0.369 * * *$ & $(0.103)$ \\
\hline Survey year 2003 & 0.139 & (0.109) & $0.565^{* * *}$ & $(0.103)$ & $0.427 * * *$ & $(0.106)$ \\
\hline Survey year 2004 & $0.195 *$ & (0.109) & $0.514 * * *$ & $(0.103)$ & $0.319 * * *$ & $(0.110)$ \\
\hline Survey year 2005 & 0.134 & $(0.120)$ & $0.441 * * *$ & (0.113) & $0.306^{* *}$ & $(0.120)$ \\
\hline Survey year 2006 & $0.194 *$ & $(0.109)$ & $0.405 * * *$ & $(0.108)$ & $0.211^{*}$ & $(0.114)$ \\
\hline Survey year 2007 & 0.159 & $(0.117)$ & $0.412 * * *$ & $(0.109)$ & $0.253 * *$ & $(0.117)$ \\
\hline Survey year 2008 & 0.069 & $(0.122)$ & $0.459 * * *$ & $(0.114)$ & $0.390 * * *$ & $(0.123)$ \\
\hline Survey year 2009 & 0.070 & $(0.124)$ & $0.323 * * *$ & $(0.117)$ & $0.253^{* *}$ & $(0.123)$ \\
\hline Survey year 2010 & 0.095 & $(0.124)$ & $0.384 * * *$ & $(0.123)$ & $0.289 * *$ & $(0.127)$ \\
\hline Survey year 2011 & $0.215^{*}$ & $(0.129)$ & $0.556 * * *$ & $(0.119)$ & $0.340 * * *$ & $(0.127)$ \\
\hline Constant & $-3.596 * * *$ & (1.040) & $-4.022 * * *$ & (1.043) & -0.426 & (1.093) \\
\hline $\mathrm{N}$ & 6805 & & 6805 & & 6805 & \\
\hline
\end{tabular}

Notes: Linear regression estimations with household-specific fixed effects. Robust standard errors, clustered by households, are in parentheses. Significance level: $*<0.1, * *<0.05, * * *<0.01$.

Source: SOEP 2000 - 2011. 
Table A2.6: Differences in financial satisfaction and financial satisfaction in mild male breadwinning couples -2

Mild male breadwinning 2: woman working part-time, man working full-time

\begin{tabular}{|c|c|c|c|c|c|c|}
\hline \multicolumn{3}{|c|}{ Within-Couple satisfaction differences } & \multicolumn{2}{|c|}{ Men's satisfaction } & \multicolumn{2}{|c|}{ Women's satisfaction } \\
\hline Income ratio & $1.174 * * *$ & $(0.389)$ & 0.090 & $(0.327)$ & $-1.084 * * *$ & $(0.385)$ \\
\hline Man's income & -0.079 & $(0.055)$ & $0.160 * *$ & $(0.071)$ & $0.239 * * *$ & $(0.066)$ \\
\hline Woman's income & 0.028 & $(0.018)$ & 0.015 & $(0.015)$ & -0.013 & $(0.017)$ \\
\hline Monthly household income, log. & 0.028 & $(0.108)$ & $0.944 * * *$ & $(0.103)$ & $0.915 * * *$ & $(0.107)$ \\
\hline Household size, log. & -0.164 & $(0.172)$ & -0.221 & $(0.153)$ & -0.057 & $(0.158)$ \\
\hline \multicolumn{7}{|l|}{$\begin{array}{l}\text { Reference category: household } \\
\text { without children }\end{array}$} \\
\hline Youngest child up to 6 years & -0.069 & $(0.069)$ & 0.005 & $(0.057)$ & 0.074 & $(0.065)$ \\
\hline Youngest child up to 10 years & 0.007 & $(0.075)$ & -0.008 & $(0.066)$ & -0.015 & $(0.074)$ \\
\hline Youngest child up to 16 years & 0.026 & $(0.085)$ & $-0.124 *$ & $(0.075)$ & $-0.150 *$ & $(0.080)$ \\
\hline Youngest child at least 16 years & 0.053 & $(0.090)$ & $-0.194 * *$ & $(0.086)$ & $-0.247 * * *$ & $(0.084)$ \\
\hline Man's self-rated health & $0.092 * * *$ & $(0.027)$ & $0.171 * * *$ & $(0.026)$ & $0.079 * * *$ & $(0.026)$ \\
\hline Woman's self-rated health & $-0.072 * * *$ & $(0.028)$ & $0.082 * * *$ & $(0.024)$ & $0.154 * * *$ & $(0.024)$ \\
\hline Man's weekly working hours & -0.002 & $(0.005)$ & 0.004 & $(0.005)$ & 0.006 & $(0.005)$ \\
\hline Woman's weekly working hours & $0.014 * * *$ & $(0.005)$ & $0.012 * *$ & $(0.005)$ & -0.002 & $(0.006)$ \\
\hline Working hours ratio & $0.932 * *$ & $(0.411)$ & 0.459 & $(0.415)$ & -0.473 & $(0.463)$ \\
\hline Living in residential property & 0.060 & $(0.072)$ & -0.067 & $(0.067)$ & $-0.127 *$ & $(0.069)$ \\
\hline Living in urban area & -0.010 & $(0.114)$ & 0.034 & $(0.097)$ & 0.045 & $(0.111)$ \\
\hline Survey year 2001 & 0.045 & $(0.075)$ & $0.125 * *$ & $(0.063)$ & 0.080 & $(0.065)$ \\
\hline Survey year 2002 & 0.001 & $(0.098)$ & $0.643 * * *$ & $(0.090)$ & $0.642 * * *$ & $(0.092)$ \\
\hline Survey year 2003 & 0.115 & $(0.094)$ & $0.588 * * *$ & $(0.087)$ & $0.473 * * *$ & $(0.091)$ \\
\hline Survey year 2004 & -0.005 & $(0.096)$ & $0.433 * * *$ & $(0.090)$ & $0.437 * * *$ & $(0.093)$ \\
\hline Survey year 2005 & -0.004 & $(0.104)$ & $0.373 * * *$ & $(0.095)$ & $0.376 * * *$ & $(0.101)$ \\
\hline Survey year 2006 & 0.022 & $(0.097)$ & $0.406^{* * *}$ & $(0.088)$ & $0.384 * * *$ & $(0.093)$ \\
\hline Survey year 2007 & -0.033 & $(0.100)$ & $0.346 * * *$ & $(0.089)$ & $0.379 * * *$ & $(0.091)$ \\
\hline Survey year 2008 & -0.058 & $(0.101)$ & $0.413 * * *$ & $(0.089)$ & $0.470 * * *$ & $(0.091)$ \\
\hline Survey year 2009 & -0.136 & $(0.101)$ & $0.482 * * *$ & $(0.086)$ & $0.619 * * *$ & $(0.090)$ \\
\hline Survey year 2010 & -0.072 & (0.099) & $0.495 * * *$ & $(0.090)$ & $0.567 * * *$ & $(0.091)$ \\
\hline Survey year 2011 & -0.067 & $(0.103)$ & $0.549 * * *$ & $(0.094)$ & $0.616 * * *$ & $(0.092)$ \\
\hline Constant & $-1.557 *$ & $(0.922)$ & $-4.135 * * *$ & $(0.886)$ & $-2.578 * * *$ & $(0.924)$ \\
\hline$\overline{\mathrm{N}}$ & 11597 & & 11597 & & 11597 & \\
\hline
\end{tabular}

Notes: Linear regression estimations with household-specific fixed effects. Robust standard errors, clustered by households, are in parentheses. Significance level: $*<0.1, * *<0.05, * * *<0.01$.

Source: SOEP 2000 - 2011. 
Table A2.7: Differences in financial satisfaction and financial satisfaction in double full-time couples -2

Double full-time: Both partners of a couple are full-time employed

\begin{tabular}{|c|c|c|c|c|c|c|}
\hline \multicolumn{3}{|c|}{ Within-Couple satisfaction differences } & \multicolumn{2}{|c|}{ Men's satisfaction } & \multicolumn{2}{|c|}{ Women's satisfaction } \\
\hline Income ratio & $2.032 * * *$ & $(0.480)$ & $1.379 * * *$ & $(0.489)$ & -0.653 & $(0.473)$ \\
\hline Man's income & $-0.126 * *$ & $(0.058)$ & 0.002 & $(0.063)$ & $0.128 * *$ & $(0.059)$ \\
\hline Woman's income & 0.087 & $(0.053)$ & $0.143 * *$ & $(0.057)$ & 0.056 & $(0.051)$ \\
\hline Monthly household income, log. & 0.072 & $(0.129)$ & $0.983 * * *$ & $(0.124)$ & $0.911 * * *$ & $(0.127)$ \\
\hline Household size, log. & -0.432 & $(0.271)$ & $-0.669 * *$ & $(0.262)$ & -0.238 & $(0.239)$ \\
\hline \multicolumn{7}{|l|}{$\begin{array}{l}\text { Reference category: household } \\
\text { without children }\end{array}$} \\
\hline Youngest child up to 6 years & $0.277 *$ & $(0.166)$ & 0.170 & $(0.166)$ & -0.106 & $(0.158)$ \\
\hline Youngest child up to 10 years & 0.171 & $(0.181)$ & -0.016 & $(0.154)$ & -0.187 & $(0.159)$ \\
\hline Youngest child up to 16 years & $0.356^{* *}$ & $(0.169)$ & 0.198 & $(0.155)$ & -0.158 & $(0.159)$ \\
\hline Youngest child at least 16 years & 0.188 & $(0.151)$ & 0.150 & $(0.140)$ & -0.037 & $(0.140)$ \\
\hline Man's self-rated health & $0.125 * * *$ & $(0.034)$ & $0.254 * * *$ & $(0.033)$ & $0.129 * * *$ & $(0.031)$ \\
\hline Woman's self-rated health & $-0.083 * *$ & $(0.034)$ & $0.076 * * *$ & $(0.029)$ & $0.160 * * *$ & $(0.031)$ \\
\hline Living in residential property & 0.075 & $(0.085)$ & 0.041 & $(0.076)$ & -0.033 & $(0.078)$ \\
\hline Living in urban area & 0.218 & $(0.144)$ & 0.086 & $(0.125)$ & -0.132 & $(0.120)$ \\
\hline Survey year 2001 & 0.052 & $(0.081)$ & 0.056 & $(0.073)$ & 0.004 & $(0.071)$ \\
\hline Survey year 2002 & 0.034 & $(0.111)$ & $0.682 * * *$ & $(0.106)$ & $0.648 * * *$ & $(0.104)$ \\
\hline Survey year 2003 & 0.129 & $(0.110)$ & $0.582 * * *$ & $(0.105)$ & $0.454 * * *$ & $(0.105)$ \\
\hline Survey year 2004 & 0.111 & $(0.111)$ & $0.547 * * *$ & (0.107) & $0.436 * * *$ & $(0.107)$ \\
\hline Survey year 2005 & $0.221 *$ & (0.119) & $0.657 * * *$ & $(0.113)$ & $0.437 * * *$ & $(0.112)$ \\
\hline Survey year 2006 & 0.145 & $(0.117)$ & $0.511 * * *$ & $(0.108)$ & $0.366 * * *$ & $(0.111)$ \\
\hline Survey year 2007 & 0.158 & $(0.112)$ & $0.567 * * *$ & $(0.111)$ & $0.409 * * *$ & (0.109) \\
\hline Survey year 2008 & 0.144 & $(0.111)$ & $0.518 * * *$ & $(0.112)$ & $0.374 * * *$ & $(0.110)$ \\
\hline Survey year 2009 & 0.125 & $(0.113)$ & $0.595 * * *$ & (0.114) & $0.469 * * *$ & $(0.113)$ \\
\hline Survey year 2010 & 0.162 & $(0.113)$ & $0.656 * * *$ & $(0.111)$ & $0.494 * * *$ & $(0.111)$ \\
\hline Survey year 2011 & 0.137 & $(0.117)$ & $0.769 * * *$ & $(0.114)$ & $0.632 * * *$ & $(0.112)$ \\
\hline Constant & -1.582 & (1.119) & $-4.366 * * *$ & (1.124) & $-2.784 * *$ & (1.139) \\
\hline$\overline{\mathrm{N}}$ & 8065 & & 8065 & & 8065 & \\
\hline
\end{tabular}

Notes: Linear regression estimations with household-specific fixed effects. Robust standard errors, clustered by households, are in parentheses. Significance level: $*<0.1, * *<0.05, * * *<0.01$.

Source: SOEP 2000 - 2011. 


\section{A3 Supplementary material for Chapter 4}

\section{A3.1 Heteroskedasticity in financial satifaction}

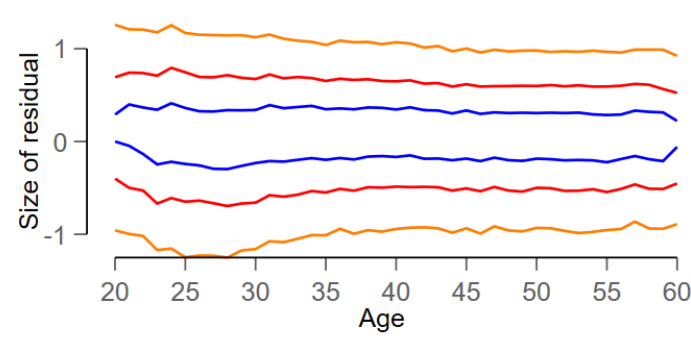

Percentiles of the distribution of residuals - 40th\&60th - 30th\&70th - 20th\&80th

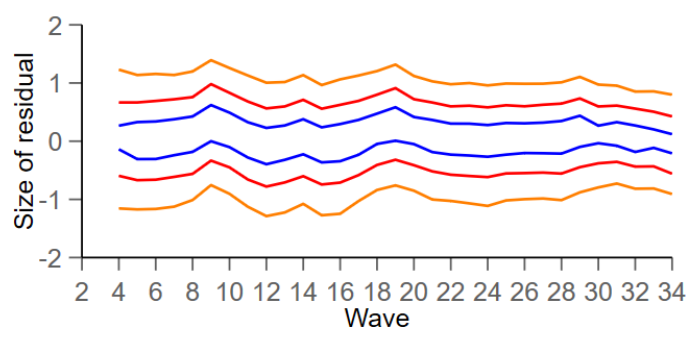

Percentiles of the distribution of residuals - 40th\&60th - 30th\&70th - 20th\&80th

Figure A3.1: Age- and wave-related heteroscedasticity in financial satisfaction

Source: SOEP v34, own calculations. 337031 person year observations of 46945 individuals.

Notes: Residuals from fixed effects regressions of financial satisfaction on age, age ${ }^{2}$, wave ${ }^{2}$ and wave $^{3}$ 


\section{A3.2 Simulated Income data}

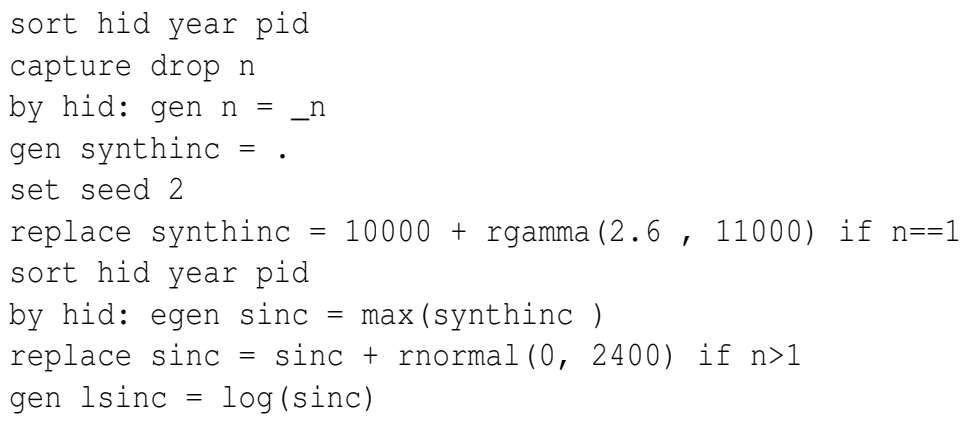

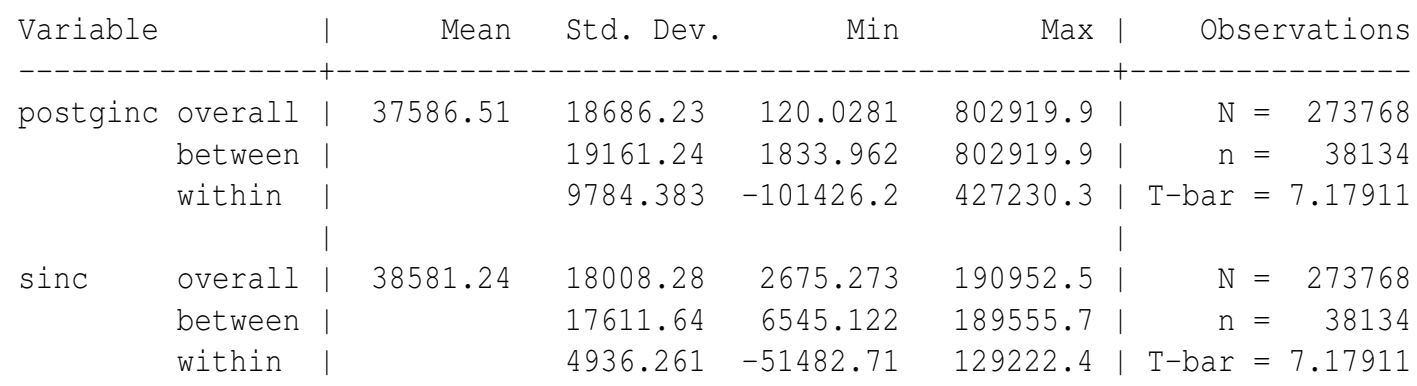

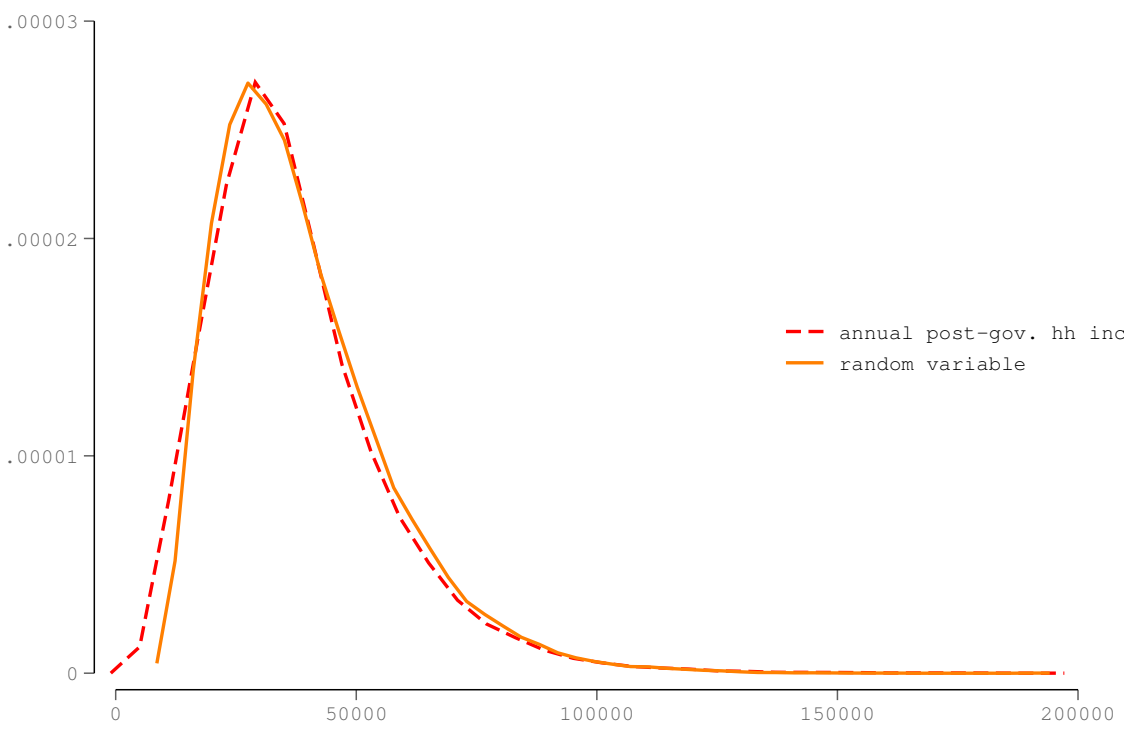

Figure A3.2: Kernel density estimation for observed income and random income-like variable

Source: SOEP v34, own calculations.

Notes: Income is post government household income, simulated income comes from a random number gamma distribution. 


\section{A3.3 Manipulated satisfaction data}

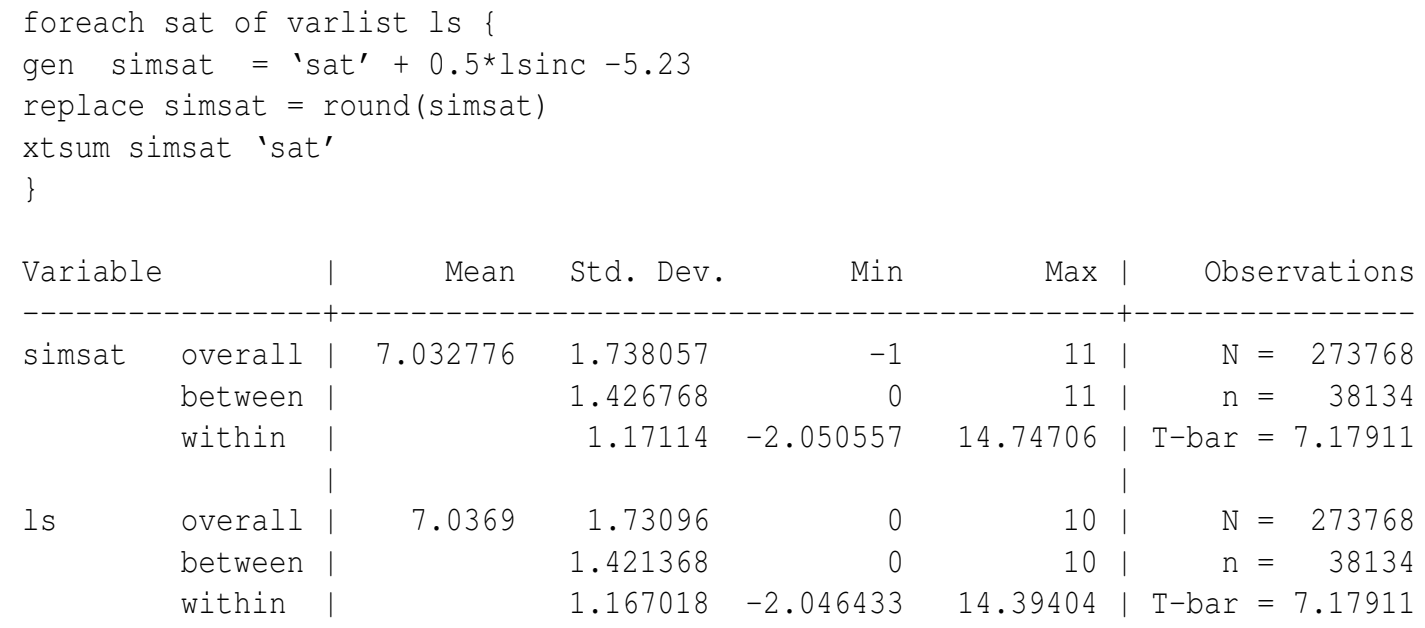

\begin{tabular}{|c|c|c|c|c|c|c|c|}
\hline Variable & & Mean & Std. Dev. & Min & $\operatorname{Max} \mid$ & $\mathrm{Obs}$ & servations \\
\hline \multirow[t]{4}{*}{ simsat } & overall & 7.032776 & 1.738057 & -1 & $11 \mid$ & & 273768 \\
\hline & between & & 1.426768 & 0 & $11 \mid$ & & 38134 \\
\hline & within & & 1.17114 & -2.050557 & 14.74706 & $\mathrm{~T}$-bar & $=7.17911$ \\
\hline & & & & & & & \\
\hline \multirow[t]{3}{*}{ ls } & overall & 7.0369 & 1.73096 & 0 & 10 & & $=273768$ \\
\hline & between & & 1.421368 & 0 & 10 & & 38134 \\
\hline & within & & 1.167018 & -2.046433 & 14.39404 & T-bar & $=7.179$ \\
\hline
\end{tabular}

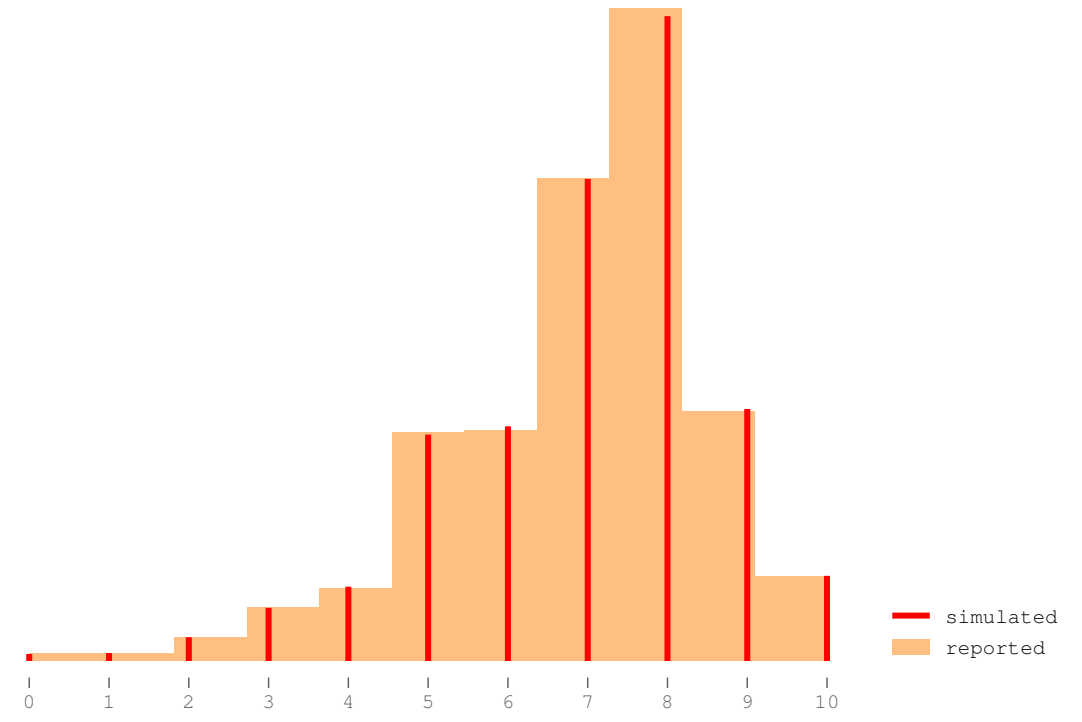

Figure A3.3: Frequencies for reported and manipulated satisfaction levels

Source: SOEP v34, own calculations. 


\section{A3.4 Complete estimations results for the tables in the paper}

Table A3.1: Estimates for RQ1: Equivalized income causing life satisfaction

\begin{tabular}{|c|c|c|c|c|c|c|}
\hline & \multicolumn{2}{|c|}{ Equiv.Income } & \multicolumn{4}{|c|}{ Life satisfaction } \\
\hline & $\begin{array}{l}\text { First } \\
\text { stage }\end{array}$ & $\begin{array}{l}\text { First } \\
\text { stage }\end{array}$ & IV-FE & $\mathrm{FE}$ & IV-FE & $\mathrm{FE}$ \\
\hline Instr.Age & $\begin{array}{l}-1.175 * * * \\
(0.113)\end{array}$ & $\begin{array}{l}-0.841 * * * \\
(0.092)\end{array}$ & & & & \\
\hline Instr.Age2 & $\begin{array}{l}0.151 * * * \\
(0.006)\end{array}$ & $\begin{array}{l}0.103 * * * \\
(0.005)\end{array}$ & & & & \\
\hline Instr.Wave2 & $\begin{array}{l}-0.018 * * * \\
(0.006)\end{array}$ & $\begin{array}{l}-0.010^{* *} \\
(0.005)\end{array}$ & & & & \\
\hline Instr.Wave3 & $\begin{array}{l}0.004 * * * \\
(0.001)\end{array}$ & $\begin{array}{l}0.003 * * * \\
(0.001)\end{array}$ & & & & \\
\hline Age & $\begin{array}{l}0.362 * * * \\
(0.021)\end{array}$ & $\begin{array}{l}0.358 * * * \\
(0.020)\end{array}$ & $\begin{array}{l}0.257 * * * \\
(0.092)\end{array}$ & $\begin{array}{c}0.148^{*} \\
(0.088)\end{array}$ & $\begin{array}{r}0.022 \\
(0.097)\end{array}$ & $\begin{array}{l}-0.112 \\
(0.090)\end{array}$ \\
\hline Age, sq. & $\begin{array}{l}-0.006 * * * \\
(0.001)\end{array}$ & $\begin{array}{l}-0.021 * * * \\
(0.001)\end{array}$ & $\begin{array}{l}-0.015 * * * \\
(0.006)\end{array}$ & $\begin{array}{l}-0.013 * * \\
(0.005)\end{array}$ & $\begin{array}{l}0.012 * \\
(0.006)\end{array}$ & $\begin{array}{l}0.020 * * * \\
(0.006)\end{array}$ \\
\hline Survey wave, sq. & $\begin{array}{l}-0.012 * * * \\
(0.001)\end{array}$ & $\begin{array}{l}-0.016 * * * \\
(0.001)\end{array}$ & $\begin{array}{l}-0.035 * * * \\
(0.004)\end{array}$ & $\begin{array}{l}-0.031 * * * \\
(0.004)\end{array}$ & $\begin{array}{l}-0.035^{* * *} \\
(0.005)\end{array}$ & $\begin{array}{l}-0.029 * * * \\
(0.004)\end{array}$ \\
\hline Survey wave, cub. & $\begin{array}{l}0.002 * * * \\
(0.000)\end{array}$ & $\begin{array}{l}0.003 * * * \\
(0.000)\end{array}$ & $\begin{array}{l}0.008 * * * \\
(0.001)\end{array}$ & $\begin{array}{l}0.007 * * * \\
(0.001)\end{array}$ & $\begin{array}{l}0.008 * * * \\
(0.001)\end{array}$ & $\begin{array}{l}0.007 * * * \\
(0.001)\end{array}$ \\
\hline Years of educ. & & $\begin{array}{l}0.019 * * * \\
(0.002)\end{array}$ & & & $\begin{array}{l}0.014 * * \\
(0.007)\end{array}$ & $\begin{array}{r}0.007 \\
(0.006)\end{array}$ \\
\hline Hospital stay & & $\begin{array}{l}-0.010 * * * \\
(0.002)\end{array}$ & & & $\begin{array}{l}-0.126 * * * \\
(0.011)\end{array}$ & $\begin{array}{l}-0.122^{* * *} \\
(0.011)\end{array}$ \\
\hline Gave birth & & $\begin{array}{l}0.012 * * \\
(0.005)\end{array}$ & & & $\begin{array}{l}0.353 * * * \\
(0.024)\end{array}$ & $\begin{array}{l}0.349 * * * \\
(0.024)\end{array}$ \\
\hline Married & & $\begin{array}{l}0.077 * * * \\
(0.005)\end{array}$ & & & $\begin{array}{l}0.274 * * * \\
(0.020)\end{array}$ & $\begin{array}{l}0.247 * * * \\
(0.019)\end{array}$ \\
\hline Kids & & $\begin{array}{l}-0.121 * * * \\
(0.003)\end{array}$ & & & $\begin{array}{r}0.019 \\
(0.018)\end{array}$ & $\begin{array}{l}0.064 * * * \\
(0.013)\end{array}$ \\
\hline East Germany & & $\begin{array}{l}0.075^{* * * *} \\
(0.017)\end{array}$ & & & $\begin{array}{l}-0.254 * * * \\
(0.059)\end{array}$ & $\begin{array}{l}-0.279 * * * \\
(0.058)\end{array}$ \\
\hline Unemployed & & $\begin{array}{l}-0.070 * * * \\
(0.004)\end{array}$ & & & $\begin{array}{l}-0.284 * * * \\
(0.019)\end{array}$ & $\begin{array}{l}-0.257 * * * \\
(0.018)\end{array}$ \\
\hline Home owner & & $\begin{array}{l}0.128 * * * \\
(0.004)\end{array}$ & & & $\begin{array}{l}0.098 * * * \\
(0.020)\end{array}$ & $\begin{array}{l}0.049 * * * \\
(0.015)\end{array}$ \\
\hline Reference income & & $\begin{array}{l}0.775^{* * *} \\
(0.006)\end{array}$ & & & $\begin{array}{r}0.127 \\
(0.088)\end{array}$ & $\begin{array}{l}-0.167 * * * \\
(0.024)\end{array}$ \\
\hline Equiv. Income & & & $\begin{array}{r}0.051 \\
(0.073)\end{array}$ & $\begin{array}{l}0.355^{* * *} \\
(0.013)\end{array}$ & $\begin{array}{l}-0.006 \\
(0.108)\end{array}$ & $\begin{array}{l}0.367 * * * \\
(0.015)\end{array}$ \\
\hline Constant & & & & $\begin{array}{l}3.734 * * * \\
(0.246)\end{array}$ & & $\begin{array}{l}5.518 \text { *** } \\
(0.301)\end{array}$ \\
\hline K-P F-Statistic & & & 267 & & 172 & \\
\hline Z-score & & & -4.102 & & -3.405 & \\
\hline Hansen $\mathbf{J}$ & & & 5.5 & & 5.9 & \\
\hline Prob $>$ Chi squared & & & 0.1360 & & 0.1164 & \\
\hline
\end{tabular}

Source: SOEP v34, own calculations. 273768 person-year observations of 38,134 individuals. Notes: Significance levels *0.10**0.05***0.01. Cluster-robust standard errors in parantheses. 
Table A3.2: Estimates for RQ2: Life satisfaction causing equivalized income

\begin{tabular}{|c|c|c|c|c|}
\hline & IV-FE & $\mathrm{FE}$ & IV-FE & $\mathrm{FE}$ \\
\hline Age & $\begin{array}{l}0.352 * * * \\
(0.023)\end{array}$ & $\begin{array}{l}0.350^{* * * *} \\
(0.023)\end{array}$ & $\begin{array}{l}0.377 * * * \\
(0.022)\end{array}$ & $\begin{array}{l}0.377^{* * * *} \\
(0.022)\end{array}$ \\
\hline Age, sq. & $\begin{array}{l}-0.006 * * * \\
(0.002)\end{array}$ & $\begin{array}{l}-0.006 * * * \\
(0.002)\end{array}$ & $\begin{array}{l}-0.011 * * * \\
(0.002)\end{array}$ & $\begin{array}{l}-0.011^{* * * *} \\
(0.002)\end{array}$ \\
\hline Survey wave, sq. & $\begin{array}{l}-0.012^{* * * *} \\
(0.001)\end{array}$ & $\begin{array}{l}-0.011 * * * \\
(0.001)\end{array}$ & $\begin{array}{l}-0.013 * * * \\
(0.001)\end{array}$ & $\begin{array}{l}-0.013^{* * *} \\
(0.001)\end{array}$ \\
\hline Survey wave, cub. & $\begin{array}{l}0.002^{* * * *} \\
(0.000)\end{array}$ & $\begin{array}{l}0.002 * * * \\
(0.000)\end{array}$ & $\begin{array}{l}0.002 * * * \\
(0.000)\end{array}$ & $\begin{array}{l}0.002 * * * \\
(0.000)\end{array}$ \\
\hline Years of education & & & $\begin{array}{l}0.017 * * * \\
(0.002)\end{array}$ & $\begin{array}{l}0.017 * * * \\
(0.002)\end{array}$ \\
\hline Hospital stay & & & $\begin{array}{r}0.003 \\
(0.002)\end{array}$ & $\begin{array}{c}0.003 * \\
(0.002)\end{array}$ \\
\hline East Germany & & & $\begin{array}{l}-0.034 \\
(0.022)\end{array}$ & $\begin{array}{l}-0.033 \\
(0.022)\end{array}$ \\
\hline Married & & & $\begin{array}{l}0.113^{* * * *} \\
(0.006)\end{array}$ & $\begin{array}{l}0.111^{* * * *} \\
(0.005)\end{array}$ \\
\hline Kids & & & $\begin{array}{l}-0.132 * * * \\
(0.003)\end{array}$ & $\begin{array}{l}-0.132 * * * \\
(0.003)\end{array}$ \\
\hline Unemployed & & & $\begin{array}{l}-0.072 * * * \\
(0.004)\end{array}$ & $\begin{array}{l}-0.071 * * * \\
(0.004)\end{array}$ \\
\hline Home owner & & & $\begin{array}{l}0.157 * * * \\
(0.005)\end{array}$ & $\begin{array}{l}0.156^{* * * *} \\
(0.005)\end{array}$ \\
\hline Life satisf. & $\begin{array}{c}0.011 * \\
(0.006)\end{array}$ & $\begin{array}{l}0.016 * * * \\
(0.001)\end{array}$ & $\begin{array}{r}0.010 \\
(0.006)\end{array}$ & $\begin{array}{l}0.014 * * * \\
(0.001)\end{array}$ \\
\hline Constant & & $\begin{array}{l}8.748 * * * \\
(0.056)\end{array}$ & & $\begin{array}{l}8.513^{* * * *} \\
(0.056)\end{array}$ \\
\hline K-P F-Statistic & 158 & & 158 & \\
\hline Z-score & -0.741 & & -0.723 & \\
\hline Hansen $\mathbf{J}$ & 2.7 & & 0.7 & \\
\hline Prob $>$ Chi squared & 0.4466 & & 0.8626 & \\
\hline
\end{tabular}

Source: SOEP v34, own calculations. 273768 person year observations of 38134 individuals.

Notes: Significance levels $* 0.10 * * 0.05 * * * 0.01$. Cluster-robust standard errors in parantheses. Income is annual net household income, equivalized to household size with the square root rule. 
Table A3.3: Estimations for RQ1 and financial satisfaction

\begin{tabular}{|c|c|c|c|c|c|}
\hline & First stage & IV-FE & $\mathrm{FE}$ & IV-FE & $\mathrm{FE}$ \\
\hline Income, log. & & $\begin{array}{l}0.917 * * * \\
(0.096)\end{array}$ & $\begin{array}{l}0.949 * * * \\
(0.018)\end{array}$ & $\begin{array}{l}1.167 * * * \\
(0.138)\end{array}$ & $\begin{array}{l}1.122 \text { *** } \\
(0.020)\end{array}$ \\
\hline Age & $\begin{array}{l}0.362 * * * \\
(0.021)\end{array}$ & $\begin{array}{l}0.790 * * * \\
(0.116)\end{array}$ & $\begin{array}{l}0.765^{* * * *} \\
(0.111)\end{array}$ & $\begin{array}{l}0.460 * * * \\
(0.123)\end{array}$ & $\begin{array}{l}0.459 * * * \\
(0.112)\end{array}$ \\
\hline Age, sq. & $\begin{array}{l}-0.006 * * * \\
(0.001)\end{array}$ & $\begin{array}{l}-0.051 * * * \\
(0.007)\end{array}$ & $\begin{array}{l}-0.049 * * * \\
(0.007)\end{array}$ & $\begin{array}{l}-0.007 \\
(0.008)\end{array}$ & $\begin{array}{l}-0.007 \\
(0.007)\end{array}$ \\
\hline S.wave, sq. & $\begin{array}{l}-0.012 * * * \\
(0.001)\end{array}$ & $\begin{array}{l}-0.056 * * * \\
(0.005)\end{array}$ & $\begin{array}{l}-0.055 * * * \\
(0.005)\end{array}$ & $\begin{array}{l}-0.049 * * * \\
(0.006)\end{array}$ & $\begin{array}{l}-0.049 * * * \\
(0.005)\end{array}$ \\
\hline S.wave, cub. & $\begin{array}{l}0.002 * * * \\
(0.000)\end{array}$ & $\begin{array}{l}0.014 * * * \\
(0.001)\end{array}$ & $\begin{array}{l}0.013 * * * \\
(0.001)\end{array}$ & $\begin{array}{l}0.012 * * * \\
(0.001)\end{array}$ & $\begin{array}{l}0.012 * * * \\
(0.001)\end{array}$ \\
\hline Years of edu & & & & $\begin{array}{r}0.011 \\
(0.009)\end{array}$ & $\begin{array}{r}0.012 \\
(0.009)\end{array}$ \\
\hline Hospital & & & & $\begin{array}{l}-0.034 * * * \\
(0.012)\end{array}$ & $\begin{array}{l}-0.035^{* * *} \\
(0.012)\end{array}$ \\
\hline Gave birth & & & & $\begin{array}{l}0.130 * * * \\
(0.030)\end{array}$ & $\begin{array}{l}0.130 * * * \\
(0.030)\end{array}$ \\
\hline Married & & & & $\begin{array}{l}0.222 * * * \\
(0.025)\end{array}$ & $\begin{array}{l}0.227 * * * \\
(0.024)\end{array}$ \\
\hline Kids & & & & $\begin{array}{l}0.087 * * * \\
(0.023)\end{array}$ & $\begin{array}{l}0.080 * * * \\
(0.016)\end{array}$ \\
\hline East & & & & $\begin{array}{l}-0.361 * * * \\
(0.079)\end{array}$ & $\begin{array}{l}-0.354 * * * \\
(0.079)\end{array}$ \\
\hline Unemployed & & & & $\begin{array}{l}-0.263 * * * \\
(0.023)\end{array}$ & $\begin{array}{l}-0.265^{* * * *} \\
(0.021)\end{array}$ \\
\hline Home owner & & & & $\begin{array}{l}0.055^{* *} \\
(0.026)\end{array}$ & $\begin{array}{l}0.063 * * * \\
(0.019)\end{array}$ \\
\hline Ref.Income & & & & $\begin{array}{l}-0.815 * * * \\
(0.112)\end{array}$ & $\begin{array}{l}-0.773 * * * \\
(0.031)\end{array}$ \\
\hline Constant & & & $\begin{array}{l}-4.354 * * * \\
(0.314)\end{array}$ & & $\begin{array}{l}1.777 * * * \\
(0.377)\end{array}$ \\
\hline Instr.Age & $\begin{array}{l}-1.175^{* * *} \\
(0.113)\end{array}$ & & & & \\
\hline Instr.Age2 & $\begin{array}{l}0.151 * * * \\
(0.006)\end{array}$ & & & & \\
\hline Instr.Wave2 & $\begin{array}{l}-0.018 * * * \\
(0.006)\end{array}$ & & & & \\
\hline Instr.Wave 3 & $\begin{array}{l}0.004 * * * \\
(0.001)\end{array}$ & & & & \\
\hline$\overline{\text { K-P F-Statistic }}$ & & 267 & & 172 & \\
\hline Z-Score & & -0.327 & & 0.321 & \\
\hline Hansen $\mathbf{J}$ & & 17.3 & & 22.5 & \\
\hline Prob $>$ Chi squared & & 0.0006 & & 0.0001 & \\
\hline
\end{tabular}

Source: SOEP v34, own calculations. 273768 person-year observations of 38134 individuals. Notes: Significance levels * $0.10 * * 0.05 * * * 0.01$. Cluster-robust standard errors in parantheses. 
Table A3.4: Estimations for RQ2 and financial satisfaction

\begin{tabular}{|c|c|c|c|c|c|}
\hline & First stage & IV-FE & $\mathrm{FE}$ & IV-FE & $\mathrm{FE}$ \\
\hline Financial satisfaction & & $\begin{array}{l}0.035^{* * *} \\
(0.004)\end{array}$ & $\begin{array}{l}0.028 \text { *** } \\
(0.001)\end{array}$ & $\begin{array}{l}0.031^{* * * *} \\
(0.004)\end{array}$ & $\begin{array}{l}0.026^{* * *} \\
(0.001)\end{array}$ \\
\hline Age & $\begin{array}{l}1.069 * * * \\
(0.106)\end{array}$ & $\begin{array}{l}0.312 * * * \\
(0.023)\end{array}$ & $\begin{array}{l}0.323 * * * \\
(0.023)\end{array}$ & $\begin{array}{l}0.347 * * * \\
(0.022)\end{array}$ & $\begin{array}{l}0.355^{* * * *} \\
(0.022)\end{array}$ \\
\hline Age, sq. & $\begin{array}{l}-0.054 * * * \\
(0.007)\end{array}$ & $\begin{array}{l}-0.004^{* *} \\
(0.002)\end{array}$ & $\begin{array}{l}-0.004 * * * \\
(0.002)\end{array}$ & $\begin{array}{l}-0.010 * * * \\
(0.001)\end{array}$ & $\begin{array}{l}-0.010^{* * * *} \\
(0.002)\end{array}$ \\
\hline S.wave, sq. & $\begin{array}{l}-0.065^{* * * *} \\
(0.005)\end{array}$ & $\begin{array}{l}-0.010 * * * \\
(0.001)\end{array}$ & $\begin{array}{l}-0.010 * * * \\
(0.001)\end{array}$ & $\begin{array}{l}-0.012 * * * \\
(0.001)\end{array}$ & $\begin{array}{l}-0.012^{* * * *} \\
(0.001)\end{array}$ \\
\hline S.wave, cub. & $\begin{array}{l}0.015 * * * \\
(0.001)\end{array}$ & $\begin{array}{l}0.001 * * * \\
(0.000)\end{array}$ & $\begin{array}{l}0.002 * * * \\
(0.000)\end{array}$ & $\begin{array}{l}0.002 * * * \\
(0.000)\end{array}$ & $\begin{array}{l}0.002 * * * * \\
(0.000)\end{array}$ \\
\hline Years of edu & & & & $\begin{array}{l}0.017 * * * \\
(0.002)\end{array}$ & $\begin{array}{l}0.017 \text { *** } \\
(0.002)\end{array}$ \\
\hline Hospital & & & & $\begin{array}{c}0.003 * \\
(0.002)\end{array}$ & $\begin{array}{r}0.003 \\
(0.002)\end{array}$ \\
\hline East & & & & $\begin{array}{l}-0.029 \\
(0.021)\end{array}$ & $\begin{array}{l}-0.029 \\
(0.021)\end{array}$ \\
\hline Married & & & & $\begin{array}{l}0.105^{* * *} \\
(0.005)\end{array}$ & $\begin{array}{l}0.107 * * * \\
(0.005)\end{array}$ \\
\hline Kids & & & & $\begin{array}{l}-0.129 * * * \\
(0.003)\end{array}$ & $\begin{array}{l}-0.130^{* * * *} \\
(0.003)\end{array}$ \\
\hline Unemployed & & & & $\begin{array}{l}-0.063^{* * *} \\
(0.004)\end{array}$ & $\begin{array}{l}-0.066^{* * * *} \\
(0.004)\end{array}$ \\
\hline Home owner & & & & $\begin{array}{l}0.152 * * * \\
(0.005)\end{array}$ & $\begin{array}{l}0.152^{* * * *} \\
(0.005)\end{array}$ \\
\hline Constant & & & $\begin{array}{l}8.744 * * * \\
(0.054)\end{array}$ & & $\begin{array}{l}8.509 \text { *** } \\
(0.055)\end{array}$ \\
\hline Instr.Age & $\begin{array}{l}-1.075 * * * \\
(0.082)\end{array}$ & & & & \\
\hline Instr.Age2 & $\begin{array}{l}0.057 * * * \\
(0.005)\end{array}$ & & & & \\
\hline Instr.Wave2 & $\begin{array}{l}0.019 * * * \\
(0.004)\end{array}$ & & & & \\
\hline Instr.Wave3 & $\begin{array}{l}-0.002 * * * \\
(0.001)\end{array}$ & & & & \\
\hline K-P F-Statistic & & 266 & & 265 & \\
\hline Z-score & & 1.788 & & 1.382 & \\
\hline Hansen $\mathbf{J}$ & & 32.6 & & 32.7 & \\
\hline Prob $>$ Chi squared & & 0.0000 & & 0.0000 & \\
\hline
\end{tabular}

Source: SOEP v34, own calculations. 273768 person year observations of 38134 individuals.

Notes: Significance levels $* 0.10 * * 0.05 * * * 0.01$. Cluster-robust standard errors in parantheses. Dependent variable is net household income, equivalized to household size with square root rule. 
FE-IV and FE estimations of $\mathrm{H} 2$ for net household income, unequiv.

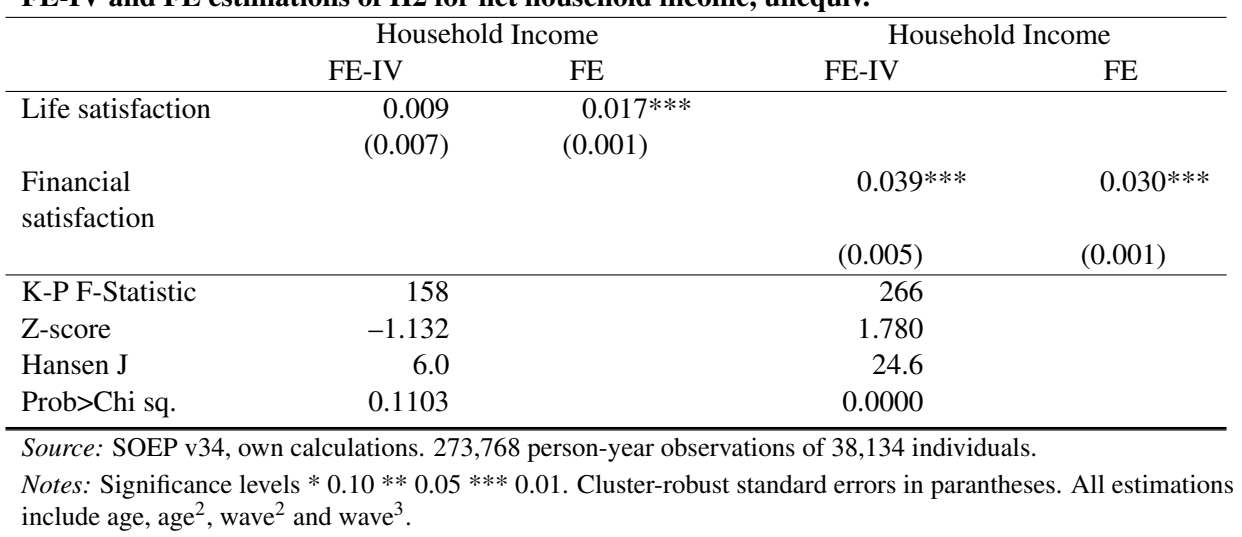

\section{A3.5 Estimates for RQ1 and RQ2 with unequivalized household income}

FE and FE-IV estimations of $\mathrm{H1}$ for net household income, unequiv.

\begin{tabular}{lrcrr}
\hline & \multicolumn{2}{c}{ Life satisfaction } & \multicolumn{2}{c}{ Financial satisfaction } \\
& FE-IV & FE & FE-IV & FE \\
\hline Household income & -0.037 & $0.330 * * *$ & $0.670 * * *$ & $0.898^{*} * *$ \\
& $(0.058)$ & $(0.013)$ & $(0.074)$ & $(0.017)$ \\
\hline K-P F-Statistic & 374 & & 374 & 17.4 \\
Hansen J & 7.4 & & 0.0006 & \\
Prob>Chi squared & 0.0599 & & -3.007 & \\
Z-score & -6.139 & & & \\
\hline \hline
\end{tabular}

Source: SOEP v34, own calculations. 273,768 person-year observations of 38,134 individuals.

Notes: Significance levels $* 0.10 * * 0.05 * * * 0.01$. Cluster-robust standard errors in parantheses. All estimations include age, age ${ }^{2}$, wave ${ }^{2}$ and wave ${ }^{3}$. 


\section{Bibliography}

Ahn, N., Ateca-Amestoy, V., and Ugidos, A. (2013). Financial satisfaction from an intra-household perspective. Journal of Happiness Studies, 15(5):1109-1123.

Alessie, R., Crossley, T. F., and Hildebrand, V. (2006). Estimating a collective household model with survey data on financial satisfaction. IFS Working Papers 06/19.

Angrist, J. and Pischke, J.-S. (2009). Mostly Harmless Econometrics. Princeton University Press, Princeton, New Jersey.

Apps, P. and Rees, R. (1988). Taxation and the household. Journal of Public Economics, 35(3):355-369.

Avendano, M., de Coulon, A., and Nafilyan, V. (2017). Does more education always improve mental health? Evidence from a British compulsory schooling reform. Health, Econometrics and Data Group (HEDG) Working Papers, (17/10).

Baetschmann, G., Staub, K. E., and Winkelmann, R. (2015). Consistent estimation of the fixed effects ordered logit model. Journal of the Royal Statistical Society A, 178(3):685-703.

Bartolini, S., Bilancini, E., and Sarracino, F. (2013). Predicting the trend of well-being in Germany: How much do comparisons, adaptation and sociability matter? Social Indicators Research, 114(2):169-191.

Bartolini, S. and Sarracino, F. (2018). Do people care about future generations? Derived preferences from happiness data. Ecological Economics, 143:253-275.

Baum, C. and Lewbel, A. (2019). Advice on using heteroskedasticity-based identification. Stata Journal, 19(4):757-767.

Baum, C. F. and Schaffer, M. E. (2012). IVREG2H: Stata module to perform instrumental variables estimation using heteroskedasticity-based instruments. Statistical Software Components, Boston College Department of Economics.

Baum, C. F., Schaffer, M. E., and Stillmand, S. (2007). Enhanced routines for instrumental variables/generalized method of moments estimation and testing. Stata Journal, 7(4):465-506.

Bayer, C. and Juessen, F. (2015). Happiness and the persistence of income shocks. American Economic Journal: Macroeconomics, 7(4):160-187.

Böckerman, P. and Ilmakunnas, P. (2012). The job satisfaction-productivity nexus: A study using matched survey and register data. ILR Review, 65(2):244-262.

Beck, U. (1987). Risikogesellschaft. Auf dem Weg in eine andere Moderne. Suhrkamp, Frankfurt /M.

Becker, G. S. (1965). A theory of the allocation of time. The Economic Journal, 75(299):493-517.

Becker, G. S. (1994). Human Capital: A Theoretical and Empirical Analysis with Special Reference to Education (3rd Edition). The University of Chicago Press. 
Bennett, F. (2013). Researching within-household distribution: Overview, developments, debates, and methodological challenges. Journal of Marriage and Family, 75(3):582-597.

Bennett, F., De Henau, J., Himmelweit, S., and Sung, S. (2012). Financial togetherness and autonomy within couples. In Scott, J., Dex, S., and Plagnol, A. C., editors, Gendered Lives. Gender Inequalities in Production and Reproduction, pages 97-122. Edwards Elgar, Cheltenhan, UK.

Bentham, J. (1789 [2000]). An Introduction to the Principles of Morals and Legislation. Batoche Books, Kitchener, Canada.

Blanchflower, D. G., Landeghem, B. V., and Oswald, A. J. (2009). Imitative obesity and relative utility. Journal of the European Economic Association, 7(2/3):528-538.

Blanchflower, D. G. and Oswald, A. J. (2004). Well-being over time in Britain and the USA. Journal of Public Economics, 88(7):1359 - 1386.

Blood, R. O. and Wolfe, D. M. (1960). Husbands \& Wives. The Dynamics of Married Living. Free Press.

Blossfeld, H.-P. and von Maurice, J. (2011). Education as a lifelong process. Zeitschrift für Erziehungswissenschaft, 14(2):19-34.

Boehm, Julia, K. and Lyubomirsky, S. (2008). Does happiness lead to career success? Journal of Career Assessment, 16(1):101-116.

Boertien, D. and Härkönen, J. (2018). Why does women's education stabilize marriages? The role of marital attraction and barriers to divorce. Demographic Research, 38(2):1241-1276.

Bond, T. N. and Lang, K. (2019). The sad truth about happiness scales. Journal of Political Economy, 127(4):16291640.

Bonke, J. and Browning, M. (2009). The distribution of well-being and income within the household. Review of Economics of the Household, 7(1):31-42.

Bourguignon, F. J., Browning, M., Chiappori, P., and Lechene, V. (1993). Intra household allocation of consumption: A model and some evidence from French data. Annales d'Économie et de Statistique, (29):137-156.

Boyce, C. J. (2010). Understanding fixed effects in human well-being. Journal of Economic Psychology, 31(1):116.

Boyce, C. J., Brown, G. D. A., and Moore, S. C. (2010). Money and happiness: Rank of income, not income, affects life satisfaction. Psychological Science, 21(4):471-475.

Boyce, C. J., Daly, M., Hounkpatin, H. O., and Wood, A. M. (2017). Money may buy happiness, but often so little that it doesn't matter. Psychological Science, 28(4):544-546.

Boyce, C. J., Wood, A. M., Banks, J., Clark, A. E., and Brown, G. D. A. (2013a). Money, well-being, and loss aversion: Does an income loss have a greater effect on well-being than an equivalent income gain? Psychological Science, 24(12):2557-2562.

Boyce, C. J., Wood, A. M., and Powdthavee, N. (2013b). Is personality fixed? Personality changes as much as "variable" economic factors and more strongly predicts changes to life satisfaction. Social Indicators Research, 111(1):287-305.

Brickman, P. and Campbell, D. (1971). Hedonic relativism and planning the good society. In Appley, M. H., editor, Adaptation-Level Theory, pages 287-305. Academic Press, New York.

Brown, S. and Gray, D. (2016). Household finances and well-being in Australia: An empirical analysis of comparison effects. Journal of Economic Psychology, 53:17-36. 
Browning, M., Bourguignon, F. J., Chiappori, P., and Lechene, V. (1994). Income and outcomes: A structural model of intrahoushold allocation. Journal of Political Economy, 102(6):1067-1096.

Brunello, G., Fort, M., Schneeweis, N., and Winter-Ebmer, R. (2016). The causal effect of education on health: What is the role of health behaviors? Health economics, 25(3):314-36.

Bryson, A., Forth, J., and Stokes, L. (2017). Does employees' subjective well-being affect workplace performance? Human Relations, 70(8):1017-1037.

Bubonya, M., Cobb-Clark, D. A., and Wooden, M. (2017). Mental health and productivity at work: Does what you do matter? Labour Economics, 46:150-165.

Buhmann, B., Rainwater, L., Schmaus, G., and Smeeding, T. M. (1988). Equivalence scales, well-being, inequality, and poverty: Sensitivity estimates across ten countries using the Luxembourg Income Study (LIS) database. Review of Income and Wealth, 34(2):115-142.

Burchardt, T. (2014). Are one man's rags another man's riches? Identifying adaptive expectations using panel data. Social Indicators Research, 74(1):57-102.

Bütikofer, A. and Gerfin, M. (2017). The economies of scale of living together and how they are shared: Estimates based on a collective household model. Review of Economics of the Household, 15(2).

Card, D. (2001). Estimating the return to schooling: Progress on some persistent econometric problems. Econometrica, 69(5):1127-1160.

Carver, T. and Grimes, A. (2019). Income or consumption: Which better predicts subjective well-being? Review of Income and Wealth, 65(S1).

Cascio, E. U. and Lewis, E. (2014). Schooling and the armed forces qualifying test: Evidence from school-entry laws. Journal of Human Resources, 41(2):294-318.

Chapman, B., , and Guven, C. (2016). Revisiting the relationship between marriage and wellbeing: Does marriage quality matter? Journal of Happiness Studies, 17(2):533-551.

Chiappori, P.-A. (1988). Rational household labor supply. Econometrica, 56(1):63-89.

Chiappori, P.-A. (1992). Collective labor supply and welfare. Journal of Political Economy, 100(3):437-367.

Clark, A., Flèche, S., Layard, R., Powdthavee, N., and Ward, G. (2018). The Origins of Happiness. Princeton University Press.

Clark, A. E. (2018). Four decades of the economics of happiness: Where next? Review of Income and Wealth, 64(2):245-269.

Clark, A. E., Diener, E., Georgellis, Y., and Lucas, R. E. (2008a). Lags and leads in life satisfaction: A test of the baseline hypothesis. The Economic Journal, 118(529):F222-F243.

Clark, A. E., Frijters, P., and Shields, M. A. (2008b). Relative income, happiness, and utility: An explanation for the easterlin paradox. Journal of Economic Literature, 46:95-144.

Clark, A. E. and Georgellis, Y. (2013). Back to baseline in Britain: Adaptation in the British Household Panel Survey. Economica, 80(319):498-512.

Courtin, E., Nafilyan, V., Avendano, M., Meneton, P., Berkman, L., Goldberg, M., Zins, M., and Dowd, J. (2019). Longer schooling but not better off? a quasi-experimental study of the effect of compulsory schooling on biomarkers in France. Social Science \& Medicine, 220:379-386.

Cutler, D. and Lleras-Muney, A. (2008). Education and health: Evaluating theories and evidence. In House, J., Schoeni, R., Kaplan, G., and Pollack, H., editors, Making Americans Healthier: Social and Economic Policy as HealthPolicy. Russell Sage Foundation, New York. 
Cutler, D. M. and Lleras-Muney, A. (2010). Understanding differences in health behaviors by education. Journal of Health Economics, 29(1):1-28.

Cygan-Rehm, K. (2017). Is additional schooling worthless? revising the zero returns to compulsory schooling in Germany. Technical report.

Cygan-Rehm, K. and Maeder, M. (2013). The effect of education on fertility: Evidence from a compulsory schooling reform. Labour Economics, 25:35-48.

Dahmann, S. C. and Schnitzlein, D. D. (2019). No evidence for a protective effect of education on mental health. Social Science \& Medicine, 241:112584.

D'Ambrosio, C. and Frick, J. R. (2012). Individual wellbeing in a dynamic perspective. Economica, 79(314):284302.

De Henau, J. and Himmelweit, S. (2013). Unpacking within-household gender differences. Journal of Marriage and Family, 75(3):611-624.

De Neve, J.-E., Diener, E., Tay, L., and Xuereb, C. (2013). The objective benefits of subjective well-being. In Helliwell, J., Layard, R., and Sachs, J., editors, World Happiness Report 2013, pages 1-35. UN Sustainable Development Solutions Network.

De Neve, J.-E. and Oswald, A. J. (2012). Estimating the influence of life satisfaction and positive affect on later income using sibling fixed effects. Proceedings of the National Academy of Sciences, 109(49):19953-19958.

Destatis (2019). Bevölkerung, Erwerbstätige und Erwerbstätigenquoten, Ergebnisse des Mikrozensus. Zentraler Auskunftsdienst, Federal Statistical Office.

Deutsch, F. M., Roksa, J., and Meeske, C. (2003). How gender counts when couples count their money. Sex Roles, 48(7,8):291-304.

Di Tella, R., Haisken-De New, J., and MacCulloch, R. (2010). Happiness adaptation to income and to status in an individual panel. Journal of Economic Behavior \& Organization, 76(3):834-852.

Diener, E. and Chan, M. Y. (2011). Happy people live longer: Subjective well-being contributes to health and longevity. Applied Psychology: Health and Well-Being, 3(1):1-43.

Diener, E. and Lucas, R. E. (1999). Personality and subjective well-being. In Kahneman, D., Diener, E., and Schwarz, N., editors, Well-Being: The Foundations of Hedonic Psychology, chapter 11, pages 213-229. Russel Sage Foundation.

Diener, E. and Oishi, S. (2000). Money and happiness: Income and subjective well being across nations. In Diener, E. and Suh, E., editors, Subjective Well-being Across Cultures, pages 185-218. MIT Press, Cambridge MA.

Diener, E. and Suh, E. M. (1999). National differences in subjective well-being. In Kahnemann, D., Diener, E., and Schwarz, N., editors, Well-Being: Foundations of Hedonic Psychology, pages 434-450. Russel Sage.

Dolan, P., Kavetsos, G., Krekel, C., Mavridis, D., Metcalfe, R., Senik, C., Szymanski, S., and Ziebarth, N. R. (2019). Quantifying the intangible impact of the Olympics using subjective well-being data. Journal of Public Economics, 177:104043.

Dolan, P., Peasgood, T., and White, M. (2008). Do we really know what makes us happy? a review of the economic literature on the factors associated with subjective well-being. Journal of Economic Psychology, 29(1):94-122.

Duesenberry, J. S. (1949). Saving and the Theory of Consumer Behavior. Harvard University Press, Cambridge, Massachusetts.

Dursun, B. and Cesur, R. (2016). Transforming lives: the impact of compulsory schooling on hope and happiness. Journal of Population Economics, 29(3):911-956. 
Easterlin, R. (1974). Does economic growth improve the human lot? Some empirical evidence. In David, P. and Reder, M., editors, Nations and Households in Economic Growth: Essays in Honor of Moses Abramovitz, pages 89-125. Academic Press.

Easterlin, R. A. (1995). Will raising the incomes of all increase the happiness of all? Journal of Economic Behavior \& Organization, 27(1):35-47.

Easterlin, R. A. (2005). Feeding the illusion of growth and happiness: A reply to Hagerty and Veenhoven. Social Indicators Research, 74(3):429-443.

Easterlin, R. A. (2017). Paradox lost? Review of Behavioral Economics, 4(4):311-339.

Easterlin, R. E. (2001). Income and happiness: Towards a unified theory. The Economic Journal, 111(473):463484.

Elsas, S. (2013). Pooling and sharing income within households: A satisfaction approach. SOEP Papers, 587.

Elsas, S. E. (2016). Income sharing within households: Evidence from data on financial satisfaction. Social Sciences, 5(47).

Eriksson, I., Undén, A.-L., and Elofsson, S. (2001). Self-rated health. Comparisons between three different measures. Results from a population study. International Journal of Epidemiology, 30:326-333.

Esri Deutschland (2019). Kreisgrenzen 2012. Bundesländerenzen 2012.

Ferrante, F. (2009). Education, aspirations and life satisfaction. Kyklos, 62(4):542-562.

Ferrer-i-Carbonell, A. (2005). Income and well-being: An empirical analysis of the comparison income effect. Journal of Public Economics, 89(5-6):997-1019.

Ferrer-i-Carbonell, A. (2013). Happiness economics. SERIEs, 4(1):35-60.

Ferrer-i-Carbonell, A. and Frijters, P. (2004). How important is methodology for the estimates of the determinants of happiness? The Economic Journal, 114:641-659.

Franz, W. (2013). Arbeitsmarktökonomik (3. Auflage). Springer-Lehrbuch. Springer.

Freeman, R. B. (1978). Job satisfaction as an economic variable. The American Economic Review, 68(2):135-141.

Frey, B. S. and Stutzer, A. (2002). What can economists learn from happiness research? Journal of Economic Literature, 40(2):402-435.

Frick, J. R., Goebel, J., Schechtman, E., Wagner, G. G., and Yitzhaki, S. (2006). Using analysis of Gini (AnoGi) for detecting whether two sub-samples represent the same universe: The German Socio-Economic Panel Study (SOEP) experience. Sociological Methods \& Research, 34(4):427-468.

Frijters, P., Haisken-DeNew, J. P., and Shields, M. A. (2004). Money does matter! evidence from increasing real income and life satisfaction in east germany following reunification. American Economic Review, 94(3):730740 .

Frijters, P., Johnston, D. W., and Shields, M. A. (2011). Life satisfaction dynamics with quarterly life event data. The Scandinavian Journal of Economics, 113(1):190-211.

Frijters, P., Johnston, D. W., Shields, M. A., and Sinha, K. (2015). A lifecycle perspective of stock market performance and wellbeing. Journal of Economic Behavior \& Organization, 112:237-250.

Garrido, S., Méndez, I., and Abellán, J.-M. (2001). Analysing the simultaneous relationship between life satisfaction and health-related quality of life. Journal of Happiness Studies, 14(6):1813 - 1838. 
Gilboa, I. and Schmeidler, D. (2001). A cognitive model of individual well-being. Social Choice and Welfare, 18(2):269-288.

Glaeser, E., Ponzetto, G., and Shleifer, A. (2005). Why does democracy need education? Journal of Economic Growth, 12(2):77-99.

Goerke, L. and Pannenberg, M. (2015). Direct evidence for income comparisons and subjective well-being across reference groups. Economics Letters, 137(C):95-101.

Graham, C., Eggers, A., and Sukhtankar, S. (2004). Does happiness pay? In Glatzer, W., Von Below, S., and Stoffregen, M., editors, Challenges for Quality of Life in the Contemporary World, volume 24 of Social Indicators Research Series, pages 179-204. Springer.

Greene, W. (2011). Fixed effects vector decomposition: A magical solution to the problem of time-invariant variables in fixed effects models? Political Analysis, 19(2):135-146.

Grossman, M. (1972). On the concept of health capital and the demand for health. Journal of Political Economy, 80(2):223-255.

Guardiola, J. and Guillen-Royo, M. (2015). Income, unemployment, higher education and wellbeing in times of economic crisis: Evidence from Granada (Spain). Social Indicators Research, 120(2):395-409.

Guven, C. (2012). Reversing the question: Does happiness affect consumption and savings behavior? Journal Economic Psychology, 33(4):62-78.

Hagenaars, A. J. M., de Vos, K., and Asghar Zaidi, M. (1994). Poverty statistics in the late 1980s: Research based on microdata. Official publications of the European Communities, Eurostat (European Commission), Luxembourg.

Hagerty, M. R. and Veenhoven, R. (2003). Wealth and happiness revisited: Growing national income does go with greater happiness. Social Indicators Research, 64(1):1-27.

Haisken-DeNew, J. P. and Frick, J. R. (2005). DTC. Desktop companion to the German Socio-Economic Panel (SOEP). http://www.diw.de/documents/dokumentenarchiv/17/diw_01.c.38951.de /dtc.409713.pdf. (Accessed on April 25, 2011).

Hamad, R., Elser, H., Tran, D. C., Rehkopf, D. H., and Goodman, S. N. (2018). How and why studies disagree about the effects of education on health: A systematic review and meta-analysis of studies of compulsory schooling laws. Social Science \& Medicine, 212:167-178.

Haybron, D. M. (2000). Two philosophical problems in the study of happiness. Journal of Happiness Studies, $1(2): 207-225$.

Heckman, J. J., Humphries, J. E., and Veramendi, G. (2016). Returns to education: The causal effects of education on earnings, health and smoking. Working Paper 22291, National Bureau of Economic Research.

Helbig, M. and Nikolai, R. (2015). Die Unvergleichbaren. Der Wandel der Schulsysteme in den deutschen Bundesländern seit 1949. Bad Heilbrunn, Klinkhardt.

Hetschko, C., Knabe, A., and Schöb, R. (2014). Changing identity: Retiring from unemployment. The Economic Journal, 124(575):149-166.

Hetschko, C., Knabe, A., and Schöb, R. (2019). Looking back in anger? Retirement and unemployment scarring. Demography, 56(3):1105-1129.

Himmelweit, S., Santos, C., Almudena, S., and Sofer, C. (2013). Sharing of resources within the family and the economics of household decision making. Journal of Marriage and Family, 75(3):625-639.

Hjalmarsson, R., Holmlund, H., and Lindquist, M. J. (2015). The effect of education on criminal convictions and incarceration: Causal evidence from micro-data. The Economic Journal, 125(587):1290-1326. 
Hotchkiss, J. (2005). Do husbands and wives pool their resources? further evidence. Journal of Human Resources, 40(2):519-531.

iab (2019). Arbeitslosigkeit im Zeitverlauf. Statistic of the federal employment agency, Federal Employment Agency.

Imai, K., Keele, L., Tingley, D., and Aymamoto, T. (2011). Unpacking the black box of causality: Learning about causal mechanisms from experimental and observational studies. American Political Science Review, 105(4):765-789.

Inglehart, R. (1997). Modernization and postmodernization: Cultural, economic, and political change in 43 societies. Princeton Univ. Press, Princeton, NJ.

Irving, L. M., Snyder, C., and Crowson Jr, J. J. (1998). Hope and coping with cancer by college women. Journal of personality, 66(2):195-214.

Jäntti, M., Kanbur, R., Nyyssölä, M., and Pirttilä, J. (2014). Poverty and welfare measurement on the basis of prospect theory. Review of Income and Wealth, 60(1):182-205.

Jenkins, S. P. (1991). Poverty measurement and the within-household distribution. Journal of Social Policy, 20(4):457-483.

Kahneman, D. and Deaton, A. (2010). High income improves evaluation of life but not emotional well-being. Proceedings of the National Academy of Sciences, 107(38):16489-16493.

Kahneman, D. and Tversky, A. (1979). Prospect theory: An analysis of decision under risk. Econometrica, 47(2):263-91.

Kaiser, C. (2018). People do not adapt to income changes: A re-evaluation of the dynamic effects of (reference) income on life satisfaction with gsoep and ukhls data. MPRA Papers, 89867.

Kaiser, C. and Vendrik, M. C. (2019a). Different versions of the easterlin paradox: New evidence for european countries. In Rojas, M., editor, The Economics of Happiness, pages 27-55. Springer.

Kaiser, C. and Vendrik, M. C. M. (2019b). How threatening are transformations of reported happiness to subjective wellbeing research? SocArXiv.

Kalugina, E., Radtchenko, N., and Sofer, C. (2009). How do spouses share their full income? Identification of the sharing rule using self-reported income. Review of Income and Wealth, 55(2):360-391.

Kantar Public (2020). SOEP-Core - 2019: Personenfragebogen, Stichproben A-L3, M1-M2 + N-O. SOEP Survey Papers, 909: Series A. Berlin: DIW/SOEP .

Kapteyn, A., Wansbeek, T., and Buyze, J. (1978). The dynamics of preference formation. Economics Letters, 1:93-98.

Kemptner, D., Jürges, H., and Reinhold, S. (2011). Changes in compulsory schooling and the causal effect of education on health: evidence from Germany. Journal of Health Economics, 30(2):340-354.

Kesavayuth, D. and Zikos, V. (2018). Happy people are less likely to be unemployed: Psychological evidence from panel data. Contemporary Economic Policy, 36(2):277-291.

Kleibergen, F. and Paap, R. (2006). Generalized reduced rank tests using the singular value decomposition. Journal of Econometrics, 133(1):97-126.

Knabe, A., Schöb, R., and Weimann, J. (2016). Partnership, gender, and the well-being cost of unemployment. Social Indicators Research, 129:1255-1275.

Knight, J., Song, L., and Gunatilaka, R. (2009). Subjective well-being and its determinants in rural china. China Economic Review, 20(4):635-649. 
Krause, A. (2013). Don't worry, be happy? Happiness and reemployment. Journal of Economic Behavior \& Organization, 96(C):1-20.

Kristoffersen, I. (2018). Great expectations: Education and subjective wellbeing. Journal of Economic Psychology, 66:64-78.

Kultusministerkonferenz (2017). Basic structure of the education system in the Federal Republic of Germany. Technical report.

Lachowska, M. (2017). The effect of income on subjective well-being: Evidence from the 2008 economic stimulus tax rebates. Journal of Human Resources, 52(2):374-417.

Lane, T. (2017). How does happiness relate to economic behaviour? A review of the literature. Journal of Behavioral and Experimental Economics, 68:62-78.

Layard, R., Clark, A. E., Cornaglia, F., Powdthavee, N., and Vernoit, J. (2014). What predicts a successful life? A life-course model of well-being. The Economic Journal, 124(580):F720-F738.

Layard, R., Mayraz, G., and Nickell, S. J. (2008). The marginal utility of income. Journal of Public Economics, 92(8-9):1846-1857.

Layard, R., Mayraz, G., and Nickell, S. J. (2010). Does relative income matter? are the critics right? In Diener, E., Helliwell, J. F., and Kahneman, D., editors, International Differences in Well-Being, chapter 6, page 139. Oxford University Press.

Lewbel, A. (2012). Using heteroscedasticity to identify and estimate mismeasured and endogenous regressor models. Journal of Business \& Economic Statistics, 30(1):67-80.

Lochner, L. and Moretti, E. (2004). The effect of education on crime: Evidence from prison inmates, arrests, and self-reports. American Economic Review, 94(1):155-189.

Lucas, R. E. (2007). Adaptation and the set-point model of subjective well-being: Does happiness change after major life events? Current Directions in Psychological Science, 16(2):75-79.

Lucas, R. E. and Diener, E. (2009). Personality and subjective well-being. In Diener, E., editor, The Science of Well-Being: The Collected Works of Ed Diener, pages 75-102. Springer Netherlands, Dordrecht.

Luhmann, M., Schimmack, U., and Eid, M. (2011). Stability and variability in the relationship between subjective well-being and income. Journal of Research in Personality, 45(2):186-197.

Lundberg, S. and Pollak, R. A. (1996). Bargaining and distribution in marriage. Journal of Economic Perspectives, (10):139-158.

Lundberg, S. J., Pollak, R. A., and Wales, T. J. (1997). Do husbands and wives pool their resources? Evidence from the United Kingdom child benefit. Journal of Human Resources, 32(3):463-480.

Luttmer, E. (2005). Neighbours as negatives: relative earnings and well-being. Quarterly Journal of Economics, 120(3):963-1002.

Machin, S., Marie, O., and Vujic, S. (2011). The crime reducing effect of education. The Economic Journal, 121(552):463-484.

MacKinnon, D. P. and Dwyer, J. H. (1993). Estimating mediated effects in preventions studies. Evaluation Review, 17(2):144-158.

MacKinnon, D. P., Fairchild, A. J., and Fritz, M. S. (2007). Mediation analysis. Annual review of psychology, 58:593-614.

Magnus, K., Diener, E., Frujita, F., and Pavot, W. (1993). Extraversion and neuroticism as predictors of objective life events: A longitudinal analysis. Journal of Personality and Social Psychology, 65(5):1046-53. 
McBride, M. (2010). Money, happiness, and aspirations: An experimental study. Journal of Economic Behavior \& Organization, 74(3):262-276.

Michael, R. T. (1972). The effect of education on efficiency in consumption. Nber books, New York.

Mill, J. S. (1844). On the definition of political economy. In Robson, J. M., editor, The Collected Works of John Stuart Mill, Vol IV. University of Toronto Press, 2013.

Milligan, K., Moretti, E., and Oreopoulos, P. (2004). Does education improve citizenship? Evidence from the United States and the United Kingdom. Journal of Public Economics, 88(9-10):1667-1695.

Mincer, J. (1974). Schooling, Experience, and Earnings. National Bureau of Economic Research, New York.

Mishra, V. and Smyth, R. (2014). It pays to be happy (if you are a man): Subjective wellbeing and the gender wage gap in urban China. International Journal of Manpower, 35(3):392-414.

Mundlak, Y. (1978). On the pooling of time series and cross section data. Econometrica, 46(1):69-85.

$\mathrm{Ng}$, W. and Diener, E. (2014). What matters to the rich and the poor? Subjective well-being, financial satisfaction, and postmaterialist needs across the world. Journal of Personality and Social Psychology, 107(2):326-338.

Nikolaev, B. (2016). Does other people's education make us less happy? Economics of Education Review, 52(Supplement C):176-191.

OECD (2008). Growing unequal? Income distribution and poverty in OECD countries. Official publications of the oecd, Organisation for Economic Co-operation and Development, Paris.

OECD (2011). Divided we stand-why inequality keeps rising. Official publications of the OECD, Organisation for Economic Co-operation and Development, Paris.

Olivetti, C. and Petrongolo, B. (2016). The evolution of gender gaps in industrialized countries. IZA Discussion Paper, (9659).

Oreopoulos, P. (2007). Do dropouts drop out too soon? Wealth, health and happiness from compulsory schooling. Journal of Public Economics, (11-12):2213-2229.

Oreopoulos, P. and Petronijevic, U. (2013). Making college worth it: A review of the returns to higher education. The Future of Children, 23(1):41-65.

Oreopoulos, P. and Salvanes, K. G. (2011). Priceless: the nonpecuniary benefits of schooling. Journal of Economic Perspectives, (1):159-184.

Oswald, A. J. (1997). Happiness and economic performance. The Economic Journal, 107(445):1815-1831.

Oswald, A. J. and Powdthavee, N. (2008). Does happiness adapt? A longitudinal study of disability with implications for economists and judges. Journal of Public Economics, 92(5):1061 - 1077.

Oswald, A. J., Proto, E., and Sgroi, D. (2015). Happiness and productivity. Journal of Labor Economics, 33(4):789-822.

Ott, N. (1992). Intrafamily Bargaining and Household Decisions. Springer, Berlin.

Pahl, J. (1989). Money \& Marriage. Macmillan, Basingstoke.

Peterson, S. J., Luthans, F., Avolio, B. J., Walumbwa, F. O., and Zhang, Z. (2011). Psychological capital and employee performance: A latent growth modeling approach. Personell Psychology, 64(2):427-450.

Peuckert, R. (2008). Familienformen im sozialen Wandel. Verlag für Sozialwissenschaften, Wiesbaden. 
Pfaff, T. (2013). Income comparisons, income adaptation, and life satisfaction: How robust are estimates from survey data? SOEPpaper, 555.

Phipps, S. A. and Burton, P. S. (1995). Sharing within families: Implications for the measurement of poverty among individuals in Canada. Canadian Journal of Economics, 28(1):177-204.

Phipps, S. A. and Burton, P. S. (1998). What's mine is yours? The influence of male and female incomes on patterns of household expenditure. Economica, 65(260):599-613.

Pischke, J.-S. (2007). The impact of length of the school year on student performance and earnings: Evidence from the German short school years. Economic Journal, 117:1216-42.

Pischke, J.-S. and von Wachter, T. (2005). Zero returns to compulsory schooling in Germany. evidence and interpretation. NBER Working Paper Series, 11414.

Pischke, J.-S. and von Wachter, T. (2008). Zero returns to compulsory schooling in Germany. evidence and interpretation. Review of Economics and Statistics, 90(3):592-598.

Pollmann-Schult, M. (2014). Parenthood and life satisfaction: Why don't children make people happy? Journal of Marriage and Family, 76(2):319-336.

Powdthavee, N. (2010). How much does money really matter? Estimating the causal effects of income on happiness. Empirical Economics, 39(1):77-92.

Powdthavee, N., Lekfuangfu, W. N., and Wooden, M. (2015). What's the good of education on our overall quality of life? a simultaneous equation model of education and life satisfaction for Australia. Journal of Behavioral and Experimental Economics, 54(Supplement C):10 - 21.

Quis, J. S. (2018). Does compressing high school duration affect students' stress and mental health? Evidence from the national educational panel study. Journal of Economics and Statistics, 238(5):441-476.

Rosenzweig, M. R. and Schultz, T. P. (1982). Market opportunities, genetic endowments, and intrafamily resource distribution: Child survival in rural India. The American Economic Review, 72(4):803-815.

Samuelsen, P. (1947). Foundations of Economic Analysis. Harvard University Press, Cambridge, MA.

Schnitzlein, D. D. and Wunder, C. (2016). Are we architects of our own happiness? The importance of family background for well-being. The B.E. Journal of Economic Analysis \& Policy, 16(1):125-149.

Schwarz, N. and Strack, F. (1999). Reports of subjective well-being: Judgmental processes and their methodological implications. In Kahnemann, D., Diener, E., and Schwarz, N., editors, Well-Being: Foundations of Hedonic Psychology, pages 61-84. Russel Sage.

Schwarze, J. (2003). Using panel data on income satisfaction to estimate equivalence scale elasticity. Review of Income and Wealth, 49(3):359-372.

Schwarze, J. and Winkelmann, R. (2011). Happiness and altruism within the extended family. Journal of Population Economics, 3(24):1033-1051.

Siedler, T. (2010). Schooling and citizenship in a young democracy: Evidence from postwar germany. The Scandinavian Journal of Economics, 112(2):315-338.

Silles, M. A. (2009). The causal effect of education on health: Evidence from the united kingdom. Economics of Education Review, 28(1):122-128.

Sirgy, J. M. (2012). The Psychology of Quality of Life: Hedonic Well-Being, Life Satisfaction, and Eudaimonia, volume 50 of Social Indicators Research Series. Springer. 
Snyder, C. R., Hoza, B., Pelham, W. E., Rapoff, M., Ware, L., Danovsky, M., Highberger, L., Ribinstein, H., and Stahl, K. J. (1997). The development and validation of the children's hope scale. Journal of Pediatric Psychology, 22(3):399-421.

Sobel, M. E. (1982). Asymptotic confidence intervals for indirect effects in structural equation models. Sociological Methodology, 13:290-312.

Solberg, E. C., Diener, E., Wirtz, D., Lucas, R. E., and Oishi, S. (2002). Wanting, having, and satisfaction: Examining the role of desire discrepancies in satisfaction with income. Journal of personality and social psychology, 83(3):725-734.

Soskice, D. W. (1993). Social skills from mass higher education: Rethinking the company-based initial training program. Oxford Review of Economic Policy, 9(3):101-113.

Staiger, D. and Stock, J. H. (1997). Instrumental variables regression with weak instruments. Econometrica, 65(3):557-586.

StataCorp.LLC (2017). Stata longitudinal-data/panel-data. Reference Manual Release 15.

Stevenson, B. and Wolfers, J. (2008). Economic growth and subjective well-being: Reassessing the easterlin paradox. Brookings Papers on Economic Activity, 39(1):1-102.

Stutzer, A. (2004). The role of income aspirations in individual happiness. Journal of Economic Behavior \& Organization, 54(1):89-109.

Stutzer, A. and Frey, B. S. (2006). Does marriage make people happy, or do happy people get married? Journal of Socio-Economics, 35(2):326-347.

Tenney, E. R., Poole, J. M., and Diener, E. (2016). Does positivity enhance work performance?: Why, when, and what we don't know. Research in Organizational Behavior, 36:27-46.

Thomas, D. (1993). The distribution of income and expenditure within the household. Annales d'Economie et de Statistique, (29):109-135.

Van Praag, B. and Ferrer-i-Carbonell, A. (2004). Happiness Quantified: A Satsifaction Calculus Approach. University Press, Oxford.

Van Praag, B. and Ferrer-i-Carbonell, A. (2008). Happiness Quantified: A Satsifaction Calculus Approach. University Press, Oxford.

Van Praag, B. M. and Frijters, P. (1999). The measurement of welfare and well-being: The Leyden approach. In Kahneman, D., Diener, E., and Schwarz, N., editors, Well-Being: The Foundations of Hedonic Psychology, pages 413-433. Russell Sage Foundation, New York.

Veenhoven, R. (2010). Capability and happiness: Conceptual difference and reality links. The Journal of SocioEconomics, 39(3):344 - 350.

Vendrik, M. (2013). Adaptation, anticipation and social interaction in happiness: An integrated error-correction approach. Journal of Public Economics, 105:131-149.

Vendrik, M. and Woltjer, G. (2007). Happiness and loss aversion: Is utility concave or convex in relative income? Journal of Public Economics, 91(7-8):1423-1448.

Vogler, C. (2005). Cohabiting couples: Rethinking money in the household at the beginning of the twenty first century. The Sociological Review, 53(1):1-29.

Wagner, G. G., Frick, J. R., and Schupp, J. (2007). The German Socio-Economic Panel Study (SOEP) - scope, evolution and enhancements. Schmollers Jahrbuch (Journal of Applied Social Science Studies), 127(1):139169. 
Walsh, L. C., Boehm, J. K., and Lyubomirsky, S. (2018). Does happiness promote career success? Revisiting the evidence. Journal of Career Assessment, 26(2):199-219.

Winkelmann, L. and Winkelmann, R. (1998). Why are the unemployed so unhappy? Evidence from panel data. Economica, 65(257):1-15.

Wooldridge, J. (2010). Correlated random effects models with unbalanced panels. Manuscript.

Woolley, F. (2000). Control over money in marriage. Carleton Economic Paper.

Wunder, C. and Schwarze, J. (2014). Is posner right? An empirical test of the posner argument for transferring health spending from old women to old men. Journal of Happiness Studies, 15(6):1239-1257.

Zevnik, L. (2014). Critical Perspectives in Happiness Research. The Birth of Modern Happiness. Springer. 